Old Dominion University

ODU Digital Commons

OEAS Faculty Publications

Ocean, Earth \& Atmospheric Sciences

2007

\title{
Simulations of Phytoplankton Species and Carbon Production in the Equatorial Pacific Ocean 1. Model Configuration and Ecosystem Dynamics
}

Baris Salihoglu

Old Dominion University

Eileen E. Hofmann

Old Dominion University, ehofmann@odu.edu

Follow this and additional works at: https://digitalcommons.odu.edu/oeas_fac_pubs

Part of the Atmospheric Sciences Commons, Marine Biology Commons, and the Oceanography Commons

\section{Repository Citation}

Salihoglu, Baris and Hofmann, Eileen E., "Simulations of Phytoplankton Species and Carbon Production in the Equatorial Pacific Ocean 1. Model Configuration and Ecosystem Dynamics" (2007). OEAS Faculty Publications. 133.

https://digitalcommons.odu.edu/oeas_fac_pubs/133

\section{Original Publication Citation}

Salihoglu, B., \& Hofmann, E.E. (2007). Simulations of phytoplankton species and carbon production in the equatorial pacific ocean 1. Model configuration and ecosystem dynamics. Journal of Marine Research, 65(2), 219-273.

This Article is brought to you for free and open access by the Ocean, Earth \& Atmospheric Sciences at ODU Digital Commons. It has been accepted for inclusion in OEAS Faculty Publications by an authorized administrator of ODU Digital Commons. For more information, please contact digitalcommons@odu.edu. 


\title{
Simulations of phytoplankton species and carbon production in the equatorial Pacific Ocean 1. Model configuration and ecosystem dynamics
}

\author{
by Baris Salihoglu ${ }^{1,2,3}$ and Eileen E. Hofmann ${ }^{1}$
}

\begin{abstract}
The primary objective of this research is to investigate phytoplankton community response to variations in physical forcing and biological processes in the Cold Tongue region of the equatorial Pacific Ocean at $0 \mathrm{~N}, 140 \mathrm{~W}$. This research objective was addressed using a one-dimensional multicomponent lower trophic level ecosystem model that includes detailed algal physiology, such as spectrally-dependent photosynthetic processes and iron limitation on algal growth. The ecosystem model is forced by a one-year (1992) time series of spectrally-dependent light, temperature, and water column mixing obtained from a Tropical Atmosphere-Ocean (TAO) Array mooring. Autotrophic growth is represented by five algal groups, which have light and nutrient utilization characteristics of low-light adapted Prochlorococcus, high-light adapted Prochlorococcus, Synechococcus, autotrophic eukaryotes, and large diatoms. The simulated distributions and rates are validated using observations from the 1992 U.S. Joint Global Ocean Flux Study Equatorial Pacific cruises. The modeldata comparisons show that the simulations successfully reproduce the temporal distribution of each algal group and that multiple algal groups are needed to fully resolve the variations observed for phytoplankton communities in the equatorial Pacific. The 1992 simulations show seasonal variations in algal species composition superimposed on shorter time scale variations (e.g., 8-20 days) that arise from changes in the upwelling/downwelling environmental structure. The simulated time evolution of the algal groups shows that eukaryotes are the most abundant group, being responsible for half of the annual biomass and $69 \%$ of the annual primary production and organic carbon export.
\end{abstract}

\section{Introduction}

The equatorial Pacific Ocean is the largest contiguous region of oceanic upwelling and as such provides waters rich in nutrients and inorganic carbon to a large part of the ocean above $100 \mathrm{~m}$. The high macronutrient concentration (e.g., typical nitrate concentrations of $\sim 5 \mu \mathrm{M}$, Chavez et al., 1996) enhances photosynthesis, new production of organic carbon, and therefore sedimentation of particulate carbon relative to the adjacent oligotrophic

1. Center for Coastal Physical Oceanography, ODU, Norfolk, Virginia, 235529, U.S.A.

2. Present address: Institute of Marine Sciences, Middle East Technical University, Erdemli, Turkey.

3. Corresponding author. email: baris@ims.metu.edu.tr 
waters. The high carbon content of the upwelled waters maintains a high partial pressure of carbon dioxide $\left(\mathrm{CO}_{2}\right)$ at the sea surface, and the large area of the equatorial Pacific makes this region the largest natural oceanic source of $\mathrm{CO}_{2}$, annually supplying 0.7 to $1.5 \mathrm{Pg}\left(10^{15} \mathrm{~g}\right)$ of carbon as $\mathrm{CO}_{2}$ to the atmosphere (Takahashi et al., 2002). The magnitude of this carbon flux is regulated by the interactions of physical and biological processes. The flux of $\mathrm{CO}_{2}$ at the air-sea interface and into the deep ocean as a result of biological processes, contributes to the processes affecting climate variations. Thus, the interactions between physical and biological processes and the relative effects of these on the lower trophic levels of the equatorial Pacific Ocean are integral to understanding and quantifying the ocean-atmosphere carbon flux.

In spite of upwelling which provides nutrients to the upper water column, the equatorial Pacific is characterized by modest chlorophyll concentrations and relatively low rates of primary production of about 0.2 to $0.3 \mu \mathrm{g} \mathrm{l}^{-1}$ and $75 \mathrm{mmol} \mathrm{C} \mathrm{m}^{-2} \mathrm{~d}^{-1}$, respectively (Chavez et al., 1999). This high-nutrient, low-chlorophyll (HNLC) environment has been attributed to low iron concentration (Martin et al., 1994; Coale et al., 1996a,b; Barber et al., 1996) and high zooplankton grazing rates (Walsh, 1976; Cullen et al., 1992). The deficiency in iron keeps phytoplankton growth rates below their physical potentials (Landry et al., 1997) and affects the composition of the phytoplankton community by selecting for smaller cells (Morel et al., 1991; Sunda and Huntsman, 1995). The grazer community, particularly microzooplankton, remove most of the daily production of phytoplankton biomass (Landry et al., 1997), thereby contributing to low chlorophyll conditions. The low iron concentrations contribute to maintenance of high nitrate conditions because iron-stress increases ammonium inhibition of nitrate uptake (Wheeler and Kokkinakis, 1990; Price et al., 1994; Armstrong, 1999).

Recently, some ecosystem models have been applied to provide a framework for examining the complex biological-physical interactions in the equatorial Pacific Ocean. These models (e.g., Chai et al., 1996; Loukos et al., 1997; Leonard et al., 1999; McClain et al., 1999; Friedrichs and Hofmann, 2001; Christian et al., 2002a) show that there are some basic problems associated with simulating phytoplankton growth and nutrient dynamics in the region. Many include only one or two species of plankton (i.e. nanoplankton and netplankton) which under-represent the dynamics of the phytoplankton community. Also, simple representations of nutrient uptake by phytoplankton results in unrealistic ambient nutrient concentrations. The model presented here aims to solve these problems by representing autotrophic growth with 5 algal groups and including detailed algal physiology (e.g., spectrally-dependent photosynthetic processes, multi-nutrient limitation on algal growth and variable cellular nutrient quotas).

The one-dimensional (1D), multi-component marine ecosystem model that is designed to include the physical and biological dynamics is used to investigate the controls on the biomass and production of the lower trophic levels in the equatorial Pacific Ocean. The primary implementation of the ecosystem model is for a site at $140 \mathrm{~W}$ on the equator, which is referred to as the Cold Tongue (Murray et al., 1992). The Cold Tongue is represented as 
an area where upwelling is persistent, which is reflected in generally high phytoplankton production.

The next section gives a summary of the data used in this study. Section 3 describes the lower trophic level model used in this study and the data sets input to the model. The results of the simulations and the model validation done for the Cold Tongue are given in Section 4. Section 5 discusses the results within the context of current understanding of the factors controlling lower trophic level production in the eastern equatorial Pacific. The final section summarizes the results from this study. The results of sensitivity studies that are designed to highlight important physical and biological processes that affect carbon production and export is given in an accompanying paper (Salihoglu and Hofmann, 2007, this issue).

\section{Data sources}

\section{a. Vertical velocity, diffusion, and mixing}

The one-dimensional lower trophic level ecosystem model, described in Section 3, includes explicit effects of vertical advection. Horizontal advective processes are not included. One approach for specifying a time-varying vertical velocity field is to estimate it using a numerical circulation model, such as the one developed for the equatorial Pacific by Murtugudde et al. (1996). However, simulated fields do not contain much of the high-frequency variability, such as Tropical Instability Waves (TIWs) and Internal Gravity Waves (IGWs), that are of interest for this study. Therefore, the approach taken here is to use direct observations of the horizontal velocities ( $u$ and $v$ ) and temperature obtained from the Tropical Ocean-Global Atmosphere (TOGA) program and the Tropical AtmosphereOcean (TAO) Array, which were obtained from moorings/buoys at fixed locations in the equatorial Pacific Ocean. Details of the TAO Array are given in McPhaden et al. (1998) and data from the mooring are available via the TAO web-site (http://www.pmel.noaa.gov/ toga-tao).

The temperature and horizontal velocity time series from the TAO Array for 1992 were used with the procedure given in Friedrichs and Hofmann (2001) to estimate vertical velocities. This approach is based on scaling vertical velocity relative to local upward movement of an isotherm and advection along a stationary, sloping isotherm. Daily estimates of local upward movement of the isotherms are obtained by evaluating the change in the depths of the isotherms measured by the TAO temperature sensors. The advection along a stationary, sloping isotherm is computed by multiplying zonal velocity data, measured by the TAO current meters, by estimates of zonal isotherm slopes.

Mixed layer depth is set to the depth where water temperature is $1 \mathrm{C}$ lower than the sea surface temperature (SST). The comparisons between the mixed layer depths observed during the U.S. Joint Global Ocean Flux Study (JGOFS) cruises and the mixed layer depths estimated using $1 \mathrm{C}$ difference from the observed SSTs gives very satisfactory results at $0 \mathrm{~N}$, 140W (not shown). These comparisons provide the justification for not explicitly using a mixed layer model (e.g., Price et al., 1986). 
The vertical diffusion $\left(K_{z}\right)$ effects are simulated with a theoretical model (Pacanowski and Philander, 1981) using the TAO mooring $(u, v, T)$ observations. All of the components (e.g., state variables) of the lower trophic level model (Section 3 ) are homogeneously distributed in the mixed layer at each time step.

\section{b. Shortwave radiation}

The TAO mooring at $0 \mathrm{~N}, 140 \mathrm{~W}$ provides time series of integrated incoming shortwave radiation. The shortwave radiation time series was used with a clear sky radiation model to estimate the spectrally-resolved underwater light field, as described in Section 3a.

\section{c. In situ observations}

The data sets used for calibration and evaluation (Section 4a) of the simulations obtained from the lower trophic level ecosystem model for the Cold Tongue were obtained from the U.S. JGOFS Equatorial Pacific process study (EqPac) (Murray et al., 1994, 1995). The data sets are from two process-oriented survey cruises that took place in February (S1) and August (S2) 1992 and two 20-day time series cruises that took place in March (TS1) and October (TS2) 1992. The time series cruises occupied a site at 0N, 140W and the survey cruises covered the area around this site (Murray et al., 1992, 1995). Data collected on these cruises were obtained via the U.S. JGOFS Data Management System, which is available at http://www1.whoi.edu/jgofs.html.

The largest suite of data available from the JGOFS EqPac cruises consists of measurements of algal biomass from direct cell counts and algal pigment concentration obtained from high-pressure liquid chromatography (Bidigare and Ondrusek, 1996; Landry et al., 1996). These data sets provide the basis for the algal groups included in the lower trophic level model as well as providing a means for evaluating the realism of the simulations. The phytoplankton cell counts were converted to microplankton carbon biomass using a factor of 53, 250, and 2,100 fg C per cell for Prochlorococcus spp., Synechecoccus, and autotrophic eukaryotes (Campbell et al., 1994; Binder et al., 1996; Landry et al., 1996), respectively.

Primary production measurements for natural in situ phytoplankton assemblages were obtained during the EqPac cruises using standard radioactive carbon $\left({ }^{14} \mathrm{C}\right)$ uptake approaches (Barber et al., 1996). The EqPac data sets provide vertical distributions of macronutrients, such as nitrate and silicate (Murray et al., 1995). In addition, measurements of dissolved trace metals, such as iron are available, which makes inclusion of explicit iron dynamics feasible in the lower trophic level ecosystem model used in this study.

Limited observations for trophic levels higher than phytoplankton are available as part of the EqPac data sets (Landry et al., 1995; Roman et al., 1995; Zhang et al., 1995). Microand mesozooplankton data consist mainly of distribution and biomass estimates. However, these are adequate for the level of detail included for this trophic level in the ecosystem model. 
An important diagnostic from the ecosystem model is the flux of carbon from the surface ocean. Limited measurements (Buesseler et al., 1995; Dunne and Murray, 1999) that can be used to constrain and evaluate the simulated carbon flux estimates were made during the two JGOFS EqPac survey cruises.

\section{Lower trophic level model}

\section{a. Model structure}

In this study a one-dimensional, algal group-based phytoplankton model (e.g., Bissett et al., 1999a) is used to simulate phytoplankton dynamics in the upper $120 \mathrm{~m}$ of equatorial Pacific Ocean. The phytoplankton model is part of a lower trophic level ecosystem model that is coupled to a larger model structure (Fig. 1) that provides the forcing fields.

The simulated surface light field, which provides input to the underwater light field is obtained from a clear sky spectral irradiance model (Gregg and Carder, 1990) that is corrected for cloud cover effects using the shortwave radiation measurements from the TOGA TAO observations described in Section $2 b$. The spectral attenuation of light energy with

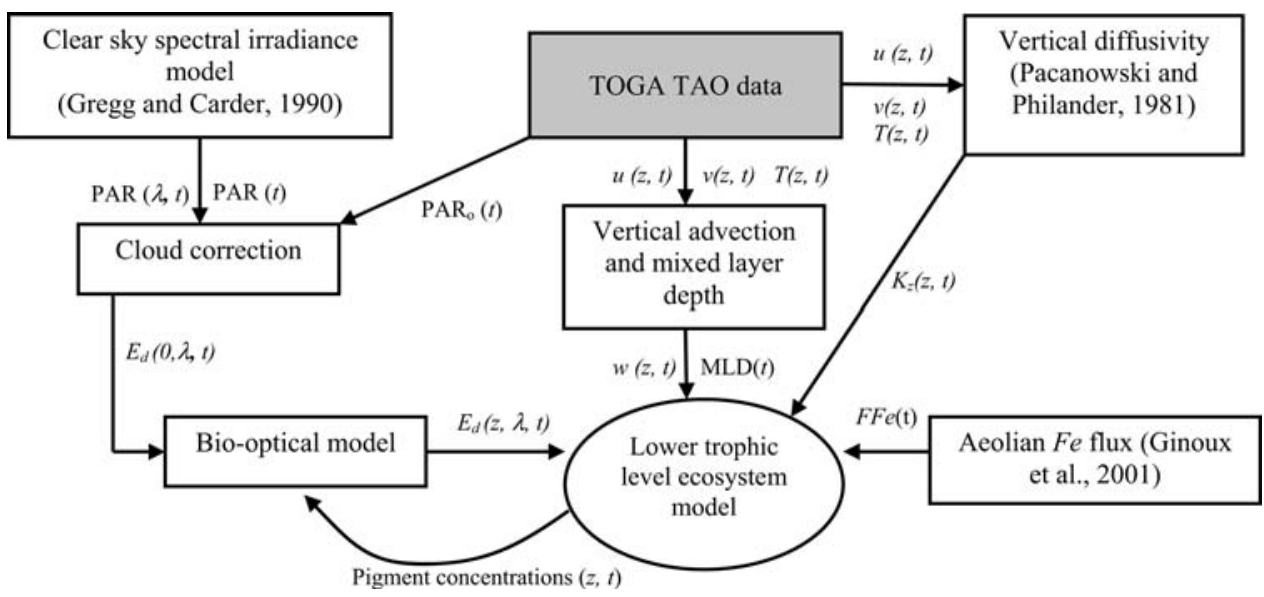

Figure 1. Schematic of the principal components of the one-dimensional lower trophic level model developed for the equatorial Pacific Ocean. The arrows indicate the direction of the transfer between the model compartments and the model process that provides the transfer. Outputs of the shaded box are the data products, outputs of other boxes are simulated products. Relevant references for the various model compartments are given. Abbreviations used on the schematic are: $\operatorname{PAR}(\lambda, t)$-spectral $(\lambda)$ and time $(t)$ dependent photosynthetically active radiation; $\operatorname{PAR}(t)$-scalar photosynthetically active radiation; $\operatorname{PAR}_{o}(t)$-observed, scalar photosynthetically active radiation, estimated from the observed shortwave radiation; $\mathrm{E}_{d}(0, \lambda, t)$-spectrally and time dependent surface downwelling irradiance; $u(z, t), v(z, t)$-horizontal velocity fields; $w(z, t)$-vertical velocity field; $T(z, t)$-temperature; $\operatorname{MLD}(t)$-mixed layer depth; $K_{z}(z, t)$-vertical diffusivity coefficient; $F e$-iron; $F F e$-aeolian iron flux. 
increased water depth is estimated as a function of the spectral absorption and backscattering of the water and particulate materials and used to force the full-spectral, algal group-based phytoplankton model. The pigment concentrations estimated for each algal group in the phytoplankton model are used to estimate particulate material concentration as a feedback into the bio-optical model. Details of the irradiance model and estimations of the algal pigment concentrations are given in Salihoglu (2005) and are not described here.

The effects of the physical environment are included in the ecosystem model using the observations from the TAO mooring as described in Section 2a. Atmospheric (aeolian) deposition of iron which is believed to limit phytoplankton growth in equatorial Pacific waters is obtained from Ginoux et al. (2001) as explained in Section 3hii.

The phytoplankton algal groups $(A G)$ included as state variables in the ecosystem model (Fig. 2) represent the dominant autotrophic biomass in the equatorial Pacific as determined from pigment and size fractionated studies (Chavez, 1989; Iriarte and Fryxell, 1995; Lindley

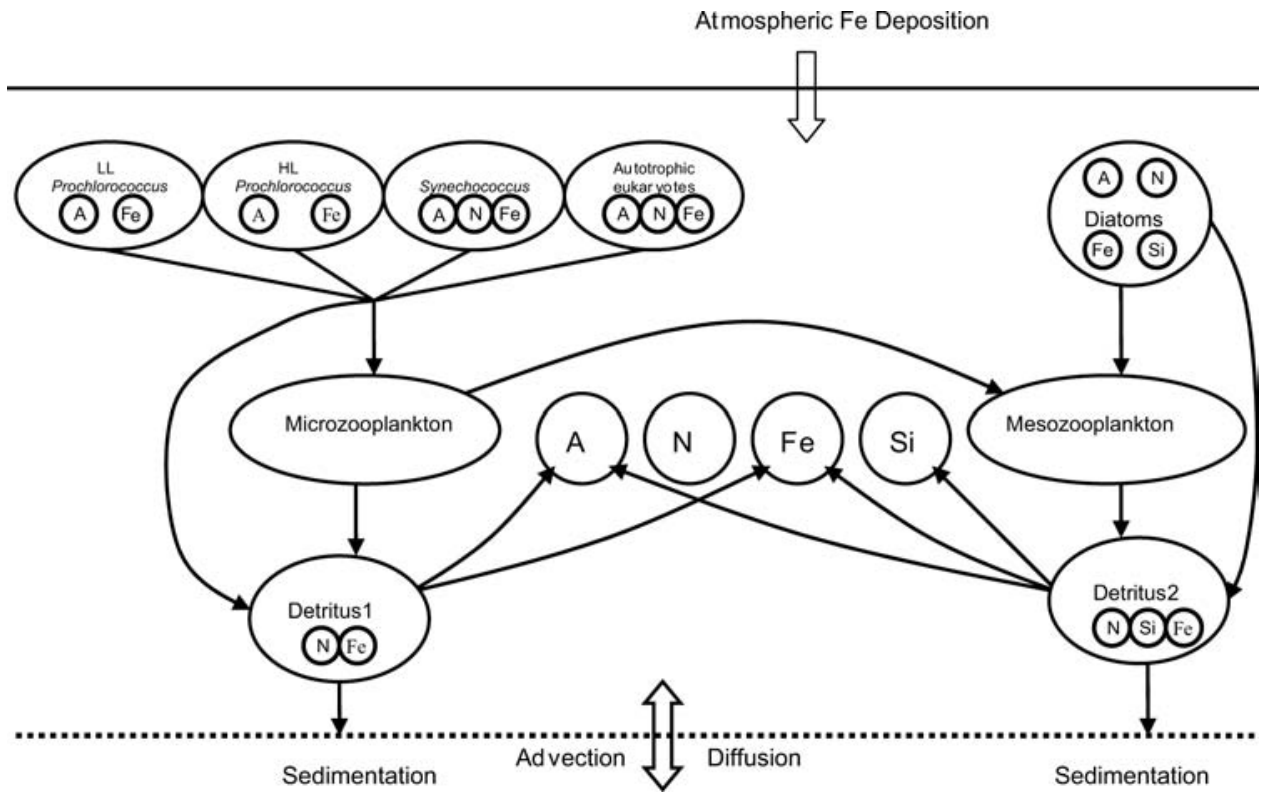

Figure 2. Schematic of the lower trophic level ecosystem model components. Each algal group, zooplankton and detritus component are expressed in terms of carbon biomass. Small circles inside the big circles indicate the internal nutrient compartments of each algal and detrital group. Interactions between nutrient, phytoplankton, zooplankton, and detritus compartments are shown by solid lines and arrows. Small arrows indicate the direction of transfer between model compartments; whereas, open arrows indicate the direction of transfer at the boundaries. Upper model boundary is indicated by a solid line, and it is only open to aeolian iron deposition. The bottom boundary is an open boundary which is indicated by a dotted line. Abbreviations used are: LL- low light-adapted; HL-high light-adapted; A-ammonium; N-nitrate; Fe-iron; Si-silicate. 
Table 1. Listing of the size and accessory pigments for the five phytoplankton algal groups $(A G)$ used in the phytoplankton model.

\section{Phytoplankton group}

AG1 LL Prochlorococcus

AG2 HL Prochlorococcus

AG3 Synechococcus

AG4 Autotrophic eukaryotes

AG5 Large diatoms

\section{Size $(\mu \mathbf{m})$}

$\sim 0.7$

$\sim 0.7$

$\sim 1$

$\sim 2.5$

$\sim 20$

\section{Accessory pigments}

$\operatorname{chl} a, \operatorname{chl} b$, PPC

$\operatorname{chl} a, \operatorname{chl} b$, PPC

$\operatorname{chl} a$, PE, PPC

chl $a$, chl c, PSC, PPC

$\operatorname{chl} a, \operatorname{chl} c$, PSC, PPC

The pigments include chlorophyll $a$ ( $\mathrm{chl} a$ ), chlorophyll $b(\mathrm{chl} b)$, chlorophyll $c$ (chl $c$ ), photosynthetic carotenoids (PSC), photoprotective carotenoids (PPC), and phycoerythrin (PE), following Bissett et al. (1999a). Other abbreviations used are: LL-low light-adapted and HL-high light-adapted.

et al., 1995; Bidigare and Ondrusek, 1996; Chavez et al., 1996; Coale et al., 1996b; Landry et al., 1996; Latasa et al., 1997; Higgins and Mackey, 2000; Landry et al., 2000a) and are sufficient to represent over $90 \%$ of the equatorial Pacific phytoplankton biomass. The accessory pigments included in the model are categorized as chlorophyll $a$, chlorophyll $b$, chlorophyll $c$, photosynthetic carotenoids, photoprotective carotenoids, and phycoerythrin. The five algal groups with their pigment suites are defined in Table 1.

The first two algal groups, which represent Prochlorococcus spp., account for a significant fraction of carbon biomass (i.e. photosynthetic carbon standing stock, 27\%-41\%) in equatorial Pacific waters (Vaulot et al., 1995; Binder et al., 1996; Landry et al., 1996). The division of Prochlorococcus into two groups represents species that grow in the low-light, subsurface chlorophyll $a$ maximum, and those that occur in the high-light surface waters (Moore et al., 1995; Partensky et al., 1999; Rippka et al., 2000; Moore et al., 2002b; Rocap et al., 2002). These two Prochlorococcus groups also show distinct nutrient utilization characteristics in that they are not able to use nitrate, but grow well on ammonium (Moore et al., 2002b). Differential nutrient use by Prochlorococcus groups is included in the model.

Algal group 3, Synechecoccus, is slightly larger than Prochlorococcus (Table 1) (Chisholm et al., 1988) and represents 7-8\% of the carbon biomass in the equatorial Pacific waters (Binder et al., 1996). Autotrophic eukaryotes are represented by algal group 4 and have been referred to as picoeukaryotes (Campbell and Vaulot, 1993), nanoeukaryotes (Landry et al., 1995), and eukaryotic ultraplankton (Li et al., 1993). Autotrophic eukaryotes account for the largest fraction of the carbon biomass (52\%-65\%) in the equatorial Pacific (Landry et al., 1996; Binder et al., 1996). The fifth algal group includes large ( $20 \mu \mathrm{m}$ cell size) diatoms. Large diatoms are the only microphytoplankton group included in the ecosystem model because this group consistently comprises $>80 \%$ of the total microphytoplankton autotrophic biomass (Iriarte and Fryxell, 1995) in the equatorial Pacific.

The current consensus is that nitrogen and iron both limit primary production in the eastern and central equatorial Pacific Ocean (Martin et al., 1990, 1991; Price et al., 1994; Behrenfeld et al., 1996; Coale et al., 1996a; Landry et al., 1997, 2000a) and that silicate limits diatom growth (Dugdale and Wilkerson, 1998). This understanding is included in 
the formulations used for growth of the five algal groups, which incorporates uptake of ammonium, nitrate, iron, and silicate. All of the algal groups use ammonium and iron; whereas, nitrate is only used by algal group 3, algal group 4, and algal group 5 (Fig. 2). Silicate is only used by algal group 5 .

Each algal group has cellular carbon, nitrogen (ammonium + nitrate), and iron compartments and algal group 5 has a cellular silicate compartment. The phytoplankton cellular nitrogen, iron, and silicate are needed to calculate uptake of nitrogen, iron and silicate by phytoplankton and to estimate nitrogen, iron and silicate limited growth rates. The chlorophyll $a$ equations are linked to cellular carbon, nitrogen, and iron state equations by variable cellular carbon to chlorophyll $a$, nitrogen to chlorophyll $a$, and iron to chlorophyll $a$ ratios. The estimation of carbon to chlorophyll $a$ ratios of each algal group are estimated using the procedure given in Bissett et al. (1999b) and explined in detail in Salihoglu (2005).

Two groups of zooplankton are included in the ecosystem model. The first group represents microzooplankton, which includes phagotrophic protists, and small animals that pass through a $200 \mu \mathrm{m}$ mesh net (Landry et al., 1995). The second group, the mesozooplankton, include $200 \mu \mathrm{m}$ to $2000 \mu \mathrm{m}$ size animals (mostly copepods) (Dam et al., 1995). In this model, microzooplankton graze on Prochlorococcus spp., Synechecoccus, and autotrophic eukaryotes (Fig. 2). The mesozooplankton graze on large diatoms and microzooplankton (Dam et al., 1995; Landry et al., 1995; Zhang et al., 1995; Verity et al., 1996).

The detrital component of the ecosystem model is divided into small (Detritus1, Fig. 2) and large detritus groups (Detritus2, Fig. 2). Detrital components are split into two groups because each group has unique sinking and remineralization rates (Nelson et al., 1995; Laws et al., 2000). The small detrital pool receives inputs from algal groups 1-4 that results from losses due to non-grazing mortality. Additional inputs to this detrital pool are from microzooplankton excretion and fecal pellet production (unassimilated ingestion). Losses by algal group 5 from non-grazing mortality and mesozooplankton excretion and fecal pellet production provide the inputs to the large detrital pool. Remineralization of small and large detritus provide sources of ammonium and iron (Laws et al., 2000). Dissolution of silicate in the large detritus compartment provides a source for this nutrient (Nelson et al., 1995).

Forcing by the physical environment acts on all model state variables. The detritus compartments are also allowed to sink at a fixed rate. Details of the irradiance model (Fig. 1) and the equations used to describe the dynamics of the model state variables (Fig. 2) are given in the sections that follow.

\section{b. Phytoplankton state equations}

The basic state equation governing phytoplankton dynamics for each algal group $\left(A G_{i}\right)$ is of the form:

$\frac{\partial A G_{i}}{\partial t}+w \frac{\partial A G_{i}}{\partial z}-\frac{\partial}{\partial z} K_{z} \frac{\partial A G_{i}}{\partial z}=\left[\min \left(\mu_{l l_{i}}, \mu_{n u l_{i}}\right)\right] A G_{i}-m_{i} A G_{i}-I_{A G_{i}} Z_{s}, \quad$ for $i=1,5$, 
where the three terms on the left side represent changes in each algal group that are produced by local time $(t)$ variations, vertical $(z)$ advection $(w)$, and vertical diffusive flux $\left(K_{z}\right)$, respectively. The right side of Eq. (1) represents the biological processes that provide sources and sinks of each algal group, which includes light- $\left(\mu_{l l_{i}}\right)$ and nutrient-limited $\left(\mu_{n u l_{i}}\right)$ growth, natural mortality, and losses due to zooplankton grazing, respectively. Algal groups 1-4 are grazed by microzooplankton, and algal group 5 is grazed by mesozooplankton (Fig. 2). All of the phytoplankton growth and loss processes are expressed in terms of carbon. The definitions and units of the parameters used in the algal group equations are given in Table 2 .

The realized net growth rate for each algal group, $\mu_{i}$, is the minimum of the light- and nutrient-limited growth rates, which limits growth by the least available resource (e.g., Walsh, 1975). The basal growth rate on which $\mu_{l l_{i}}$ and $\mu_{n u l_{i}}$ are based is determined from temperature $(T)$ using the specific growth relationship given by Eppley (1972), which is of the form:

$$
\mu_{m t_{i}}(z, t)=\mu_{m_{i}}(z, t) \exp ^{0.0633(T(z)-27)},
$$

where $\mu_{m t_{i}}$ is the temperature-dependent maximum growth rate for each algal group, which is calculated for each time and depth interval, and $\mu_{m_{i}}$ is the maximum growth rate at $27^{\circ} \mathrm{C}$ for each algal group (Table 3). Details of the formulations used to obtain $\mu_{l l_{i}}$ and $\mu_{n u l_{i}}$ are given in Sections $3 \mathrm{c}$ and $3 \mathrm{~d}$, respectively.

Because $\sim 80 \%$ of the daily production of algal groups $1-4$ is removed by grazing in the equatorial Pacific (Landry et al., 1995), natural mortality is assumed to have no effect on these algal groups (Table 3). The natural mortality rate for algal group 5 (Table 3) is such that $15 \%$ of these phytoplankton cells are removed in one day.

Losses due to grazing by microzooplankton (algal groups 1-4) and mesozooplankton (algal group 5) are obtained using the formulation given by Franks et al. (1986) which is of the form:

$$
I_{A G_{i}}=g_{A G_{i}} \Lambda A G_{i}\left(1-e^{-\Lambda A G_{i}}\right),
$$

where $g_{A G_{i}}$ is the maximum grazing rate of zooplankton on each algal group (Table 3) and $\Lambda$ is the Ivlev (1955) coefficient for zooplankton grazing (Table 4). This particular parameterization for zooplankton grazing losses provides model solutions that are stable for a wide range of parameter values (Franks et al., 1986).

Phytoplankton particulate nitrogen is an integral component of the dynamics governing each algal group because the nitrogen uptake and nitrogen-limited growth rates of each algal group are estimated as a function of particulate nitrogen $\left(A G N_{i}\right)$ as:

$$
\frac{\partial A G N_{i}}{\partial t}+w \frac{\partial A G N_{i}}{\partial z}-\frac{\partial}{\partial z} K_{z} \frac{\partial A G N_{i}}{\partial z}=\rho_{N O_{3} i}+\rho_{N H_{4} i}-m_{i} A G N_{i}-I_{A G N_{i}} Z_{s+l},
$$

where the terms on the left side of Eq. (4) represent the same physical processes included in Eq. (1). The first two terms on the right side of Eq. (4) represent sources as nitrate and ammonium uptake, respectively. The third and fourth terms represent losses by natural mortality of each algal group and grazing by microzooplankton and mesozooplankton, 
Table 2. Definitions and units of variables or parameters used in the equations that describe the dynamics of phytoplankton particulate carbon, nitrogen, iron, and silicate for each algal group.

\section{Symbol}

$\mu_{l l}$

$\mu_{\text {nul }}$

$m$

$I_{A G}$

$\mu$

$\mu_{m t}$

$\mu_{m}$

$g_{A G}$

$\Lambda$

$\rho_{\mathrm{NO}_{3}^{-}}$

$\rho_{N H_{4}^{+}}$

$\rho_{F e}$

$\rho_{S i}$

$\alpha$

$\mathrm{E}_{o}$

$\mathrm{E}_{o} \mathrm{cp}$

$d r$

$\mathrm{E}_{o}$ inb

$\phi_{m}$

$a_{p h_{p}}^{*}$

$\mathrm{K}_{\mathrm{SNO}}$

$\psi$

$K_{s N H_{4}^{+}}$

$K_{S F e}$

$K_{S} \mathrm{Si}$

$K_{Q N}$

$Q_{N}$

$K_{Q F e}$

$Q_{F e}$

$K_{Q S i}$

$Q_{S i}$

$Q N_{\text {max }}$

$Q F e_{\text {max }}$

$Q S i_{\text {max }}$

$\bar{\mu}$

\section{Definition}

Light-limited carbon specific growth rate

Nutrient-limited carbon specific growth rate

Phytoplankton specific death rate

Zoooplankton grazing rate

Realized net carbon specific growth rate

Maximum, temperature dependent carbon

specific growth rate

Maximum, $24 \mathrm{~h}$, carbon specific growth rate at $27^{\circ} \mathrm{C}$

Phytoplankton specific grazing coefficient

Ivlev coefficient of grazing

Absolute nitrate transport flux

Absolute ammonium transport flux

Absolute iron transport flux

Absolute silicate transport flux

Photosynthetic efficiency

Scalar irradiance at depth $z$

Compensation irradiance

The coefficient of exponential decay of

light-limited growth rate

Inhibiting light level

Maximum quantum yield

Photosynthetic absorption coefficient

Half saturation constant for nitrate uptake

Nitrate uptake repression exponent

Half saturation constant for ammonium

uptake

Half saturation constant for iron uptake

Half saturation constant for silicate uptake

Subsistence quota for nitrogen-limited growth

Cellular nitrogen status of the algal group

Subsistence quota for iron-limited growth

Cellular iron status of the algal group

Subsistence quota for silicate-limited growth

Cellular silicate status of the algal group

Maximum allowed nitrogen to carbon ratio

in each algal group

Maximum allowed iron to carbon ratio in each algal group

Maximum allowed silicate to carbon ratio

in each algal group

Growth rate at maximum cellular

nutrient concentrations

\section{Units}

$\mathrm{hr}^{-1}$
$\mathrm{hr}^{-1}$
$\mathrm{hr}^{-1}$
$\mathrm{hr}^{-1}$
$\mathrm{hr}^{-1}$
$\mathrm{hr}^{-1}$
$\mathrm{~d}^{-1}$

$\mathrm{d}^{-1}$

$\left(\mathrm{mmol} \mathrm{C} \mathrm{m}{ }^{-3}\right)^{-1}$

$\mu \mathrm{mol} \mathrm{N}{ }^{-1} \mathrm{~d}^{-1}$

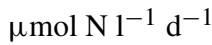

nmol Fe $1^{-1} d^{-1}$

$\mu \mathrm{mol} \mathrm{Si}{ }^{-1} \mathrm{~d}^{-1}$

$\left(\mu \mathrm{mol} \text { quanta } \mathrm{m}^{-2}\right)^{-1}$

$\mu$ mol quanta $\mathrm{m}^{-2} \mathrm{~s}^{-1}$

$\mu$ mol quanta $\mathrm{m}^{-2} \mathrm{~s}^{-1}$

${\text { ( } \mu \text { mol quanta })^{-1}}^{-1}$

$\mu$ mol quanta $\mathrm{m}^{-2} \mathrm{~s}^{-1}$

$\mu$ mol C ( $\mu$ mol quanta $)^{-1}$

$\mathrm{m}^{-1}$

$\mu \mathrm{mol} \mathrm{NO}-1^{-1}$

$\left(\mu \mathrm{mol} \mathrm{NH}{ }_{4}^{+} 1^{-1}\right)^{-1}$

$\mu \mathrm{mol} \mathrm{NO}-1^{-1}$

nmol Fe $1^{-1}$

$\mu \mathrm{mol} \mathrm{Si} 1^{-1}$

$\mu \mathrm{mol} \mathrm{N}(\mu \mathrm{mol} \mathrm{C})^{-1}$

$\mu \mathrm{mol} \mathrm{N}(\mu \mathrm{mol} \mathrm{C})^{-1}$

nmol Fe $(\mu \mathrm{mol} \mathrm{C})^{-1}$

$\mu \mathrm{mol} \mathrm{Fe}(\mu \mathrm{mol} \mathrm{C})^{-1}$

$\mu \mathrm{mol} \mathrm{Si}(\mu \mathrm{mol} \mathrm{C})^{-1}$

$\mu \mathrm{mol} \mathrm{Fe}(\mu \mathrm{mol} \mathrm{C})^{-1}$

$\mu \mathrm{mol} \mathrm{N}(\mu \mathrm{mol} \mathrm{C})^{-1}$

nmol Fe $(\mu \mathrm{mol} \mathrm{C})^{-1}$

$\mu \mathrm{mol} \mathrm{Si}(\mu \mathrm{mol} \mathrm{C})^{-1}$

$\mathrm{d}^{-1}$ 
Table 3. Values of parameters, defined in Table 2, used in the equations describing the dynamics of each algal group $(A G)$.

Parameter

AG1
AG3

$0^{1}$

$m$

$\mu_{m}$

$g_{A G}$

$E_{o} \mathrm{cp}$

$d r$

$E_{o}$ inb

$\phi_{m}$

$\mathrm{K}_{S N \mathrm{O}_{3}}$

$\psi$

$K_{S N H_{4}}$

$K_{S F e}$

$K_{S S i}$

$K_{Q N}$

$K_{Q F e}$

$K_{Q S i}$

$Q N_{\text {max }}$

$Q F e_{\text {max }}$

$Q S i_{\text {max }}$
$0^{1}$

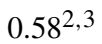

$4^{7,8}$

$1.0^{2}$

$0.1^{13}$

$40^{2}$

$0.0833^{3}$

$0.1^{15}$

$1000^{16}$

$0.05^{15}$

$0.01^{16}$

$\overline{0.18^{5}}$

$2 \times 10^{-3^{6}}$

$0.29^{5}$

$31 \times 10^{-3^{6}}$
$0^{1}$

AG2

$0.56^{2,3}$

$4^{7,8}$

$6^{2}$

$0.001^{13}$

$105^{2}$

$0.0833^{3}$

$0.1^{15}$

$1000^{16}$

$0.05^{15}$

$0.01^{16}$

$0.18^{5}$

$2 \times 10^{-3^{6}}$

$0.29^{5}$

$31 \times 10^{-3^{6}}$
$0.8^{2,4,5}$

$4^{7,8}$

$6^{2}$

-

$0.0833^{14}$

$0.167^{16}$

$6.5^{16}$

$0.083^{16}$

$0.01^{16}$

$0.18^{5}$

$2 \times 10^{-3^{6}}$

$0.29^{5}$

$31 \times 10^{-3^{6}}$
AG4

AG5

$0.15^{1}$

$1.0^{6}$ $5^{9,10}$

$8^{11}$

Superscripts refer to the references that provide the source for the parameter value given in the table, and the citation is provided below. The parameters that are not required by a particular algal group are indicated by - . ${ }^{1}$ Leonard et al. (1999); ${ }^{2}$ Moore et al. (1995); ${ }^{3}$ Partensky et al. (1993); ${ }^{4}$ Cuhel and Waterbury (1984); ${ }^{5}$ Kana and Glibert (1987a); ${ }^{6}$ Sunda and Huntsman (1995); ${ }^{7}$ Landry et al. (1995); ${ }^{8}$ Verity et al. (1996); ${ }^{9}$ Dam et al. (1995); ${ }^{10}$ Roman and Gauzens (1997); ${ }^{11}$ Richardson et al. (1983); ${ }^{12}$ Sakshaug et al. (1987); ${ }^{13}$ Bissett et al. (1999b); ${ }^{14}$ Sakshaug et al. (1991); ${ }^{15}$ Harrison et al. (1996); ${ }^{16}$ See text for calculations; ${ }^{17}$ Zhang and Zou (1997); ${ }^{18}$ Wroblewski (1977); ${ }^{19}$ Coale et al. (1996b); ${ }^{20}$ Fitzwater et al. (1996); ${ }^{21}$ Nelson and Treguer (1992); ${ }^{22}$ Laws and Bannister (1980); ${ }^{23}$ Sakshaug et al. (1989); ${ }^{24}$ Flynn et al. (1994); ${ }^{25}$ Geider et al. (1998); ${ }^{26}$ Takeda (1998).

represented by $Z_{(s+l)}$. Details of the approach used to obtain nutrient uptake rates are given in Section 3d.

The phytoplankton particulate iron $\left(A G F e_{i}\right)$ equation is of the form:

$$
\frac{\partial A G F e_{i}}{\partial t}+w \frac{\partial A G F e_{i}}{\partial z}-\frac{\partial}{\partial z} K_{z} \frac{\partial A G F e_{i}}{\partial z}=\rho_{F e_{i}}-m_{i} A G F e_{i}-I_{A G F e_{i}} Z_{(s+l)},
$$

The biological terms on the right side of Eq. (5) represent uptake of iron by each algal group, loss of iron by natural mortality of the algal groups, and removal of iron via zooplankton grazing, respectively.

Of the algal groups included in the model, only algal group 5, the diatoms, depend on silicate for growth (cf. Fig. 2). The phytoplankton particulate silicate equation of algal 
Table 4. Definitions, values, and units of the parameters used in the microzooplankton, mesozooplankton, nutrient, large detritus, and small detritus governing equations.

\section{Symbol}

$\Lambda$

$\lambda^{*}$

$e_{S}$

$m_{Z_{s}}$

$e_{l}$

$m_{Z_{l}}$

$g_{Z_{s}}$

$c_{a}^{*}$

$c_{F e}^{*}$

$\mathrm{FFe}$

$\mathrm{fe}_{\text {sol }}$

fesca

$c_{S i}^{*}$

$s c_{\text {des }}$

$s c_{d e l}$

$c_{c}^{*}$
Definition

Ivlev coefficient of grazing

Zooplankton assimilation efficiency

Mesozooplankton excretion rate

Mesozooplankton death rate

Microzooplankton excretion rate

Microzooplankton death rate

Mesozooplankton specific grazing

coefficient

Remineralization rate of detritus

to ammonium

Remineralization rate of detritus to iron

Aeolian iron deposition at the surface

Soluble fraction of aeolian iron

Particle scavenging loss term for iron

Dissolution rate of detritus to silicate

Small detritus sinking rate

Large detritus sinking rate

Remineralization rate of detritus

to carbon
Value

$1^{1}$

$0.75^{1}$

$0.1^{2,3}$

0.6

$0.1^{2,3}$

0.5

$15^{4}$

$0.05^{5}$

$0.1^{5}$

estimated

$0.1^{6}$

estimated

$0.1^{7}$

$10^{5}$

$20^{5}$

$0.1^{5}$
Units

$\left.(\mathrm{mmol} \mathrm{C} \mathrm{m})^{-3}\right)^{-1}$

unitless

$\mathrm{d}^{-1}$

$\mathrm{d}^{-1}$

$\mathrm{d}^{-1}$

$\mathrm{d}^{-1}$

$\mathrm{d}^{-1}$

$\mathrm{d}^{-1}$

$\mathrm{d}^{-1}$

nmol $\mathrm{l}^{-1} \mathrm{~d}^{-1}$

unitless

nmol $1^{-1} \mathrm{~d}^{-1}$

$\mathrm{d}^{-1}$

$\mathrm{m} \mathrm{d}^{-1}$

$\mathrm{m} \mathrm{d}^{-1}$

$\mathrm{d}^{-1}$

Superscripts refer to the references that provide the source for the parameter value and the citations are as follows: ${ }^{1}$ Leonard et al. (1999); ${ }^{2}$ Landry et al. (1996); ${ }^{3}$ Hutchins and Bruland (1995); ${ }^{4}$ Dam et al. (1995); ${ }^{5}$ Laws et al. (2000); ${ }^{6}$ Duce and Tindale (1991); ${ }^{7}$ Nelson et al. (1995).

group 5 is of the form:

$$
\frac{\partial A G S i_{5}}{\partial t}+w \frac{\partial A G S i_{5}}{\partial z}-\frac{\partial}{\partial z} K_{z} \frac{\partial A G S i_{5}}{\partial z}=\rho_{S i_{5}}-m_{5} A G S i_{5}-I_{A G S i_{5}} Z_{l},
$$

where the terms on the right side represent silicate uptake by diatoms, and losses of silicate from cell natural mortality and grazing by mesozooplankton $\left(Z_{l}\right)$, respectively.

\section{c. Formulation of algal group light-limited growth}

The light-limited growth rate for each phytoplankton algal group $\left(\mu_{l l_{i}}\right)$ is assumed to be governed by a hyperbolic tangent function (Jassby and Platt, 1976):

$$
\mu_{l l_{i}}(z, t)=\tanh \left[\frac{\alpha_{i}\left(E_{o}(z)-E_{o} c p_{i}\right)}{\mu_{m t_{i}}(z, t)}\right] e^{-d r_{i}\left(E_{o}(z)-E_{o} i n b_{i}\right)} \mu_{m t_{i}}(z, t), \quad \text { for } i=1,5,
$$

where $\alpha_{i}$ and $\mu_{m t_{i}}$ are the photosynthetic efficiency and temperature-dependent growth rate (obtained from Eq. (2)) for each algal group, respectively. The scalar irradiance at a depth $z\left(E_{o}(z)\right)$ is obtained by spectrally-integrating the downwelling spectral irradiance 
$\left(E_{d}(\lambda, z)\right)$ obtained using the irradiance model (Salihoglu, 2005). The compensation light flux $\left(E_{o} c p_{i}\right)$, which is the irradiance value at which net growth is zero, is obtained for each algal group from experimental studies (Table 3 ). This value sets a depth limit on algal group production.

The exponential portion of Eq. (7) allows for light inhibition of algal growth, which occurs at a rate given by $d r_{i}$. The formulations used for light-dependent growth are such that light inhibition affects only algal groups 1 and 2 (Table 3). Experimental studies (Moore et al., 1995) show that the growth of these phytoplankton cells is limited by high-light environments. Algal groups 3 to 5 do not exhibit similar growth inhibition in high-light regimes (Anderson and Roels, 1981; Falkowski et al., 1985; Post et al., 1985; Kana and Glibert, 1987a,b; Sakshaug et al., 1989; Iriarte and Purdie, 1993; Moore et al., 1995).

The photosynthetic efficiency for each algal group $\left(\alpha_{i}\right)$ is obtained from scaling the spectrally-integrated specific absorption coefficient of the photosynthetically active pigments for each algal group, $a_{p h_{p} i}^{*}$, by a maximum quantum yield of photosynthesis for each group $\left(\phi_{m_{i}}\right)($ Kirk, 1994) as

$$
\alpha_{i}(z)=\phi_{m_{i}} a_{p h_{p} i}^{*}(z) .
$$

For this study, a value of 12 mole quanta needed to fix one mole carbon $\left(\phi_{m_{i}}^{-1}\right)$ was used (Partensky et al., 1993), which gives a value of $\phi_{m}$ of 0.083 (Table 3). This value was experimentally determined and represents a conservative estimate of maximum photosynthesis quantum yield.

The spectrally-integrated specific absorption coefficient for the photosynthetically active pigments for each algal group is obtained by integrating the spectrally-dependent absorption spectra $\left(a_{p h_{i}}(\lambda, z)\right)$ over the Photosynthetically Available Radiation (PAR) portion of the irradiance spectrum $(400-700 \mathrm{~nm})$ as:

$$
a_{p h_{p} i}^{*}(z)=\frac{\int_{400}^{700} a_{p h_{i}}(\lambda, z) E_{d}(\lambda, z) d \lambda}{\int_{400}^{700} E_{d}(\lambda, z) d \lambda},
$$

where $E_{d}(\lambda, z)$ is the spectral irradiance for each wavelength $(\lambda)$ at depth $(z)$ and is obtained from the underwater light model (Salihoglu, 2005).

\section{d. Formulation of algal group nutrient-limited growth}

The specific rates of phytoplankton nutrient uptake and growth can be uncoupled depending upon the nutritional status of the phytoplankton cell (Droop, 1973; Goldman, 1980, 1982; Goldman and Glibert, 1983). Thus, use of a parameterization that assumes that phytoplankton growth is a direct function of nutrient uptake is appropriate only for population growth at maximal rates (Goldman and Glibert, 1983) and does not allow for phytoplankton species assemblages to shift in relative abundance of the different algal groups in response to differential nutrient uptake rates, cell physiology, and environmental variability. This study has objectives that focus on understanding the effects of physical and biological processes 
on phytoplankton community composition in the equatorial Pacific. Therefore, the nutrient limited growth rate $\left(\mu_{n u l_{i}}\right.$ in Eq. (1)) was formulated using separate parameterizations for nutrient uptake and growth rates as follows.

The rate at which the different algal groups remove nitrate (first term, right side of Eq. (4)) is related via a hyperbolic function to the ambient nitrate concentration as

$$
\rho_{N O_{3}^{-} i}(z, t)=\mu_{m t_{i}}(z, t) A G N_{i}\left[\frac{N O_{3}^{-}}{K_{s N O_{3}^{-} i}+N O_{3}^{-}} e^{-\psi_{i} N H_{4}^{+}}\right],
$$

where the maximum rate of uptake is determined by the temperature-dependent specific growth rate $\left(\mu_{m t_{i}}(z, t)\right.$, Eq. (2)), and the nitrate concentration at which one-half the maximum rate is obtained as given by $K_{\mathrm{SNO}_{3}^{-}}$(Table 3). The nitrate uptake inhibition by ammonium (Wroblewski, 1977; Flynn, 1991; Price et al., 1994) is represented by the exponential term in Eq. (10). The degree to which nitrate uptake is inhibited by ammonium is given by $\psi_{i}$ (Table 3 ). The inhibition value for diatoms, algal group 5, is similar to that used in other models that include this phytoplankton group (e.g., Wroblewski, 1977). The inhibition parameter values for algal groups 3 and 4 reflect the lower half saturation constants measured for these phytoplankton (Table 3). These nitrate uptake inhibition parameter values are estimated from the value used for diatoms by assuming an inverse relationship with nitrate uptake inhibition and cell size. This gives a value for algal groups 1 and 2 (Table 3) that prevents nitrate uptake by these phytoplankton. This is supported by studies that have shown that Prochlorococcus spp. are incapable of using nitrate as a nitrogen source (Miller and Castenholz, 2001; Moore et al., 2002b; Rocap et al., 2002; Scanlan and West, 2002). The rate of nitrate uptake is also modified by the particulate nitrogen concentration of each algal group $\left(A G N_{i}\right)$. Thus, Eq. (10) represents a nitrate transport flux into each algal group.

The uptake of ammonium is obtained for each algal group using a similar hyperbolic relationship of the form:

$$
\rho_{N H_{4}^{+} i}(z, t)=\mu_{m t_{i}}(z, t) A G N_{i}\left[\frac{N H_{4}^{+}}{K_{s N H_{4}^{+} i}+N H_{4}^{+}}\right],
$$

where the parameter definitions are similar to those in Eq. (10) and are given in Table 3.

Similarly the uptake of iron and silicate are given by:

$$
\rho_{F e_{i}}(z, t)=\mu_{m t_{i}}(z, t) A G F e_{i}\left[\frac{F e}{K_{s F e_{i}}+F e}\right],
$$

and

$$
\rho_{S i_{5}}(z, t)=\mu_{m t_{5}}(z, t) A G S i_{5}\left[\frac{S i}{K_{s S i_{5}}+S i}\right],
$$

where the cellular iron and silicate concentrations, $A G F e_{i}$ and $A G \mathrm{Si}_{5}$, are given by Eqs. (5 and 6), respectively. The parameter values are given in Table 3. 
The ability of phytoplankton to take up excess nutrients for use at a later time, termed luxury consumption, is related to cell size, with large cells having a greater capacity for nutrient storage (Wheeler, 1983). For the algal groups included in this study, diatoms have the largest potential for luxury consumption, followed by the autotrophic eukaryotes and finally the smaller Synechococcus and Prochlorococcus spp. Luxury uptake and storage of iron is also valid, and the largest luxury uptake occurs in the diatoms (Sunda and Huntsman, 1995, Table 3).

The effect of cellular nutrient concentrations in modifying the nutrient-limited growth rate $\left(\mu_{n u l_{i}}(z, t)\right)$ was included using a Droop (1973) equation which provides a realistic mathematical representation of growth under nutrient limiting conditions (Marra et al., 1990; Haney and Jackson, 1996) and is of the form:

$$
\mu_{n u l_{i}}(z, t)=\bar{\mu}_{i}(z, t)\left[1-\frac{K_{Q N_{i}}}{Q_{N_{i}}(z, t)}\right]\left[1-\frac{K_{Q F e_{i}}}{Q_{F e_{i}}(z, t)}\right]\left[1-\frac{K_{Q S i_{5}}}{Q_{S i_{5}}(z, t)}\right],
$$

where $\bar{\mu}_{i}(z, t)$ is the algal group growth rate that occurs at maximum ratios of algal group particulate nitrogen to carbon $\left(A G N_{i}: A G_{i}\right)$, particulate iron to carbon $\left(A G F e_{i}: A G_{i}\right)$, and particulate silicate to carbon $\left(A G S i_{5}: A G_{5}\right)$ ratios. The actual algal group particulate nitrogen (nitrate + ammonium) to carbon, particulate iron to carbon and particulate silicate to carbon ratios are represented by $Q_{N_{i}}(z, t), Q_{F_{i}}(z, t)$, and $Q_{S i_{5}}(z, t)$ (note that silicate is only limiting for AG5), respectively. The subsistence algal nitrogen, iron, and silicate to carbon ratios are given by $K_{Q N_{i}}, K_{Q F e_{i}}$, and $K_{Q S i_{5}}$, respectively. These subsistence quotas define the algal particulate nitrogen, iron, and silicate to carbon ratios $\left(Q_{N_{i}}(z, t), Q_{F e_{i}}(z, t)\right.$, and $Q_{S i_{5}}(z, t)$ ) where zero growth rate for each algal group occurs (Droop, 1973), and values for these are given in Table 3.

The actual cellular nitrogen to carbon ratio that controls the nitrogen-based algal growth rate is obtained from

$$
Q_{N_{i}}(z, t)=\frac{A G N_{i}}{A G_{i}} .
$$

The cellular nutrient ratios controlling iron- and silicate-based growth are similar:

$$
Q_{F e_{i}}(z, t)=\frac{A G F e_{i}}{A G_{i}} \text { and } Q_{S i_{5}}(z, t)=\frac{A G S i_{5}}{A G_{5}} .
$$

The actual growth rate $\left(\mu_{m t}\right.$, Eq. (2)) uses a true maximum growth rate $\left(\bar{\mu}_{i}\right)$ which is reached when the algal group particulate nitrogen to carbon, particulate iron to carbon, and particulate silicate to carbon ratios are maximized. Because $\mu_{m t}$ changes with time and depth, $\bar{\mu}_{i}$ is calculated for each time and depth from

$$
\bar{\mu}_{i}(z, t)=\mu_{m t_{i}}(z, t)\left[1-\frac{K_{Q N_{i}}}{Q N_{\max _{i}}}\right]^{-1}\left[1-\frac{K_{Q F e_{i}}}{Q F e_{\max _{i}}}\right]^{-1}\left[1-\frac{K_{Q S i_{5}}}{Q S i_{\max _{5}}}\right]^{-1},
$$


which is a modified form of Eq. (14) in which $\mu_{m t_{i}}(z, t)$ replaces $\mu_{n u l_{i}}(z, t)$ and the maximum particulate nitrogen to carbon, iron to carbon, and silicate to carbon ratios for each algal group are used, which are given by $Q N_{\max _{i}}, Q F e_{\max _{i}}, Q S i_{\text {max }_{i}}$, respectively (Table 3).

\section{e. Zooplankton state equations}

The governing equation for microzooplankton $\left(Z_{s}\right)$ is assumed to be of the form:

$$
\frac{\partial Z_{s}}{\partial t}+w \frac{\partial Z_{s}}{\partial z}-\frac{\partial}{\partial z} K_{z} \frac{\partial Z_{s}}{\partial z}=\sum_{i=1}^{4} \lambda^{*} I_{P_{i}} Z_{s}-I_{Z_{s}} Z_{l}-e_{s} Z_{s}-m_{z_{s}} Z_{s}, \quad \text { for } i=1,4
$$

The gains and losses to the microzooplankton biomass, represented by the terms on the right side of Eq. (18), are assimilated ingestion of the grazed phytoplankton biomass, grazing on microzooplankton by mesozooplankton, excretion, and mortality, respectively.

Microzooplankton graze algal groups 1 to 4 and the assimilated ingestion represents the sum of the biomass grazed from these four algal pools. The efficiency at which the grazed algal biomass is assimilated is given by $\lambda^{*}$, which has the same value for all algal groups (Table 4).

Removal of microzooplankton by mesozooplankton grazing $\left(I_{Z_{s}}\right)$ is parameterized similar to what was done for grazing on phytoplankton (Eq. (3)). The values used for the microzooplankton specific grazing rate $\left(g_{Z_{s}}\right)$ and Ivlev constant $(\Lambda)$ are given in Table 4.

The microzooplankton excretion loss rate is given by $e_{s}$ and the value of this coefficient is given in Table 4. The microzooplankton mortality includes natural as well as predation mortality. This rate at which mortality occurs $\left(m_{z_{s}}\right.$, Table 4$)$ is such that $50 \%$ of the microzooplankton biomass is removed each day, which is consistent with observations (Dam et al., 1995; Zhang et al., 1995).

The equation governing the mesozooplankton $\left(Z_{l}\right)$ dynamics is similar to Eq. (18) and is of the form

$$
\frac{\partial Z_{l}}{\partial t}+w \frac{\partial Z_{l}}{\partial z}-\frac{\partial}{\partial z} K_{z} \frac{\partial Z_{l}}{\partial z}=\lambda^{*} I_{P_{5}} Z_{l}+\lambda^{*} I_{Z_{s}} Z_{l}-e_{l} Z_{l}-m_{z_{l}} Z_{l} .
$$

Increases in mesozooplankton biomass are supported by grazing on diatoms (algal group 5) and microzooplankton. The grazed biomass is assimilated with an efficiency given by $\lambda^{*}$ (Table 4). Losses to the mesozooplankton biomass occur via excretion and mortality, and values for the rates at which these processes occur are given in Table 4.

\section{f. Nutrient state equations}

The ambient nutrient concentrations are an integral component of the dynamics governing the nutrient uptake by each algal group as described in Section 3d. The nitrogen is partitioned 
into two components, ammonium (recycled nitrogen) and nitrate (new nitrogen). The basic state equation governing nitrate dynamics is of the form:

$$
\frac{\partial N O_{3}^{-}}{\partial t}+w \frac{\partial N O_{3}^{-}}{\partial z}-\frac{\partial}{\partial z} K_{z} \frac{\partial N O_{3}^{-}}{\partial z}=-\sum_{i=1}^{5} \rho_{N O_{3}^{-} i},
$$

The only biological loss term for nitrate is uptake by each phytoplankton algal group (Section 3d), which is represented by the term on the right side of Eq. (20).

The basic state equation of ammonium is of the form

$$
\begin{aligned}
& \frac{\partial N H_{4}^{+}}{\partial t}+w \frac{\partial N H_{4}^{+}}{\partial z}-\frac{\partial}{\partial z} K_{z} \frac{\partial N H_{4}^{+}}{\partial z} \\
& \quad=\sum_{i=1}^{5}\left(-\rho_{N H_{4_{i}}^{+}}\right)+e_{s} Z_{s}\left(\frac{N}{C}\right)_{Z_{s}}+e_{l} Z_{l}\left(\frac{N}{C}\right)_{Z_{l}}+c_{a} D e_{s} N+c_{a} D e_{l} N .
\end{aligned}
$$

The biological processes represented by the terms on the right side of Eq. (21), are uptake by each algal group, excretion by microzooplankton, excretion by mesozooplankton, and remineralization of small detrital nitrogen $\left(D e_{S} N\right)$ and large detrital nitrogen $\left(D e_{l} N\right)$.

The loss term for ammonium represents the uptake by each phytoplankton algal group. The excretion losses by microzooplankton $\left(e_{s} Z_{s}\right)$ and mesozooplankton $\left(e_{s} Z_{s}\right)$, which are described in Section 3e, are assumed to directly enter the ammonium pool. The particulate carbon pools of each zooplankton group are converted to a nitrogen equivalent using a nitrogen to carbon ratio $\left(\frac{N}{C}\right)$, for each group to estimate the amount of nitrogen in the excretion. This ratio is estimated by tracking the nitrogen to carbon ratio in the phytoplankton grazed by each zooplankton group, and it is calculated at each time and depth. Thus, this ratio is a dynamically evolving quantity rather than being a fixed constant value.

The other source for ammonium is the remineralization of small $\left(D e_{s} N\right)$ and large detrital nitrogen $\left(D e_{l} N\right)$ (Laws et al., 2000), which is described in Section 3g. The remineralization rate of detrital nitrogen to ammonium, $c_{a}(z)$, is assumed to be modified by temperature as:

$$
c_{a}(z)=c_{a}^{*} T_{\text {func }}(z)
$$

where

$$
T_{\text {func }}(z)=e^{(0.0967(T(z)-25))},
$$

where $T(z)$ is water temperature in $\mathrm{C}$ at depth, $z$. The temperature function $\left(T_{\text {func }}(z)\right)$ for the equatorial Pacific is obtained from Christian and Karl (1995). The value used for remineralization rate of detrital nitrogen at $25^{\circ} \mathrm{C}, c_{a}^{*}$, is given in Table 4 . 
The iron dynamics are assumed to be governed by an equation that is similar to that used for ammonium except for a surface deposition term $(F F e)$ and a scavenged iron term (fesca):

$$
\begin{aligned}
\frac{\partial F e}{\partial t}+w \frac{\partial F e}{\partial z}-\frac{\partial}{\partial z} K_{z} \frac{\partial F e}{\partial z}= & \sum_{i=1}^{5}\left(-\rho_{F e_{i}}\right)+e_{s} Z_{s}\left(\frac{F e}{C}\right)_{Z_{s}}+e_{l} Z_{l}\left(\frac{F e}{C}\right)_{Z_{l}}+c_{F e} D e_{s} F e \\
& +c_{F e} D e_{l} F e+\delta(z) F F e f e_{s o l}-f e s c a(z) .
\end{aligned}
$$

The terms on the right side of Eq. (24) are iron uptake by each algal group, excretion by microzooplankton, excretion by mesozooplankton, remineralization of small detrital iron $\left(D e_{s} \mathrm{Fe}\right)$ and large detrital iron $\left(\mathrm{De} e_{l} \mathrm{Fe}\right)$, aeolian iron deposition, and scavenging of iron.

The particulate carbon pools of each zooplankton group are converted to an iron equivalent using an iron to carbon ratio $\left(\frac{F e}{C}\right)$ for each group to estimate the amount of iron produced by excretion. The remineralization rate of detritus to iron, $c_{F e}(z)$, is also assumed to vary as a function of temperature $\left(c_{F e}^{*} T_{f u n c}(z)\right)$. The value of $c_{F e}^{*}$ is given in Table 4.

The aeolian iron deposition $(F F e)$ is simulated using the Kronecker delta $(\delta[z=0]=1$; $\delta[z>0]=0)$ to ensure that the atmospheric iron flux is applied at the air-sea interface only. The value for the soluble iron fraction of the aeolian input $\left(f e_{\text {sol }}\right.$, Section 3 hii) is given in Table 4.

The particle scavenging iron loss term $(f \operatorname{esca}(z))$ is adopted from Moore et al. (2002a). It is assumed that at low iron concentrations $(<0.6 \mathrm{nM})$ most dissolved iron is bound to organic ligands, but is still weakly particle reactive and at iron concentrations above 0.6 $\mathrm{nM}$ particle scavenging rates increase rapidly with increasing iron concentrations. For these assumptions, the iron scavenging can be modeled as:

$$
f e s c a(z)=2.74 \times 10^{-5} \mathrm{Fe}(z) \text { for } \mathrm{Fe}(z)<0.6 \mathrm{nM},
$$

and

$$
f \operatorname{esca}(z)=1.64 \times 10^{-5}+0.027(F e(z)-0.6) \frac{F e(z)-0.6}{F e(z)+1.4} \quad \text { for } F e(z)>0.6 \mathrm{nM} .
$$

The scavenged iron is added to the small detrital pool which may remineralize during sinking.

The basic state equation for silicate, which is only used by algal group 5, the diatoms, is of the form

$$
\frac{\partial S i}{\partial t}+w \frac{\partial S i}{\partial z}-\frac{\partial}{\partial z} K_{z} \frac{\partial S i}{\partial z}=-\rho_{S i_{5}}+c_{S i} D e_{l} S i .
$$

The silicate equation is similar to nitrate equation (Eq. 20) except for the addition of silicate through dissolution of large detritus silicate $\left(c_{S i} D e_{l} S i\right)$ (Nelson et al., 1995).

The loss term for silicate is via uptake by algal group 5 only, $-\rho_{S i_{5}}$. The dissolution rate of detrital silicate, $c_{S i}(z)$, is assumed to follow the temperature function given by Eq. (23) $\left(c_{S i}^{*} T_{f u n c}(z)\right)$. 


\section{g. Detritus state equations}

The governing equation for small detrital carbon $\left(D e_{s}\right)$ is assumed to be of the form:

$$
\begin{aligned}
& \frac{\partial D e_{s}}{\partial t}+\left(w+s c_{d e s}\right) \frac{\partial D e_{s}}{\partial z}-\frac{\partial}{\partial z} K_{z} \frac{\partial D e_{s}}{\partial z} \\
& =\sum_{i=1}^{4}\left[m_{i} P_{i}+\left(1-\lambda^{*}\right) I_{P_{i}} Z_{s}\right]+\left(e_{s}+m_{Z s}\right) Z_{s}-c_{c} D e_{s}
\end{aligned}
$$

where the three terms on the left side represent changes in $D e_{s}$ that are produced by local time variations, vertical advection and sinking $\left(s c_{d e s}\right)$, and vertical diffusive fluxes, respectively. Sinking of the small detritus pool is assumed to occur at a constant rate. The right side of Eq. (28) includes a source term through the death and unassimilated grazed fraction of algal groups 1 to 4, excretion and mortality of microzooplankton, and a loss term due to remineralization of $D e_{s}$, respectively. Remineralization of small detritus carbon is modified by temperature $\left(c_{c}^{*} T_{f u n c}(z)\right)$ similar to what was done for remineralization of nitrogen (Eq. 22).

The governing equation for the large detrital carbon $\left(D e_{l}\right)$ dynamics is similar to Eq. (28) and is of the form:

$$
\begin{aligned}
& \frac{\partial D e_{l}}{\partial t}+\left(w+s c_{d e l}\right) \frac{\partial D e_{l}}{\partial z}-\frac{\partial}{\partial z} K_{z} \frac{\partial D e_{l}}{\partial z} \\
& \quad=m_{5} P_{5}+\left(1-\lambda^{*}\right)\left(I_{P_{5}}+I_{Z_{s}}\right) Z_{l}+\left(e_{l}+m_{Z l}\right) Z_{l}-c_{c} D e_{l} .
\end{aligned}
$$

where increases in large detrital carbon are supported by mortality of algal group 5 , the unassimilated fraction $\left(1-\lambda^{*}\right)$ of algal group 5 and the microzooplankton biomass that are grazed by mesozooplankton, and excretion $\left(e_{l}\right)$ and mortality $\left(m_{Z l}\right)$ by mesozooplankton, respectively. Loss from the large detrital carbon occurs via remineralization $\left(c_{c}\right)$ which is assumed to occur in a similar manner to small detrital carbon. The definitions, values, and units of the parameters used in the $D e_{s}$ and $D e_{l}$ equations are given in Table 4.

The state equations for detrital nitrogen, iron, and silicate are similar to Eqs. (28) and (29) except that scavenged iron is assumed to transfer into the small detrital iron pool, and only the large detrital pool is available to provide input to the silicate pool via remineralization (Fig. 2).

\section{h. Model implementation}

$i$. Numerical methods. The one-dimensional lower trophic level model was implemented with a coordinate system with the origin at the sea surface and the vertical coordinate positive downward. The model domain extends from the sea surface to $120 \mathrm{~m}$, which is below the $1 \%$ light level. This is sufficiently deep to include the total phytoplankton production in the upper waters of the equatorial Pacific.

The system of equations describing the physical and biological dynamics of the state equations (Eqs. 1, 4-6, 18-21, 24, 27-29) was solved numerically using a Crank-Nicholson 
scheme (Crank, 1956). This numerical integration scheme is unconditionally stable for the parameter ranges used in this study. The vertical coordinate was represented at 1-m intervals, which is sufficient resolution to define features such as the deep chlorophyll maximum that occurs in equatorial Pacific waters (Lindley et al., 1995). A one-hour interval was used for the time integration, which allows resolution of the diurnal periodicity in phytoplankton growth kinetics.

ii. Surface and bottom boundary conditions. Surface boundary conditions were specified as no flux conditions (i.e. Neumann conditions) for all model state variables except for iron. For iron, the daily atmospheric dust flux in $\mathrm{g} \mathrm{m}^{-2} \mathrm{hr}^{-1}$, obtained from Ginoux et al. (2001), was used to specify an input which is the sum of four dust size classes $(0.1-1,1-2,2-3$ and 3-6 $\mu \mathrm{m})$. The mass fraction of iron in the mineral dust aerosol was assumed to be 0.05 for the first size class and 0.012 for the remaining size classes (Fung et al., 2000). The soluble iron fraction $\left(f e_{s o l}\right.$, Eq. 24$)$ was taken to be 0.1 , which is at the high end of current estimates (Duce et al., 1991; Duce and Tindale, 1991; Fung et al., 2000). The dust flux in $\mathrm{g} \mathrm{m}^{-2}$ $\mathrm{hr}^{-1}$ was converted to a flux in nmol $1^{-1} \mathrm{hr}^{-1}$ (FFe in Eq. 24) by using appropriate scaling factors. It was assumed that the dust deposited on $1 \mathrm{~m}^{2}$ at the sea surface was introduced to a $1 \mathrm{~m}^{3}$ water volume.

The bottom boundary conditions for nitrate, silicate and iron were specified using a temperature-nutrient relationship. The nitrate $\left(\mathrm{NO}_{3}^{-}\right)$and iron $(\mathrm{Fe})$ dependencies on temperature $(T)$ were taken from Barber and Chavez (1991) and Leonard et al. (1999), respectively, and are given as

$$
\begin{gathered}
N O_{3}^{-}(z, t)=66.70-3.90 T(z, t)+0.06 T(z, t)^{2}, \\
F e(z, t)=0.50-0.019 T(z, t),
\end{gathered}
$$

where $\mathrm{NO}_{3}^{-}$and $\mathrm{Fe}$ are in $\mu \mathrm{mol} \mathrm{l}^{-1}$ and nmol $1^{-1}$, respectively. The depth and time varying temperature was obtained from the time series measured at TAO mooring arrays.

A silicate $(\mathrm{Si})$ to temperature $(T)$ regression was developed using data from four 1992 U.S. JGOFS EqPac cruises:

$$
\operatorname{Si}(z, t)=26.35-0.90 T(z, t) .
$$

An ammonium to temperature relationship does not exist and therefore the Christian et al. (2002a) simulation was used to set the ammonium bottom boundary conditions at $120 \mathrm{~m}$.

iii. Initial vertical profiles. Initial profiles of phytoplankton, small and large zooplankton and detritus, and ammonium were obtained from the Christian et al. (2002a) simulation at 20 depth intervals and linearly interpolated to 1-m depth intervals. The small and large phytoplankton compartments obtained from the Christian et al. (2002a) simulation were partitioned into 5 algal groups based on the relative ratios of these algal groups measured 
during the U.S. JGOFS cruises (Landry et al., 1996; Iriarte and Fryxell, 1995). The initial profiles of nitrate, iron, and silicate were estimated using the nutrient to temperature relations. Very small $\left(0.0001 \mu \mathrm{mol} \mathrm{C1^{-1 }}\right)$ threshold values were set for the phytoplankton and zooplankton state variables, so that these concentrations do not become zero. This provides a refuge for these ecosystem components so they can respond when conditions become favorable for growth.

iv. Nutrient and light limitation conditions. Nutrient uptake is calculated separately from carbon growth and all nutrients taken up by phytoplankton are added to the particulate nutrient pool of each algal group (see Section 3b). During light limitation, the nutrient uptake rate can greatly exceed that of the light-limited carbon growth rate. For example, the cellular nitrogen to carbon $\left(A G N_{1}: A G_{1}\right)$ ratio and cellular iron to carbon $\left(A G F e_{1}: A G_{1}\right)$ ratio for algal group 1 are allowed to drop to minima of $0.18 \mu \mathrm{mol} \mathrm{N}(\mu \mathrm{mol} \mathrm{C})^{-1}$ and $0.031 \mathrm{nmol} \mathrm{Fe}(\mu \mathrm{mol} \mathrm{C})^{-1}$, respectively, during uptake of nitrogen and iron (Table 3). Nutrient uptake continues over 24 hours and is subject to the minimum carbon to nutrient ratios. The minimum carbon to nutrient ratios of each $A G$ and for each limiting nutrient are given in Table 3 in the form of maximum nutrient to carbon ratios (e.g., $Q_{N_{\max }}$ for nitrogen to carbon ratio).

Light begins to inhibit algal group 1 and algal group 2 at 40 and $105 \mu$ mol quanta $\mathrm{m}^{-2} \mathrm{~s}^{-1}$, and a zero growth rate is reached at 110 and $10300 \mu$ mol quanta $\mathrm{m}^{-2} \mathrm{~s}^{-1}$, respectively (Moore et al., 1995). The zero growth light intensities were determined by extrapolating the log-linear plot of growth versus irradiance given in Moore et al. (1995) to its zero intercept. Inhibition is assumed to exponentially reduce the maximum growth rate (see Section 3c).

\section{Results}

\section{a. Reference simulation}

The ecosystem model was first used to establish a reference simulation that provides the basis for comparisons with other simulations that are designed to test model sensitivity to variations in processes and parameter values (cf. Salihoglu and Hofmann, 2007, this issue). The reference simulation is for one year, 1992, and for a site at $0 \mathrm{~N}, 140 \mathrm{~W}$. This time and location correspond to the U.S. JGOFS EqPac cruises (Murray et al., 1995). The observations from these cruises (Section 2c) provide verification of the results obtained from the reference simulation.

i. Reference simulation forcing. The surface temperature time series (Fig. 3A) obtained at $0 \mathrm{~N}, 140 \mathrm{~W}$ from the TAO mooring shows values of 28 to 29C from January to about May 1992 which is indicative of El Niño conditions (Murray et al., 1992). In May 1992, the surface temperature decreases by about $4 \mathrm{C}$ over two months to about $25 \mathrm{C}$. This decrease is associated with the transition from El Niño to non-El Niño conditions. The latter portion of 

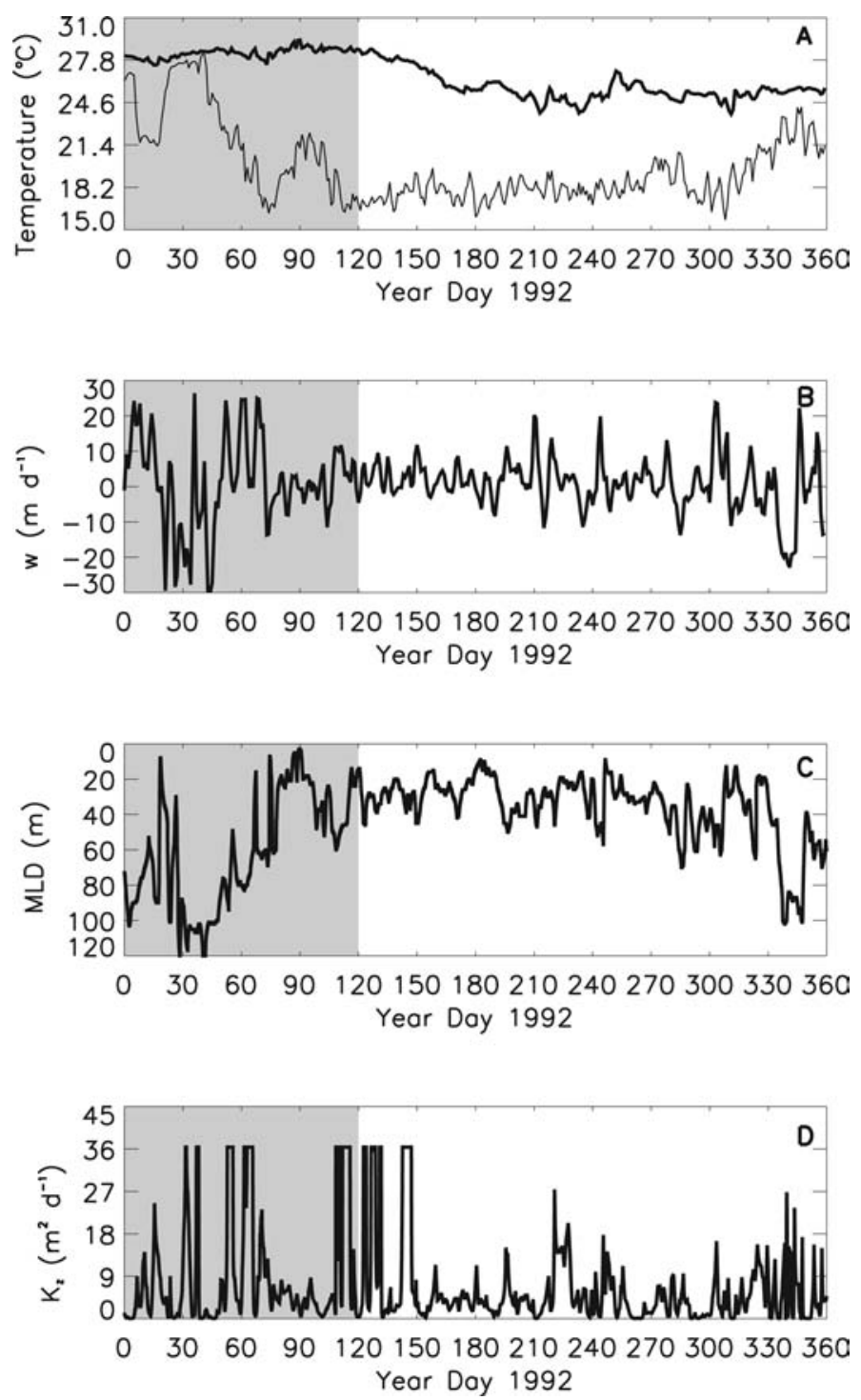

Figure 3. Time series of (A) surface temperature (thick solid line) and temperature at $120 \mathrm{~m}$ (thin solid line), (B) vertical velocity $(w)$ at $40 \mathrm{~m}$, (C) mixed layer depth (MLD), and (D) vertical diffusivity coefficient $\left(K_{z}\right)$ at $25 \mathrm{~m}$ estimated from observations obtained from the TAO mooring at 0N, 140W as discussed in Section 2a. Shaded regions denote the El Niño season.

the surface temperature time series (Fig. 3A) shows some high frequency variability, such as the events that occur at Year Day (YD) 210, YD260, and YD310. This variability, which occurs with about a 20-day time scale, is associated with TIWs (Qiao and Weisberg, 1995; Yu et al., 1995; Friedrichs and Hofmann, 2001). 
The subsurface temperatures at $120 \mathrm{~m}$ started to drop by the end of February, indicating the waning of El Niño conditions. Wunsch and Gill (1976) and Friedrichs and Hofmann (2001) show that physical variability in the central equatorial Pacific is also present at frequencies shorter than the 20-day events, and that these short period events produce subsurface temperature oscillations of 2-4C, with periods of 6-8-days (Fig. 3A). These temperature oscillations are consistent with the period of the IGWs (Wunsch and Gill, 1976).

The estimated vertical velocities (Section 3a) during the first three months of 1992 show the passage of a low frequency wave with a period of 60 days which is associated with a Kelvin wave (Kessler et al., 1995). During the same time vertical velocities show periods of strong upwelling and downwelling, with maximum magnitudes of $\pm 30 \mathrm{~m} \mathrm{~d}^{-1}$. These strong upwelling/downwelling velocities are associated with IGWs. From about YD100 through the transition to non-El Niño conditions at about YD200 (late summer) vertical velocity variability is reduced $\left( \pm 10 \mathrm{~m} \mathrm{~d}^{-1}\right)$ and is characterized by variability that occurs at a 6-8-day interval, which is associated with IGWs. The latter portion of the vertical velocity time series (YD210 onwards) is characterized by higher vertical velocities (10-20 $\mathrm{m} \mathrm{d}^{-1}$ ), and 7 strong upwelling/downwelling events, which occurred with a frequency of $\sim 20$-days. These events are associated with the passage of TIWs (Qiao and Weisberg, 1995; Friedrichs and Hofmann, 2001).

The mixed layer depth time series (Fig. 3C) (Section 3a), shows depths in excess of $100 \mathrm{~m}$ during El Niño conditions. These depths are consistent with the deeper mixed layers that occur in the eastern equatorial Pacific during El Niño conditions, which were measured during the S1 and TS1 cruises (not shown). The extended period of relatively shallow mixed layer depths from about YD150 to YD190 is the result of isotherm shoaling during the transition period.

The time series of the vertical diffusivity coefficient $\left(K_{z}\right)$ at $25 \mathrm{~m}$ (Fig. 3D), which is computed as described in Section 3a, shows high values from about YD20 to YD75 that correspond to the time of maximum downwelling velocities (Fig. 3B) and mixed layer depth (Fig. 3C). The maximum value for this coefficient is $36 \mathrm{~m}^{2} \mathrm{~d}^{-1}$ which is set in the Pacanowski and Philander (1981) formulations. The values of $K_{z}$ derived from the TAO mooring observations using the Pacanowski and Philander (1981) formulations are consistent with those reported in other studies of the mixing dynamics of the equatorial Pacific (Peters et al., 1981).

The large fluctuations and reduced irradiance during the first five months of 1992 (Fig. 4A) result from extensive cloud cover that is characteristic of El Niño conditions in the eastern equatorial Pacific (Philander, 1990). After transition to non-El Niño conditions, fluctuations in the simulated irradiance just below the sea surface were dampened and the high frequency fluctuations that occur are consistent with the clear skies and reduced cloudiness that occurs when these conditions prevail (Philander, 1990). In general, the 10\% and 1\% light levels are located between 70-90 m and 100-120 m, respectively, throughout 1992 . These values are consistent with other estimates of euphotic zone depths for this region (Walsh et al., 1995). 

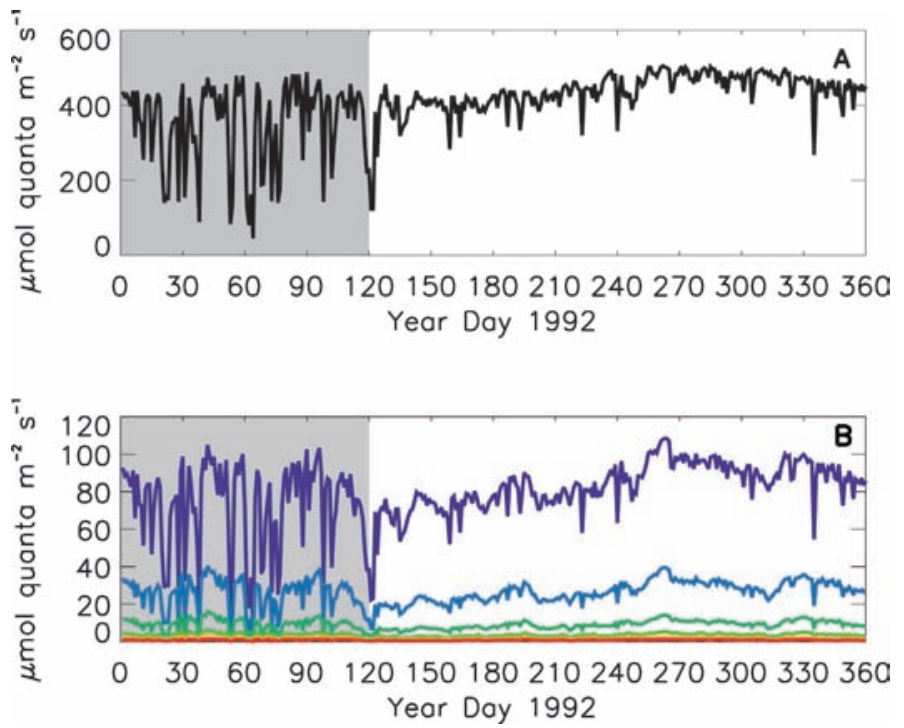

Figure 4. Time series of (A) simulated daily integrated downwelling irradiance (PAR) just below the surface and simulated daily integrated downwelling irradiance arriving at (B) $20 \mathrm{~m}$ (dark blue line), $40 \mathrm{~m}$ (light blue line), $60 \mathrm{~m}$ (green line), $80 \mathrm{~m}$ (light green line), $100 \mathrm{~m}$ (red line). The depth-dependent irradiance values are obtained from the irradiance model described in section 3.1. Shaded regions denote the El Niño season.

ii. Simulation of algal groups. The simulated depth-time distributions in the upper $100 \mathrm{~m}$ of the five algal groups at $0 \mathrm{~N}, 140 \mathrm{~W}$ for 1992 show the general features of low biomass during the first 100 days followed by increased biomass from about YD120 on and persisting for the remainder of 1992 (Fig. 5). The initial low biomass corresponds to El Niño conditions and deep mixed layers (Fig. 3C). Throughout the latter part of the simulation each algal group shows episodic increases/decreases in biomass, with these events lasting for 6 to 20 days. The integrated annual biomass in the upper $120 \mathrm{~m}$ of the ocean estimated from these simulated algal group distributions was 61,667 $\mathrm{mmol} \mathrm{C} \mathrm{m}^{-2} \mathrm{yr}^{-1}$ (Table 5).

The low light-limited Prochlorococcus (Fig. 5A) group has very low concentrations during El Niño conditions and blooms only after the transition to non-El Niño conditions. The biomass maximum for this algal group occurs below the mixed layer at depths greater than $40 \mathrm{~m}$. The maximum concentration obtained for this algal group during the one-year simulation was $0.34 \mu \mathrm{mol} \mathrm{C}{ }^{-1}$ and occurred at $50 \mathrm{~m}$ on YD117 (Fig. 5A).

The high-light adapted Prochlorococcus occurs in the upper water column, generally above $40 \mathrm{~m}$ (Fig. 5B). The simulated distribution of this algal group shows a large bloom, maximum concentration of $0.47 \mu \mathrm{mol} \mathrm{Cl}^{-1}$, that occurs just after the transition from El Niño to non-El Niño conditions. Throughout the latter portion of the simulation, algal group 2 shows episodic blooms, but the magnitude is less than the first large bloom. 

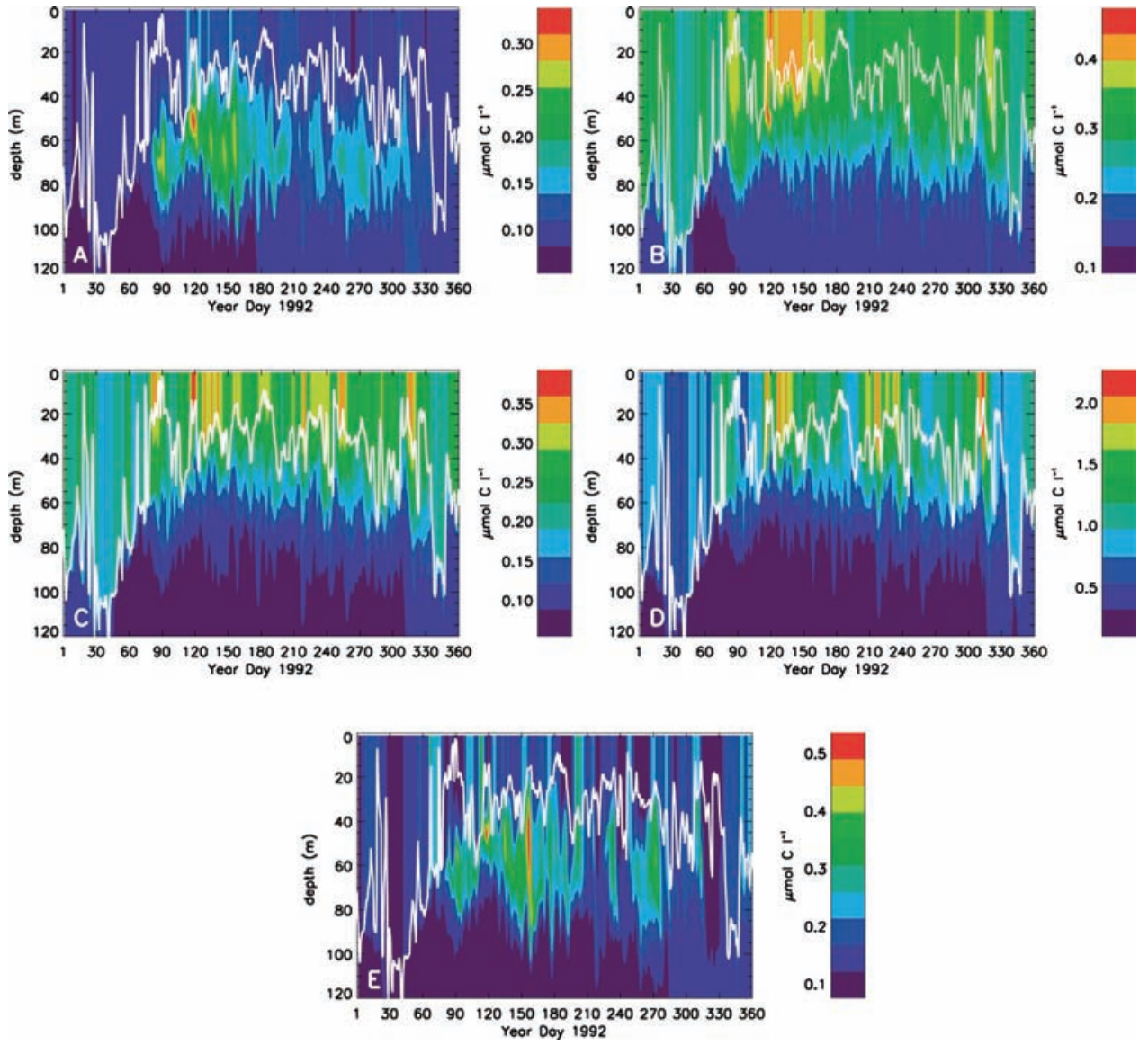

Figure 5. Simulated depth-time distributions of daily-averaged algal biomass ( $\left.\mu \mathrm{mol} \mathrm{Cl}^{-1}\right)$ of (A) low light-adapted Prochlorococcus (algal group 1), (B) high light-adapted Prochlorococcus (algal group 2), (C) Synechococcus (algal group 3), (D) autotrophic eukaryotes (algal group 4), and (E) large diatoms (algal group 5). Overlaid solid white line represents the mixed layer depth, which is obtained as described in Section 2a.

Algal group 3, Synechecoccus, blooms repeatedly over the course of the one-year simulation (Fig. 5C). The blooms are of short duration, 10 to 20 days, and are characterized by biomass greater than $0.3 \mu \mathrm{mol} \mathrm{C}^{-1}$. The maximum simulated biomass for this algal group was $0.39 \mu \mathrm{mol} \mathrm{C} \mathrm{^{-1 }}$ which occurred on YD117 in the upper $10 \mathrm{~m}$ of the water column (Fig. 5C). However, despite the numerous episodic blooms of this algal group, the biomass integrated over $120 \mathrm{~m}$ for Synechecoccus $\left(21 \mathrm{mmol} \mathrm{C} \mathrm{m}^{-2}\right)$ is less than that for Prochlorococcus $\left(43 \mathrm{mmol} \mathrm{C} \mathrm{m}^{-2}\right)$.

The simulated biomass for algal group 4, the autotrophic eukaryotes, is the highest of all five algal groups (Fig. 5D, Table 5). This algal group showed 12 intense blooms during 
Table 5. Annual integrated carbon biomass (Biomass, mmol $\mathrm{C} \mathrm{m}^{-2} \mathrm{yr}^{-1}$ ), percentage of total biomass, annual integrated primary production ( $\mathrm{PP}, \mathrm{mmol} \mathrm{C} \mathrm{m}^{-2} \mathrm{yr}^{-1}$ ), and percentage of total primary production for each algal group $(A G)$ calculated from the reference simulation done at $0 \mathrm{~N}$, 140W for 1992.

$\begin{array}{lcccc} & \text { Biomass } & \text { Total biomass }(\%) & \text { PP } & \text { Total PP }(\%) \\ A G 1 & 4,888 & 8 & 390 & 2 \\ A G 2 & 10,831 & 18 & 2,597 & 12 \\ A G 3 & 7,527 & 13 & 2,634 & 12 \\ A G 4 & 3,060 & 50 & 15,689 & 69 \\ A G 5 & 7,358 & 12 & 1,166 & 6\end{array}$

the one-year simulation (Fig. 5D), which were at least double the background biomass

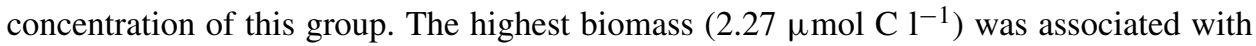
the bloom that occurred between YD300 and YD330. The majority (52\%) of the biomass of algal group 4 occurs in the mixed layer at depths shallower than $45 \mathrm{~m}$.

Algal group 5, the large diatoms, are mostly present below the mixed layer (Fig. 5E).

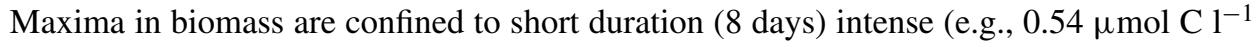
on YD117) blooms. Similar to algal group 1, the diatoms are essentially not present during the initial part of 1992 when El Niño conditions prevail.

\section{Chlorophyll a distributions}

The simulated chlorophyll $a$ distribution, which is the sum of all five algal groups (Fig. 6), shows patterns similar to those of the simulated biomass distributions. A deep chlorophyll maximum always exists during the year, but it is lower and deeper during the El Niño period compared to the rest of the year.
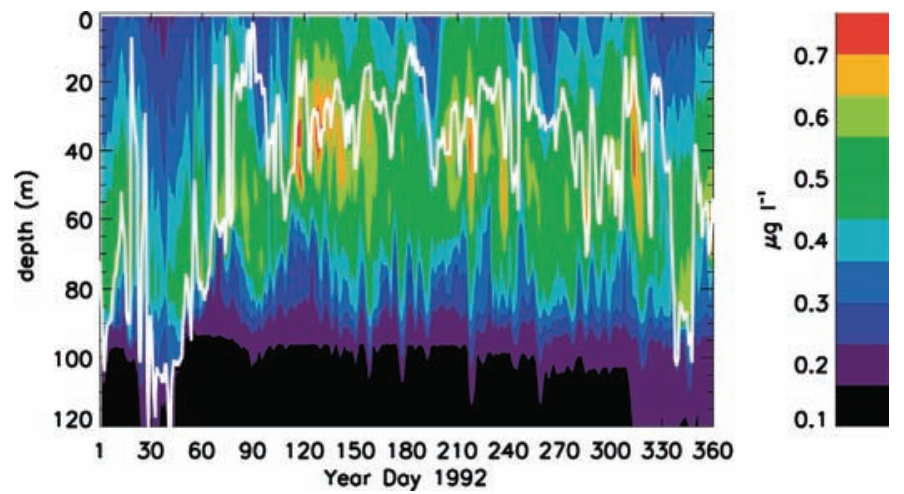

Figure 6. Simulated depth-time distribution of daily-averaged chlorophyll $a\left(\mu \mathrm{g}^{-1}\right)$ obtained from the sum of all five algal groups. Overlaid solid white line represents the mixed layer depth. 
Chlorophyll $a$ concentrations show a non-homogeneous distribution in the mixed layer being low at the surface, then they increase towards the bottom of the mixed layer. This difference between the carbon biomass and chlorophyll distributions is due to the influence of light and nutrient conditions on the chlorophyll. The deep chlorophyll maximum is generally located just below the mixed layer during most of the year, but during periods of extensive deepening of the mixed layer (YD25-40 and YD340-350) it is situated above the mixed layer. At around $100 \mathrm{~m}$, chlorophyll $a$ concentrations drop below $0.15 \mu \mathrm{g}^{-1}$. A weak deep chlorophyll maximum is observed around $80 \mathrm{~m}$ during the first three months of the year; whereas, during the rest of the year it is stronger with a maximum value of $0.75 \mu \mathrm{g} \mathrm{l}^{-1}$ on YD127 at $35 \mathrm{~m}$.

\section{Simulated algal group rates}

Primary production. The simulated distribution of primary production for the five algal groups (Fig. 7) is vertically less dispersed compared to the biomass distributions (Fig. 5). Primary production is low during El Niño conditions, increases during non-El Niño conditions and occurs in episodic events of varying duration.

Primary production for algal group 1 (Fig. 7A) appears in a narrow band below the mixed layer between 45 and $70 \mathrm{~m}$. Maximum production occurs between YD80 and YD160, with

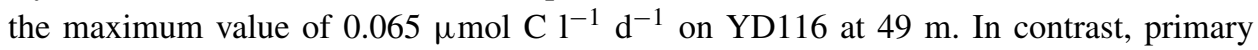
production of the high-light adapted Prochlorococcus occurs at shallower depths (with

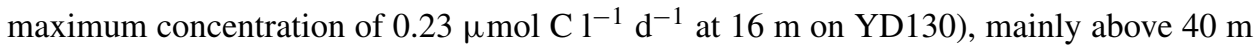
throughout the one-year simulation (Fig. 7B). The most intense primary production event by this algal group, between YD120 and YD150, accounts for 20\% of primary production of the algal group for 1992 .

Primary production for algal groups 3 and 4 is confined to the upper $20-40 \mathrm{~m}$ and occurs in several episodic events. The timing of the maxima in primary production for the two algal groups is similar. However, the primary production of algal group 4 is considerably higher than that of algal group 3, 15,689 $\mathrm{mmol} \mathrm{C} \mathrm{m}^{-2} \mathrm{yr}^{-1}$ versus 2,634 $\mathrm{mmol} \mathrm{C} \mathrm{m}^{-2} \mathrm{yr}^{-1}$, respectively (Table 5).

The primary production associated with algal group 5 is centered in a band at about $40 \mathrm{~m}$. The highest primary production by this group appears on YD155 at $30 \mathrm{~m}$. Short duration intense pulses characterize the overall pattern of primary production for this algal group, and as such it differs from what is observed for the other algal groups. As a result, the contribution of this algal group to the integrated annual primary production is only $6 \%$ (Table 5).

Growth rates. The maximum daily growth rates for each algal group occur at different depths and days (Figs. 8A-E). All groups reach their maximum actual growth rates during the first half of the year (Table 6) when El Niño conditions prevail. Higher water temperatures during this time result in higher growth rates (cf. Section 5ai). The narrow bands of low 

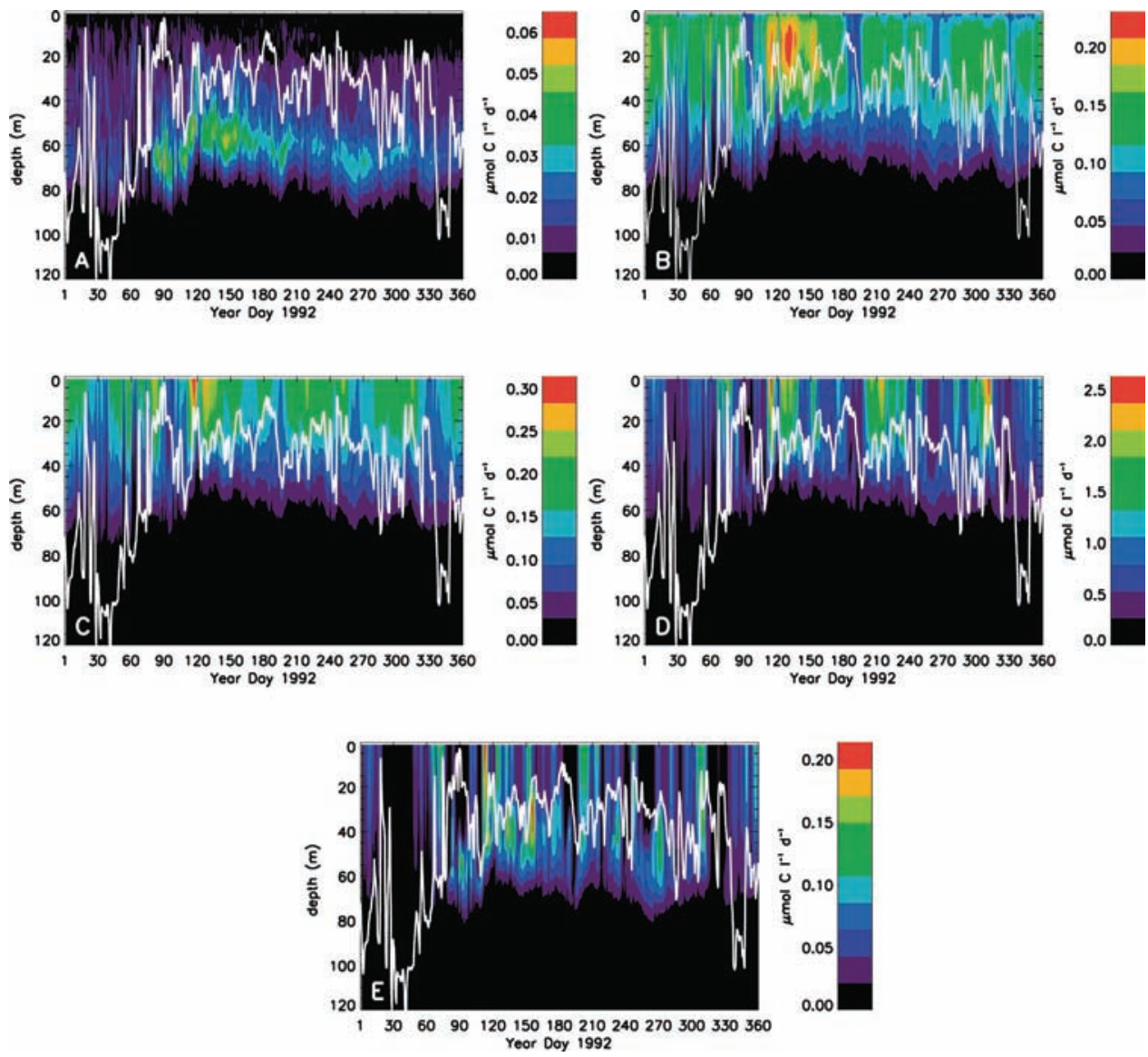

Figure 7. Simulated depth-time distributions of daily-averaged algal primary production $\left(\mu \mathrm{mol} \mathrm{C}{ }^{-1}\right.$ $\mathrm{d}^{-1}$ ) of (A) low light-adapted Prochlorococcus (algal group 1), (B) high light-adapted Prochlorococcus (algal group 2), (C) Synechococcus (algal group 3), (D) autotrophic eukaryotes (algal group 4), and (E) large diatoms (algal group 5). Overlaid solid white line represents the mixed layer depth.

light-limited growth rates are distributed among high light-limited growth rates during this part of the year, resulting in a high variability in light-limited growth rates. The highest nutrient-limited growth rates are also observed during El Niño conditions (Fig. 9B), but these high growth rates generally occur below the mixed layer, except for algal group 1. Within the mixed layer, all algal groups, except algal group 1 are nutrient-limited and the levels of nutrient limitation experienced by each algal group show temporal variability.

The simulated light-limited growth rate for algal group 1 increases from a value of zero at the surface to a maximum value between 40 and $60 \mathrm{~m}$, after which it decreases (Salihoglu, 2005). There are short periods of high light-limited growth rates reached by this group that 

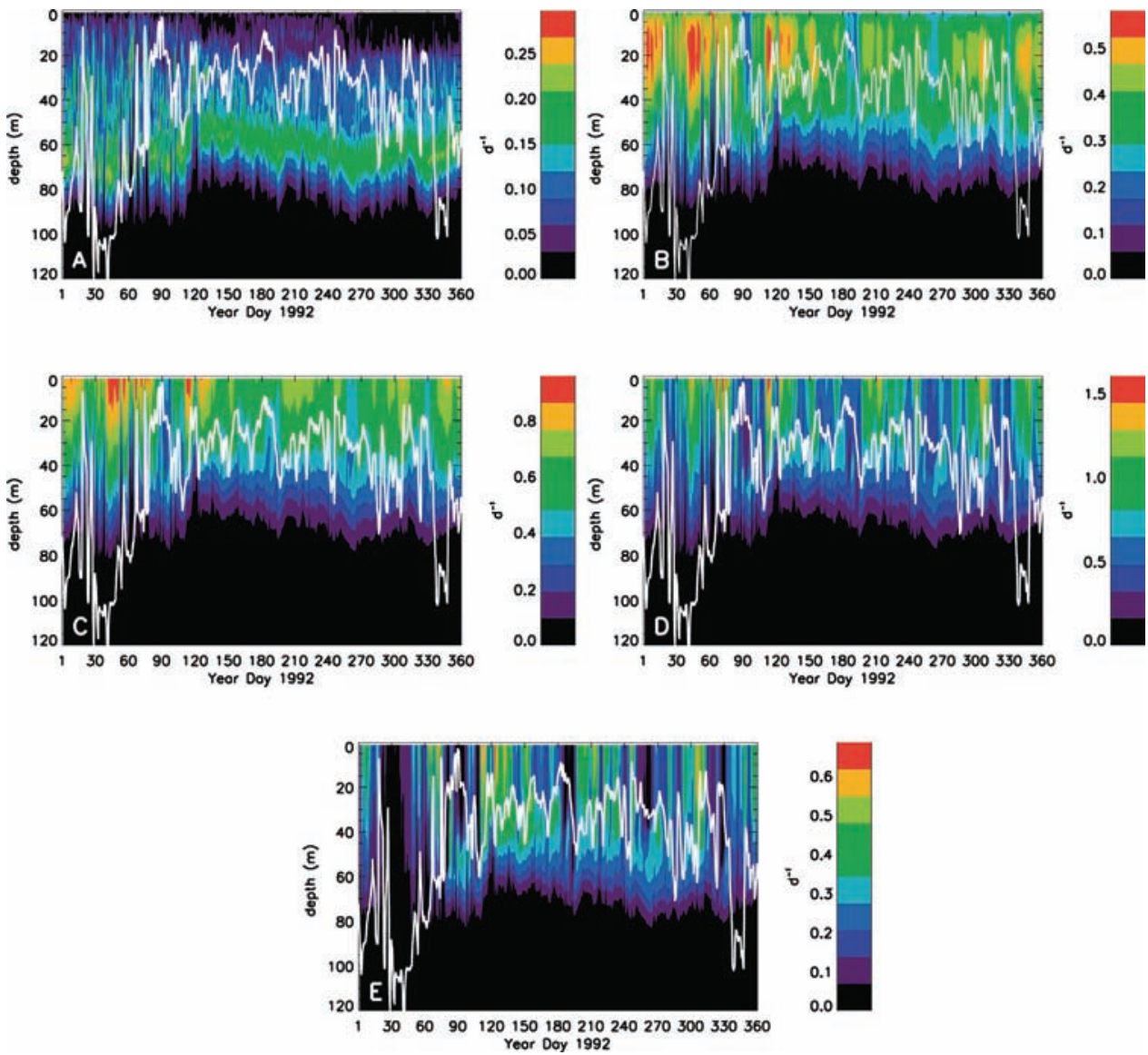

Figure 8. Simulated depth-time distributions of daily averaged actual growth rates $\left(\mathrm{d}^{-1}\right)$ of (A) low light-adapted Prochlorococcus (algal group 1), (B) high light-adapted Prochlorococcus (algal group 2), (C) Synechococcus (algal group 3), (D) autotrophic eukaryotes (algal group 4), and (E) large diatoms (algal group 5). Overlaid solid white line represents the mixed layer depth.

Table 6. Maximum (Max) actual growth rate, day of occurrence, and depth of occurrence for each algal group.

\section{Max growth rate $\left(d^{-1}\right)$}

$\begin{array}{ll}A G 1 & 1.32 \\ A G 2 & 1.56 \\ A G 3 & 2.18 \\ A G 4 & 3.9 \\ A G 5 & 1.77\end{array}$

Time of occurrence (YD)

38

113

113

109
Depth (m)

13

surface

surface

59

Maximum rates were obtained from the reference simulation done at 0N, 140W for 1992 . 

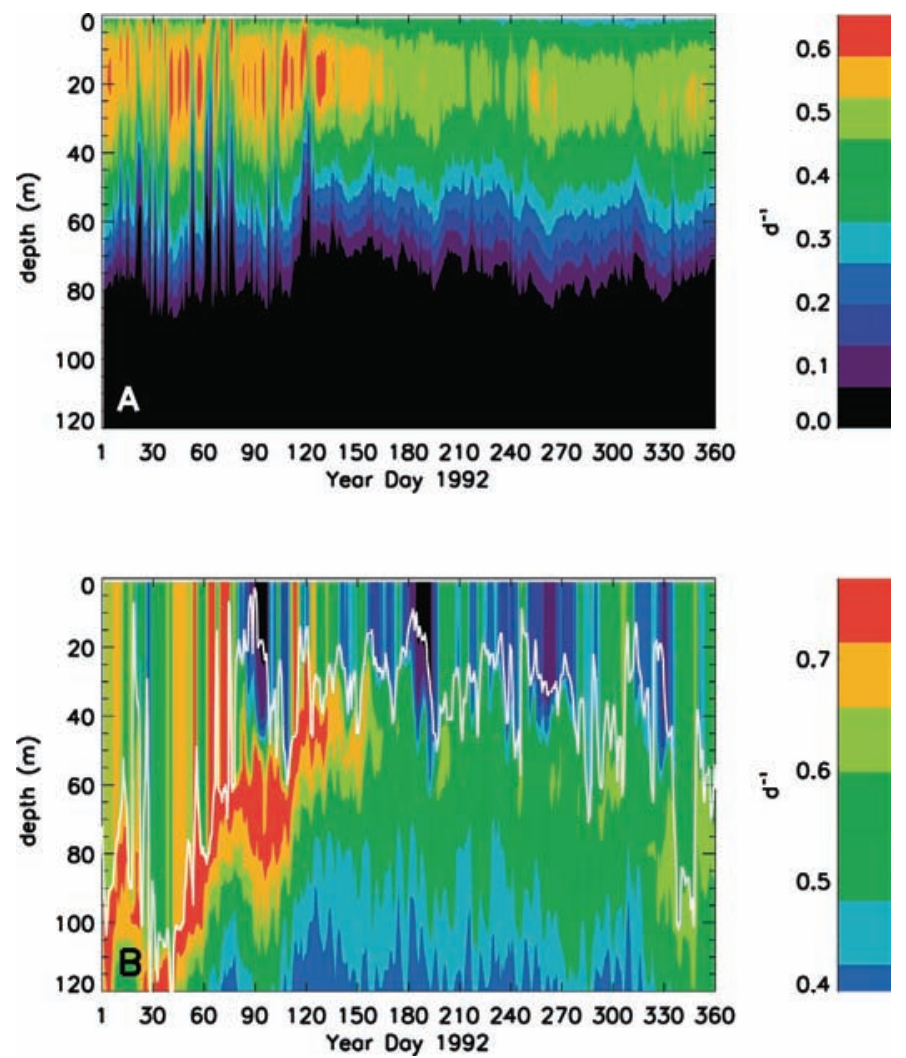

Figure 9. Simulated depth-time distributions of daily-averaged (A) light-limited and (B) nutrientlimited growth rates $\left(\mathrm{d}^{-1}\right)$ of high light-adapted Prochlorococcus (algal group 2). Only the growth rates of algal group 2 are given to set an example. Overlaid solid white line represents the mixed layer depth.

occur at shallow depths (i.e. $20 \mathrm{~m}$ ). These periods are especially common during El Niño conditions, such as the event on YD60-YD75 at $\sim 20 \mathrm{~m}$, which coincides with high cloud cover (Fig. 4A). The nutrient-limited growth rate of this group shows little variation over the one-year simulation. In the surface waters, algal group 1 is strongly light inhibited and nutrient limitation has a very weak effect on this algal group. As a result, the actual growth rate of algal group 1 is similar to the light-limited growth rate distribution for this group. This indicates that the growth of this group is controlled mainly by light.

In the surface waters, the light-limited growth rate of algal group 2 is below its maximum value due to light inhibition and it reaches its maximum value between 10-30 m (Fig. 9A). Similar to algal group 1, short periods of high light-limited growth rate values of this algal group occur at shallow depths when El Niño conditions are present. Nutrient limitation on the growth rate of algal group 2 occurs for short periods during YD70-YD100, YD180-YD200, 


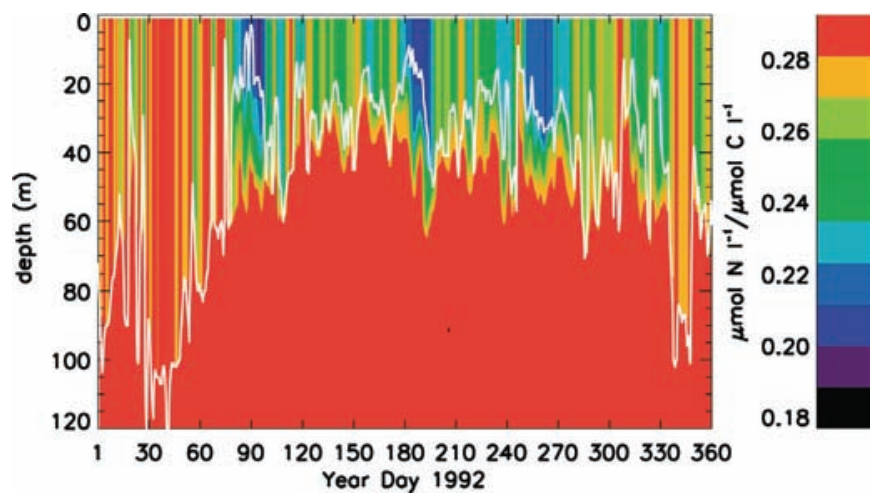

Figure 10. Simulated depth-time distribution of cellular nitrogen to carbon ratios $\left(\mu \mathrm{mol} \mathrm{N}{ }^{-1} / \mu \mathrm{mol}\right.$ $\mathrm{C}^{-1}$ ) of high light-adapted Prochlorococcus (algal group 2). The ratios of other groups always stay at their maximum values, therefore they are not given. Overlaid solid white line represents the mixed layer depth.

and YD250-YD260 in the mixed layer (Fig. 9B). As a result, the combined effects of light inhibition and nutrient limitation control the growth rate of algal group 2, and the actual growth rate (Fig. 8B) of this group reflects the effects of both processes.

The effect of light limitation on the growth rates of algal groups 3 to 5 is similar (Salihoglu, 2005). These groups do not experience any light limitation in the surface waters and their growth rates gradually decline below $20 \mathrm{~m}$, dropping to zero around $80 \mathrm{~m}$. The influence of nutrient limitation on growth is less on algal group 3 compared to algal groups 4 and 5 . Algal group 5 is most strongly limited by nutrients compared to the other algal groups. The combined effect of light and nutrients on algal groups 3 to 5 is such that the daily-averaged actual growth rates of these algal groups are mainly controlled by nutrient limitation in the mixed layer and by light limitation below the mixed layer (Figs. 8C-E).

\section{Algal group cellular nutrient ratios}

Cellular nutrient to carbon ratios of the algal groups are good indicators of nutrient-limited growth. High nitrate concentrations in the region keep the simulated cellular nitrogen to carbon ratios of all algal groups at their maximum values (Salihoglu, 2005) except algal group 2 (Fig. 10). This indicates that only algal group 2 is limited by nitrogen during the year. The cellular nitrogen to carbon ratios for this group show considerable temporal variability during the year and that nitrogen limitation occurs primarily in the mixed layer.

The cellular iron to carbon ratios of all groups begin to increase at the bottom of the mixed layer, reaching their maximum values 5 to $30 \mathrm{~m}$ below the mixed layer (Figs. 11A-E). The iron to carbon ratios of algal group 1 are always at their maximum values (Fig. 11A), which indicates that this group is not iron limited. Iron to carbon ratios of algal groups 2 and 3 remain lower than their maximum values within the mixed layer except for YD60-75, YD210-225, and YD310-320 (Figs. 11B and C). For algal groups 4 and 5, iron to carbon 

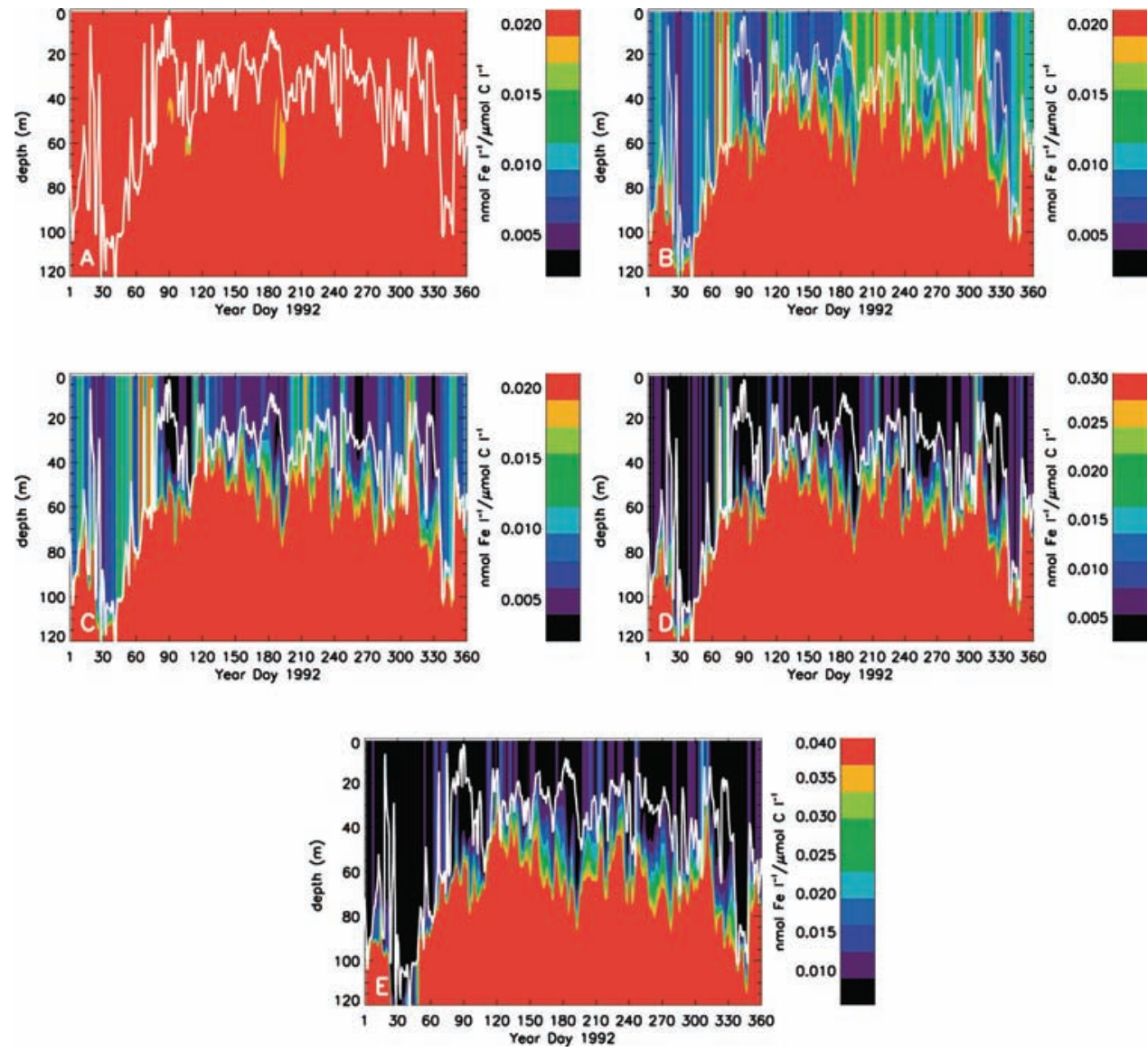

Figure 11. Simulated depth-time distributions of cellular iron to carbon ratios (nmol $\mathrm{Fe} \mathrm{1}^{-1} / \mu \mathrm{mol} \mathrm{C}$ $1^{-1}$ ) of (A) low light-adapted Prochlorococcus (algal group 1), (B) high light-adapted Prochlorococcus (algal group 2), (C) Synechococcus (algal group 3), (D) autotrophic eukaryotes (algal group 4), and (E) large diatoms (algal group 5). Overlaid solid white line represents the mixed layer depth.

ratios are at their minimum values within the mixed layer during most of the year (Figs. 11D and E). For these groups, the cellular iron to carbon ratios never reach their maximum value within the mixed layer, with the exception of algal group 4 , which reaches its maximum ratio value at YD307.

In the model, only algal group 5 has a cellular silicate compartment (Fig. 2). The cellular silicate to carbon ratios (Salihoglu, 2005) for this algal group are always at their maximum value, indicating that this group is not silicate limited.

iii. Zooplankton. The simulated distributions show little temporal variability in microzooplankton biomass concentration throughout the year (Fig. 12A). However, in contrast, 

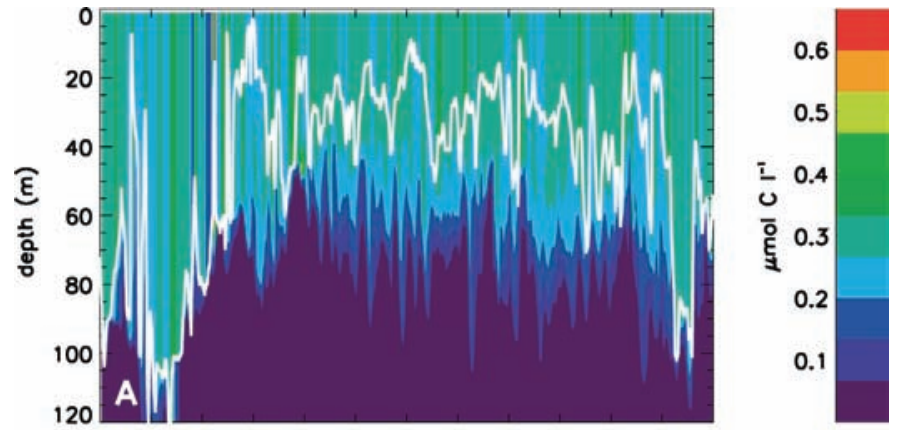

$130 \quad 60 \quad 90 \quad 120150180210240270300330360$ Yeor Doy 1992
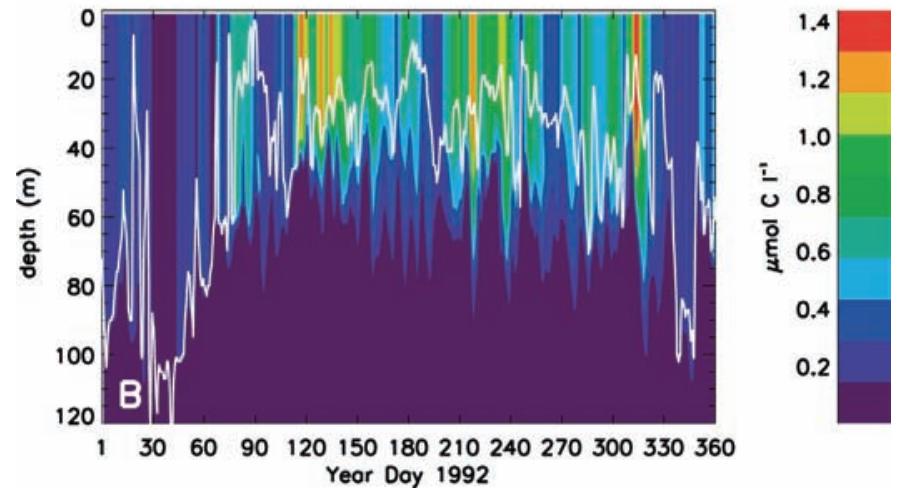

Figure 12. Simulated depth-time distributions of biomass $\left(\mu \mathrm{mol} \mathrm{C}{ }^{-1}\right)$ of $(\mathrm{A})$ microzooplankton, and (B) mesozooplankton. Overlaid solid white line represents the mixed layer depth.

considerable temporal variability occurs in the mesozooplankton concentration (Fig. 12B). The distribution of mesozooplankton shows the general features of low biomass during the first 100 days, followed by increased biomass which persists for the remainder of 1992. The initial low mesozooplankton biomass corresponds to El Niño conditions and deep mixed layers. Throughout the latter part of the year, the micro- and mesozooplankton show episodic increases/decreases in biomass, although these fluctuations are very weak for microzooplankton. These events persist for 6 to 20 days.

$i v$. Nutrients. The simulated distributions of nitrate, iron, and silicate concentrations in the upper $100 \mathrm{~m}$ show the general features of low nutrient conditions during the first 100 days, which correspond to El Niño conditions, followed by increased concentrations at about YD120, which persist for the remainder of 1992 (Figs. 13A, C and D). The simulated ammonium distribution (Fig. 13B) differs from the other nutrients in that its concentration is higher between YD70 and YD180 compared to the rest of the year. Distributions of all 

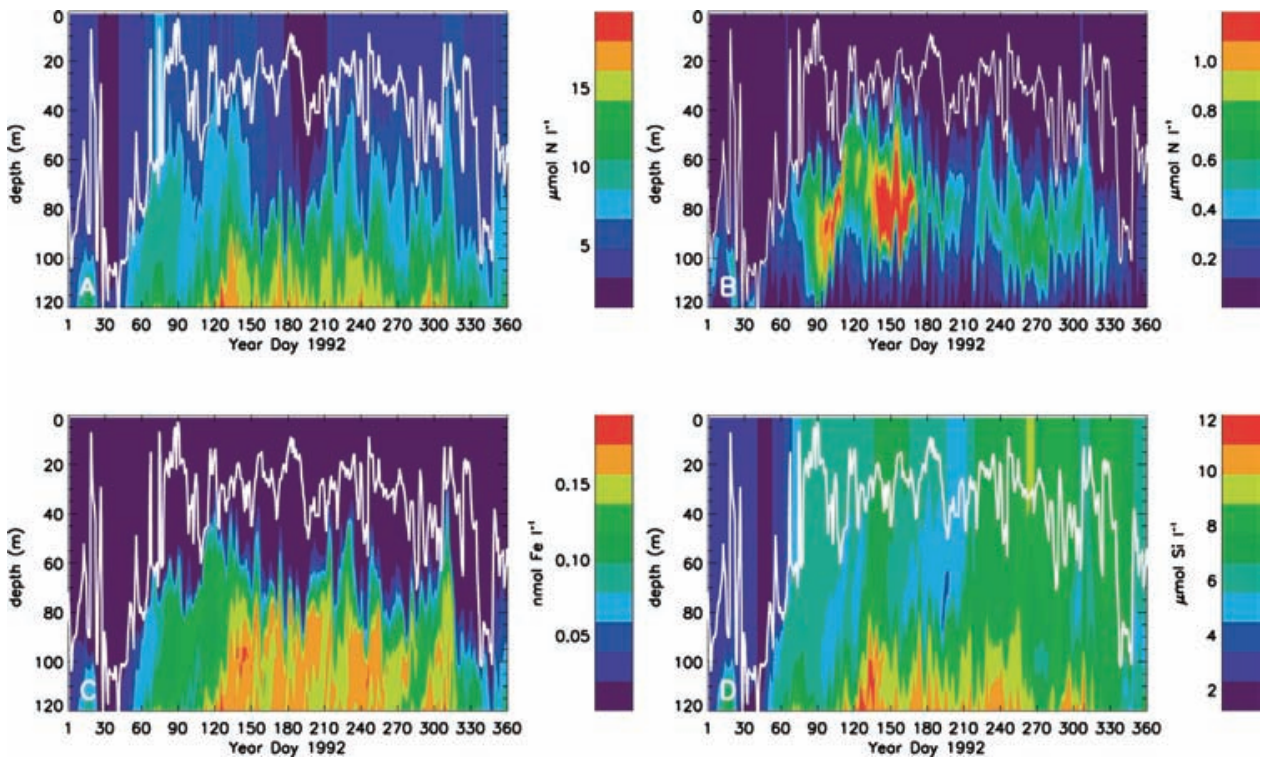

Figure 13. Simulated depth-time distributions of concentrations of (A) nitrate $\left(\mu \mathrm{mol}^{-1}\right)$, (B) ammonium $\left(\mu \mathrm{mol} 1^{-1}\right),(\mathrm{C})$ iron $\left(\mathrm{nmol} 1^{-1}\right)$, and (D) silicate $\left(\mu \mathrm{mol} \mathrm{l}^{-1}\right)$. Overlaid solid white line represents the mixed layer depth.

nutrients are homogeneous within the mixed layer. All nutrients increase with depth except for ammonium.

Nitrate concentrations are lower during El Niño conditions, although this nutrient is never depleted $\left(>2 \mu \mathrm{mol}^{-1}\right.$ ) within the water column (Fig. 13). Increases in nitrate concentration coincide with episodic upwelling events that persist for 6 to 20 days (Fig. 3).

Ammonium is depleted $\left(<0.1 \mu \mathrm{mol}^{-1}\right)$ within the mixed layer (Fig. 13B) where phytoplankton demand for this nutrient is high. The ammonium maximum occurs below the mixed layer where the majority of nitrogen regeneration occurs. The peaks in ammonium concentration follow increases in algal group primary production (Figs. 7A-E). Ammonium concentrations are higher during the first half of the year with maximum values of $1.1 \mu \mathrm{mol}^{-1}$ between YD130 and YD175. These maxima follow persistently high primary production values observed during YD105-165 (Fig. 7).

Iron concentrations are lower during El Niño conditions (Fig. 13C). Similar to ammonium, iron is also depleted in the mixed layer $\left(<0.03 \mathrm{nmol}^{-1}\right)$. Iron concentrations are higher during the second half of the year below the mixed layer, showing a maximum value of $0.195 \mathrm{nmol} \mathrm{l}^{-1}$ on YD308 at $120 \mathrm{~m}$. The strongest injection of iron into the mixed layer occurs around YD315.

Silicate follows a similar trend to nitrate (Fig. 13D). Silicate is never depleted within the water column and attains a minimum value of $1.8 \mu \mathrm{mol} \mathrm{l}^{-1}$ on YD43. 


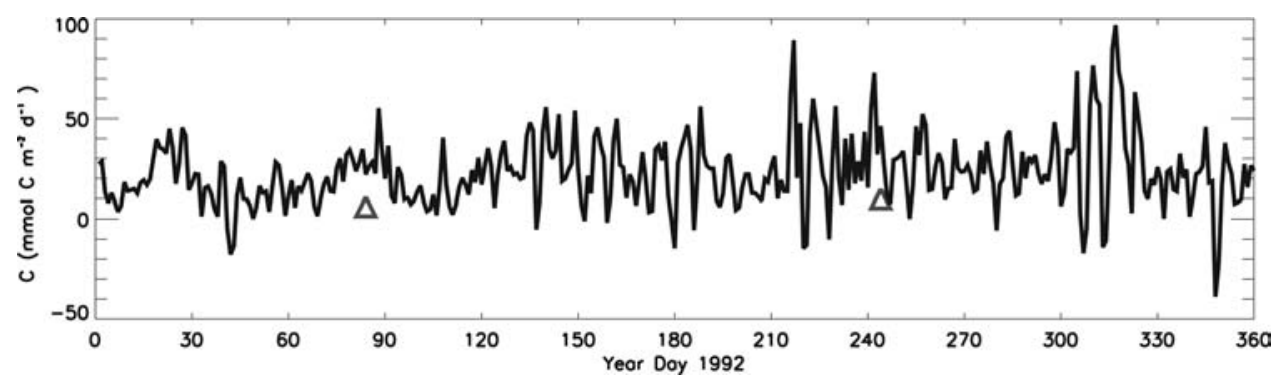

Figure 14. Simulated time distribution of organic particulate carbon fluxes $\left(\mathrm{mmol} \mathrm{C} \mathrm{m}^{-2} \mathrm{~d}^{-1}\right)$ at $120 \mathrm{~m}$. Positive values indicate that the flux is towards the ocean bottom and the negative values indicate that the flux is towards the ocean surface. The carbon fluxes at $120 \mathrm{~m}(\triangle)$ measured during the two U.S. JGOFS EqPac survey cruises, S1 and S2, are shown for comparison.

v. Particulate carbon fluxes. The flux of organic particulate carbon is obtained from the sum of the small and large detrital carbon fluxes at $120 \mathrm{~m}$. Daily particulate carbon fluxes through the model bottom boundary at $120 \mathrm{~m}$ show high temporal variability during the year (Fig. 14). Similar to primary production, carbon export is also lower during the El Niño period.

The carbon fluxes are highest when a downwelling event (Fig. 3B) follows a period of high primary production, such as the events that occur on YD15-30, YD75-90, YD 120170, YD220-240, and YD300-320 (Fig. 7). The annual integrated particulate carbon flux past $120 \mathrm{~m}$ is $10,416 \mathrm{mmol} \mathrm{C} \mathrm{m}^{-2} \mathrm{yr}^{-1}$. A similar calculation for the carbon flux past $50 \mathrm{~m}$ yields an annual value of $10,735 \mathrm{mmol} \mathrm{C} \mathrm{m}^{-2} \mathrm{yr}^{-1}$. The small decrease in these estimated carbon fluxes indicate the effect of remineralization processes on the vertical flux of particulate carbon.

vi. Simulated upper water column carbon budget. Analyses of the distributions obtained from the reference simulation indicate that microzooplankton grazing of algal groups 2-4 ( $\sim 40 \mathrm{mmol} \mathrm{C} \mathrm{m} \mathrm{m}^{-2} \mathrm{~d}^{-1}$ ) provides the primary pathway for carbon transfer between the primary and secondary producers (Fig. 15). Micrograzers remove $71 \%$ of the small phytoplankton, which is consistent with observations (Landry et al., 1995) that show 53-83\% of small phytoplankton grazed by microzooplankton. Dam et al. (1995) reported that mesozooplankton only removed $1-12 \%$ of the daily primary production, almost all due to grazing on diatoms (Bidigare and Ondrusek, 1996). The simulated mesozooplankton grazing removes only $4 \%$ of the daily production as diatoms which is consistent with observations. The simulated microzooplankton contribution to mesozooplankton grazing is $\sim 80 \%$ (19 mmol $\mathrm{C} \mathrm{m}^{-2} \mathrm{~d}^{-1}$ ) and Zhang et al. (1995) reported that small animals (200-500 $\left.\mu \mathrm{m}\right)$ contributed more than $50 \%$ (range $34-80 \%$ ) of total mesozooplankton grazing.

The simulated carbon transfers between the two zooplankton compartments and the two detritus compartments are similar $\left(\sim 29 \mathrm{mmol} \mathrm{C} \mathrm{m} \mathrm{m}^{-2} \mathrm{~d}^{-1}\right.$, Fig. 15). The removal of 




Figure 15. Flowchart of the simulated carbon budget $\left(\mathrm{mmol} \mathrm{C} \mathrm{m}^{-2} \mathrm{~d}^{-1}\right)$ obtained for the lower trophic level model structure used in this study. Arrows indicate the direction of carbon transfer between model compartments in mmol $\mathrm{C} \mathrm{m}^{-2} \mathrm{~d}^{-1}$. The ecosystem variables are daily averaged over the euphotic zone $(0-120 \mathrm{~m})$. The numbers in the algal group and zooplankton compartments are the net daily primary production and assimilated part of grazed carbon, respectively. Arrows between algal groups and zooplankton compartments and the arrow between microzooplankton and mesozooplankton compartments indicate net daily grazing. Arrows between zooplankton and small (Detritus1) detritus and large (Detritus2) detritus compartments indicate the carbon loss from zooplankton resulting from unassimilated grazing, mortality and excretion. Arrows between the detritus compartments and the dissolved organic carbon (DOC, which is not tracked in the model) indicate the loss of carbon from the detritus compartments by remineralization. Abbreviations on the flow chart are: LL-low light-adapted; HL-high light-adapted; DOC-dissolved organic carbon.

particulate carbon through remineralization comprises a major part of both small and large detrital carbon pools. About $72 \%$ of the simulated small detrital carbon and $50 \%$ of the simulated large detrital carbon are converted to dissolved organic carbon in the euphotic zone $(0-120 \mathrm{~m})$.

The simulated annual-averaged vertical distributions of carbon production and removal suggest that microzooplankton grazing exceeds the production by light inhibited species (i.e. algal groups 1 and 2) at the surface (Figs. 16A and B), and it exceeds the production by all algal groups at deeper parts of the euphotic zone where growth is light limited (Figs. 16A and E). Grazing removes all the daily algal group 5 production in the upper $45 \mathrm{~m}$ (Fig. 16E), although the growth of this group is not inhibited by light over this depth range as is the case for algal groups 1 and 2. However, nutrient limitation is a strong effect on this algal group in the surface waters, which extensively reduces growth rates. Between 40 and $70 \mathrm{~m}$, nutrient limitation is less, which allows algal group 5 production to exceed removal by mesozooplankton. 

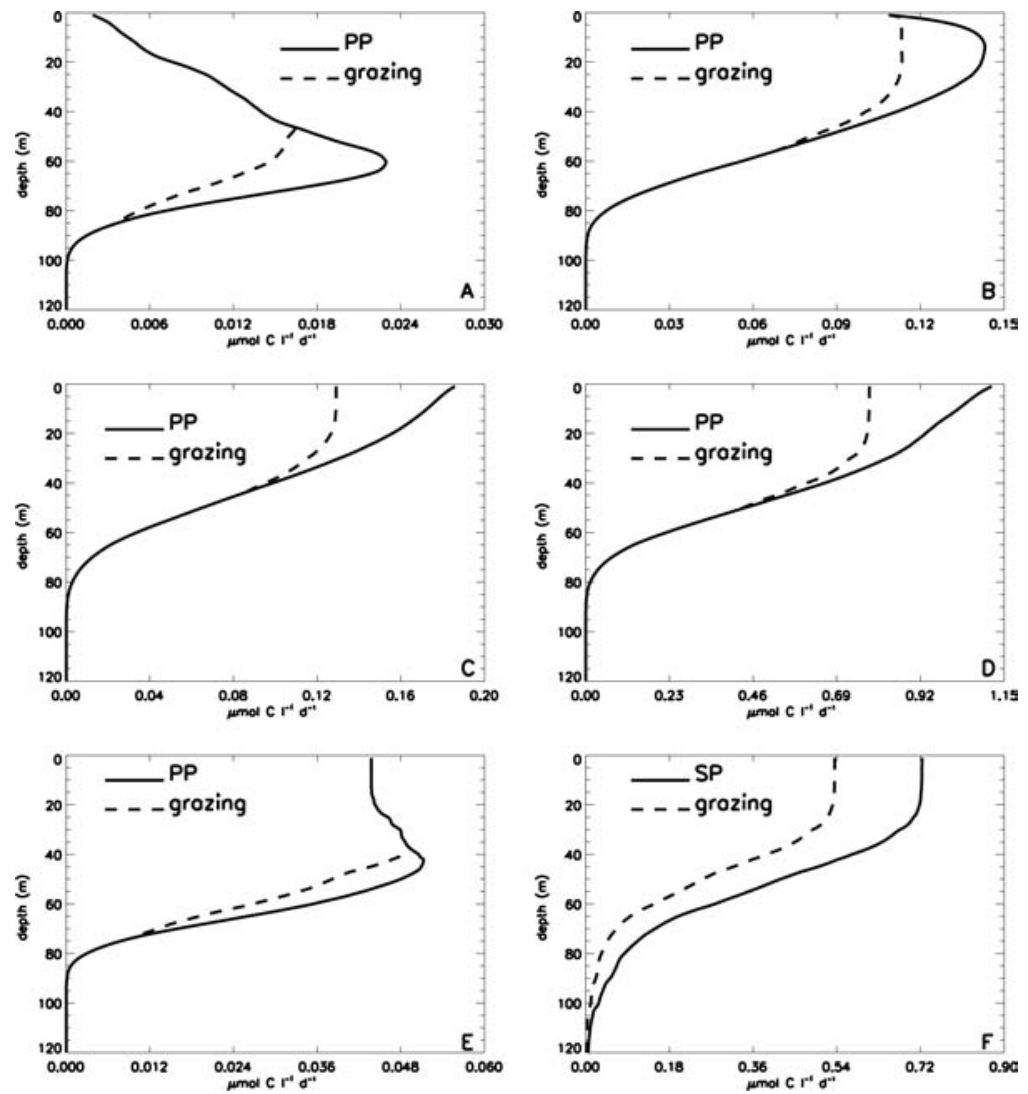

Figure 16. Simulated profiles of annual-averaged carbon production (solid line) and removal of carbon production by grazing (dashed line) $\left(\mathrm{mmol} \mathrm{C}^{-1} \mathrm{~d}^{-1}\right)$ of (A) low light-adapted Prochlorococcus (algal group 1), (B) high light-adapted Prochlorococcus (algal group 2), (C) Synechococcus (algal group 3), (D) autotrophic eukaryotes (algal group 4), (E) large diatoms (algal group 5) and (F) microzooplankton. Microzooplankton graze algal groups 1-4 and mesozooplankton graze algal group 5 and microzooplankton, as explained in section 3.1. Abbreviations used are: PP-primary production by algal groups; SP- secondary production by microzooplankton.

The simulated mesozooplankton production is supported by grazing of algal group 5 as well as by grazing of microzooplankton (Fig. 2). The simulated profiles show that daily microzooplankton secondary production exceeds removal by mesozooplankton throughout the whole water column (Fig. 16F). The grazing removal corresponds to $\sim 65 \%$ of daily secondary production by microzooplankton throughout the water column.

\section{b. Model-data comparison}

The biogeochemical data measured during the U.S. JGOFS EqPac field studies (Murray et al., 1994, 1995) are used for comparison with the simulated distributions for specific days 


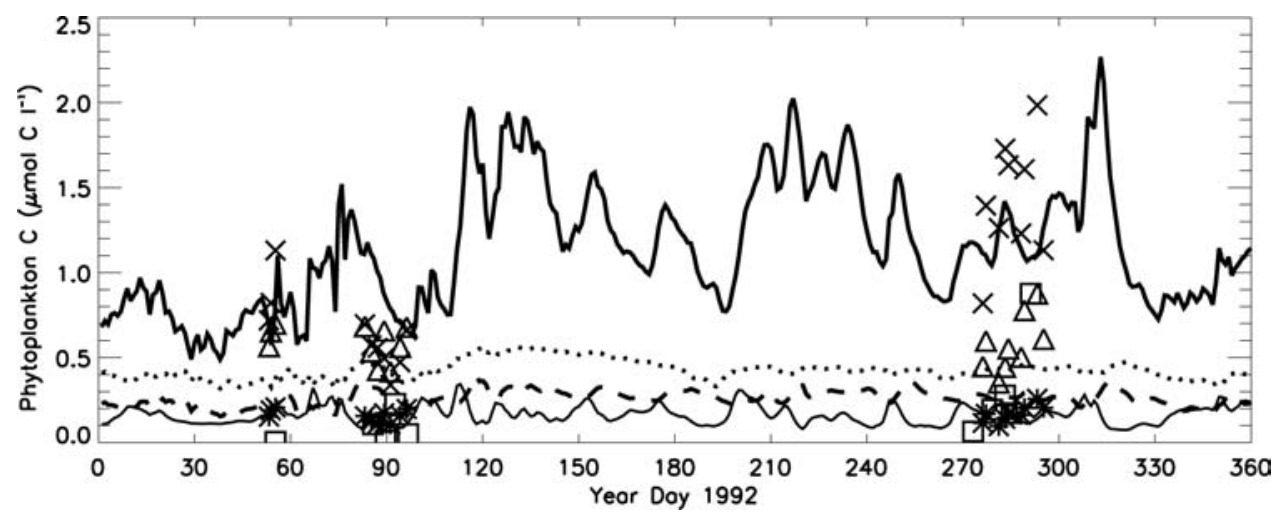

Figure 17. Simulated time distribution of the combined low light-adapted and high light-adapted Prochlorococcus (dotted line), Synechococcus (dashed line), autotrophic eukaryotes (thick solid

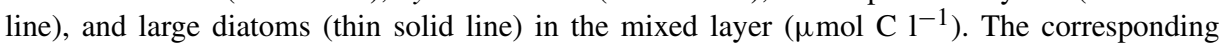
measurements for each algal group from the four U.S. JGOFS EqPac cruises are shown by $\Delta, *, \times$, and $\square$, respectively. Measurements from the cruises do not distinguish between the two ecotypes of Prochlorococcus spp. Therefor, the simulated biomass values of algal groups 1 and 2 are summed up for comparison with the cruise measurements.

and depths, as well as for comparisons on a depth-integrated basis. Some of the estimated physical and optical terms used in the simulations were also compared with cruise data. The mixed layer depth and underwater spectral irradiance values obtained at the nominal wavelengths $(410,441,488,520,550,560,589,633,656,671,683,694 \mathrm{~nm})$ during TS1 and TS2 cruises compare well with the simulated values (not shown).

The simulated mixed layer biomass concentrations of each algal group (Fig. 17), as well as the $120-\mathrm{m}$ integrated values are in the same dynamic range with the corresponding concentrations calculated for the same time period from the data. The simulated distribution shows three blooms of Prochlorococcus (algal groups 1 and 2) between YD110-YD160, YD200-YD255, and YD300-YD320, for which the biomass is as high as measured biomass during TS2.

The simulated time distribution of the algal groups shows a wide range of temporal variability, including a strong 6-8-day periodicity. This high frequency variability is not captured in cruise observations. However, general features observed during the cruises are reproduced by the simulations. The observations and simulation results show that the phytoplankton biomass is dominated by algal group 4 throughout the year, with algal groups $1+2$ being secondary in dominance (Fig. 17). Early in the year, during El Niño conditions, the biomass associated with algal group 4 (autotrophic eukaryotes) and algal group $1+2$ are similar and algal group 3 dominates over algal group 5 in observations and simulations. During the latter part of the year, the simulated biomass of algal group 4 is double that of algal group $1+2$ which is in agreement with the observations. Also, the observations and simulations show increases in the biomass of algal groups 3 and 5 during the second part of 


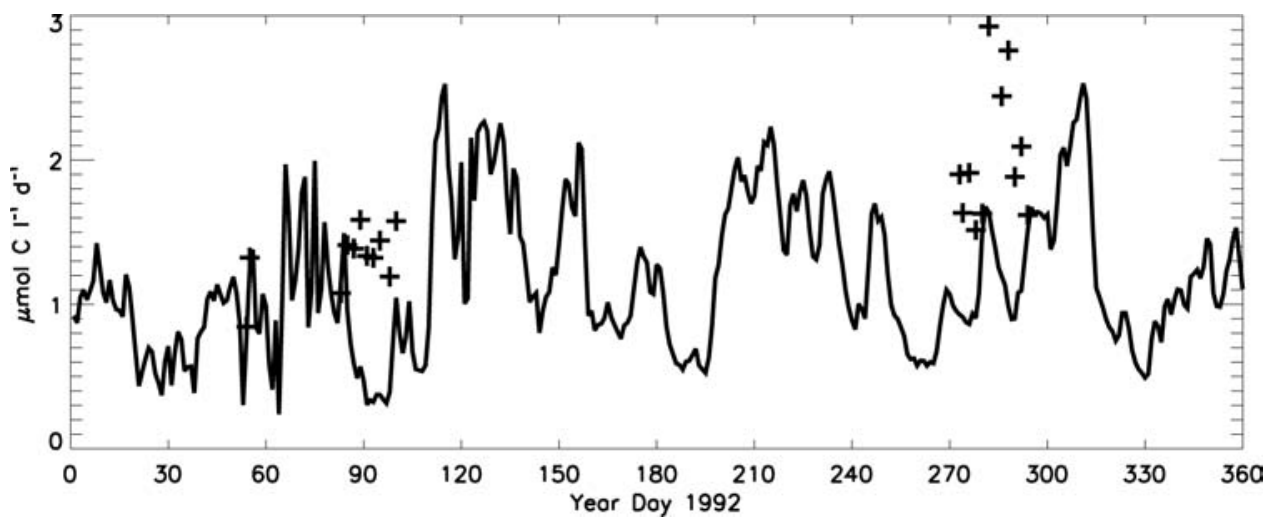

Figure 18. Simulated time distribution of daily-averaged primary production in the mixed layer $(\mu \mathrm{mol}$ $\left.\mathrm{C}^{-1} \mathrm{~d}^{-1}\right)$. The corresponding measurements from the four U.S. JGOFS EqPac cruises are shown with + .

the year and the magnitude of this increase is comparable for both groups. The simulated distributions show that the temporal variability in the biomass of algal group 5 is higher than that for algal group 3 and that algal group 5 occasionally dominates over algal group 3 . The exceptionally high diatom (algal group 5) concentration $\left(1 \mu \mathrm{mol} \mathrm{C}{ }^{-1}\right)$ observed during the TS2 cruise on YD295 is not reproduced in the simulation.

The simulated mixed layer (Fig. 18) and integrated primary production underestimates measured values from the cruises. However, the simulated primary production values do reproduce the relative increase in primary production observed during the TS2 cruise which occurred during the latter part of the year. Primary production goes through several max$\mathrm{ima} /$ minima cycles during the year, with the maximum rate of $2.62 \mu \mathrm{mol} \mathrm{Cl}^{-1} \mathrm{~d}^{-1}$ occurring on YD315. The simulated maxima in primary production on YD115-Y160, YD200-YD255, and YD300-YD315 are comparable to the primary production rates measured during the TS2 cruise.

The simulated and observed accessory pigments in the mixed layer are in reasonable agreement (Fig. 19). Observations indicate that below $60 \mathrm{~m}$ chlorophyll $a$ and other pigment concentrations were higher during the S1 and TS1 cruises compared to the S2 and TS2 cruises; whereas, surface values were slightly lower during S1 and TS1. The model successfully reproduces this difference in the chlorophyll $a$ and pigment concentrations between two seasons.

The vertical profiles of chlorophyll $a$ measured during the two time series cruises provide an additional comparison for the simulated chlorophyll $a$ values (Figs. 20A and B). The measured chlorophyll $a$ profiles show a deep chlorophyll maximum between 50 and $80 \mathrm{~m}$ during the first cruise (YD83 to YD98), which is deeper than the chlorophyll maximum observed during the second cruise (YD272 to YD284) which occurred between 45 and $65 \mathrm{~m}$. The simulated chlorophyll $a$ profile reproduces the change in depth and the magnitude 


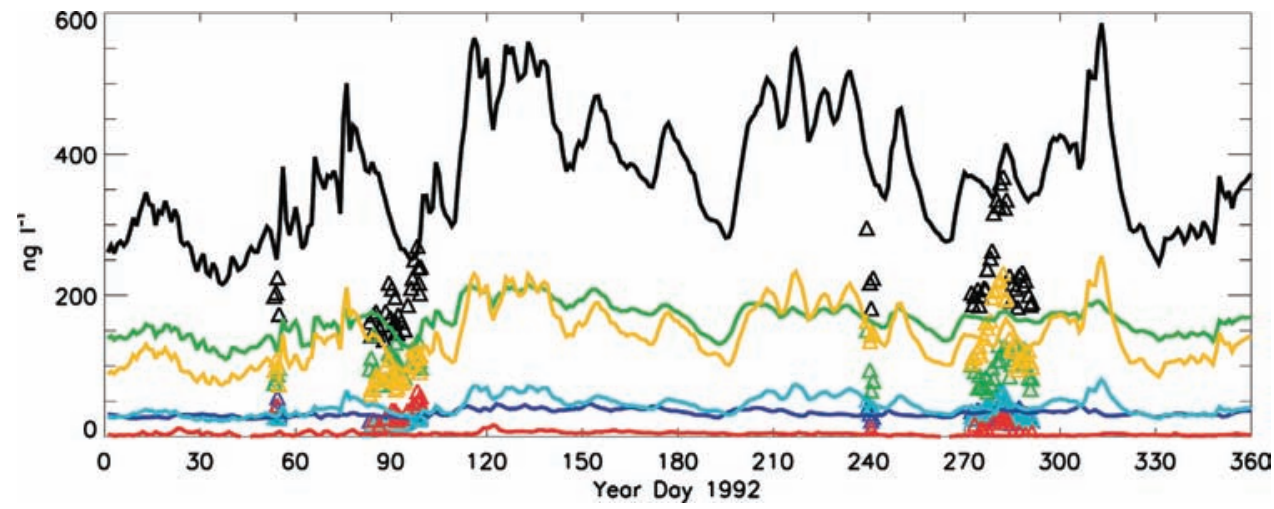

Figure 19. Simulated time distribution of daily-averaged chlorophyll $a$ (solid black line), chlorophyll $b$ (purple), chlorophyll $c$ (blue), photoprotective carotenoids (green), photosynthetic carotenoids (yellow), and phycoerithyrin (red) in the mixed layer $\left(\mathrm{ng} \mathrm{l}^{-1}\right.$ ). The corresponding pigment measurements from the four U.S. JGOFS EqPac cruises are shown with $\Delta, *, \square,+, \Delta$ and $\times$, respectively.
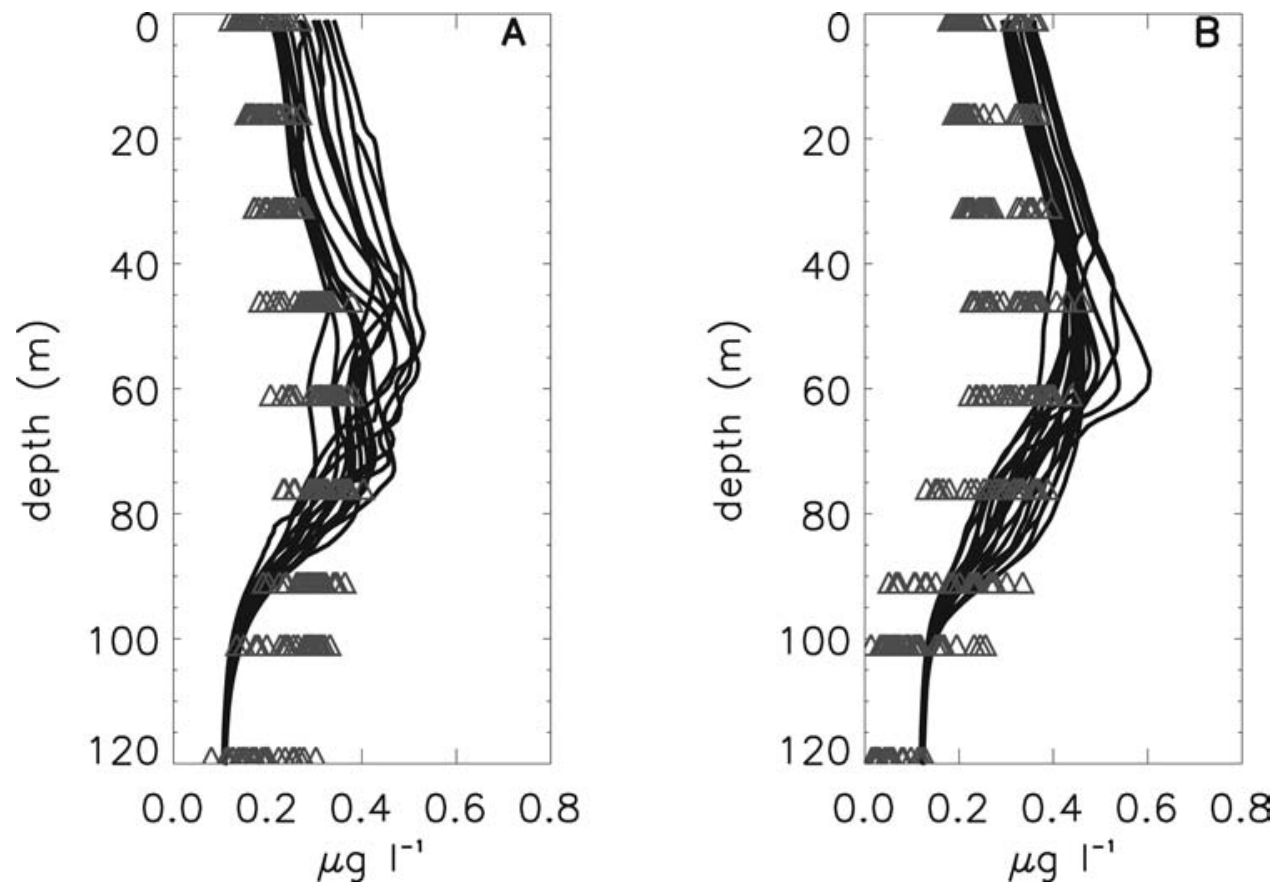

Figure 20. Simulated profiles of chlorophyll $a\left(\mu \mathrm{g} 1^{-1}\right)$ for (A) YD83-YD98 and (B) YD272-YD284. The corresponding chlorophyll $a$ measurements $(\triangle)$ from the two U.S. JGOFS EqPac time series cruises are shown for comparison. 


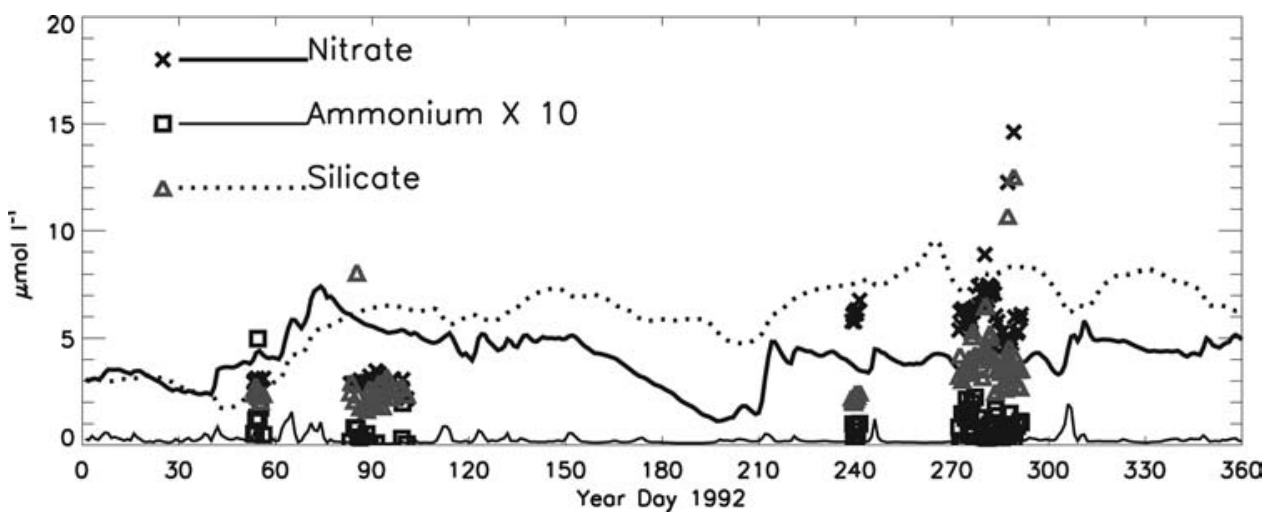

Figure 21. Simulated time distribution of daily-averaged nitrate (thick solid line), ammonium (thin solid line), and silicate (dotted line) in the mixed layer $\left(\mu \mathrm{moll}^{-1}\right)$. The corresponding measurements for nitrate $(\times)$, ammonium $(\square)$, and silicate $(\triangle)$ from the four U.S. JGOFS EqPac cruises are shown for comparison. Ammonium concentrations are scaled by a factor of 10 for comparison purposes.

of the deep chlorophyll maxima observed between the two cruises. The chlorophyll $a$ concentrations obtained during the TS1 cruises show that chlorophyll $a$ concentrations below $80 \mathrm{~m}$ are as high as the surface values, which are underestimated by the model (Fig. 20A).

The simulated concentrations of nitrate and ammonium compare well with observations (Fig. 21). However, the simulated mixed layer silicate concentrations overestimated observed values. Below the mixed layer, the decrease in ammonium concentrations seen in the TS2 cruise data is reproduced in the simulated distributions (Salihoglu, 2005).

The measured iron concentrations in the surface waters were typically below the detection limit for this micronutrient. The simulated surface water iron concentration was near zero throughout the year. The simulated iron concentrations at $120 \mathrm{~m}$ (Fig. 22) were within the range measured during the time series cruises.

The simulated micro- and mesozooplankton biomass and distribution are difficult to verify with measurements. However, some limited data are available. The simulated microand mesozooplankton concentrations are almost double the measured values $(\sim 18$ versus $\sim 10 \mathrm{mmol} \mathrm{m}^{-2}$ for microzooplankton and $\sim 25$ versus $\sim 12 \mathrm{mmol} \mathrm{m}^{-2}$ for mesozooplankton). Direct comparison of the simulated and observed zooplankton biomass is problematic because they do not necessarily represent the same quantity. The mesozooplankton compartment is the closure term in the model and the transfer of mesozooplankton biomass to higher trophic levels is not included. Thus, agreement within a factor of 2 is taken to be acceptable.

Similarly, little data are available for comparison with the simulated surface carbon fluxes (Fig. 14). The limited measurements that are available can be subject to considerable experimental error (Dunne and Murray, 1999). However, comparison of the simulated organic 


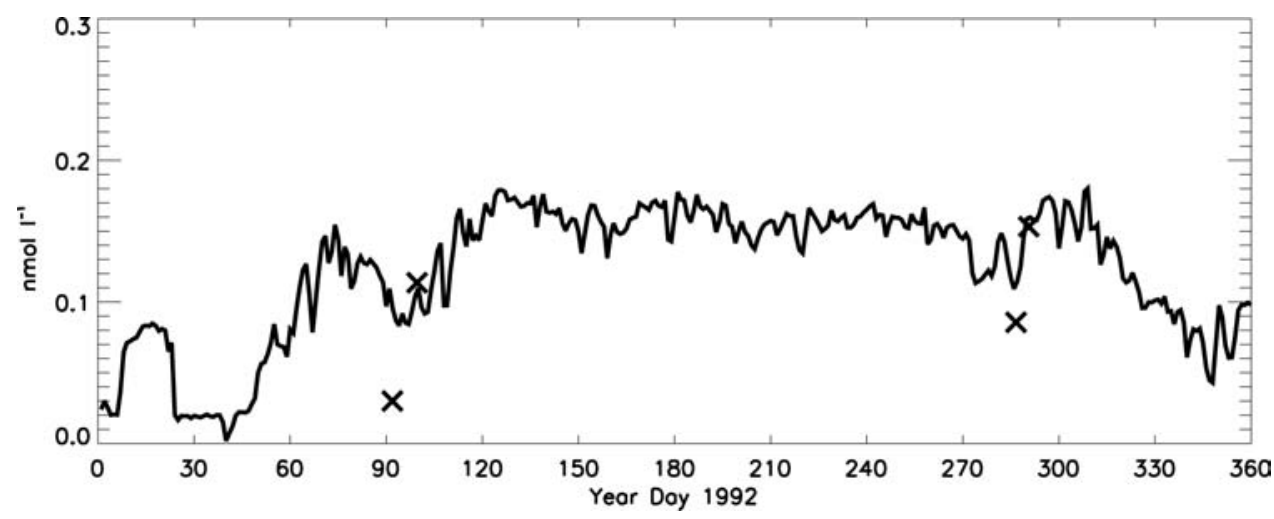

Figure 22. Simulated time distribution of daily-averaged iron $\left(\mathrm{nmol}^{-1}\right)$ at $120 \mathrm{~m}$. The corresponding iron measurements $(x)$ from U.S. JGOFS EqPac cruises are shown for comparison.

particulate carbon flux to measurements is promising (Fig. 14). The simulated fluxes overestimate the measured fluxes, but direct comparisons between the two are difficult because the measured and simulated fluxes may not represent the same quantities. Possible explanations of this mismatch are discussed in Section 5aiv. The simulated and observed organic particulate carbon fluxes show an increase in the latter part of 1992.

\section{Discussion}

a. Cause and effect of patterns in model state variables and derived fields

$i$. Phytoplankton structure. Many of the ecosystem models developed for the equatorial Pacific Ocean (e.g., Chai et al., 1996; Loukos et al., 1997; Leonard et al., 1999; McClain et al., 1999; Friedrichs and Hofmann, 2001; Christian et al., 2002a) include one or two species of plankton (i.e. nanoplankton and netplankton) which underrepresent the dynamics of the phytoplankton community. For example, in the two-species models that include iron (e.g., Leonard et al., 1999; Christian et al., 2002a), it is assumed that the large phytoplankton growth rates are strongly limited by iron and that the maximal rates of grazing mortality are less for these cells than for the small phytoplankton. These assumptions allow the netplankton to escape grazing control under strong upwelling conditions and become dominant because the small phytoplankton remain under strong grazer control. However, in the equatorial Pacific the netplankton (e.g., diatoms) do not exceed $15 \%$ of the total biomass even under strong upwelling conditions (Chavez, 1989; Iriarte and Fryxell, 1995; Bidigare and Ondrusek, 1996). Moreover, Bidigare and Ondrusek (1996) suggested that in the equatorial Pacific region some nanoplankton do not experience strong grazer control and that they bloom during strong upwelling conditions.

The multiple algal group model used in this study avoids these limitations in dynamics by including algal group 4 (i.e. autotrophic eukaryotes), which falls between the large and 
small phytoplankton groups used in other models (e.g., Christian et al., 2002a), and by inclusion of three smaller forms (algal groups 1 to 3). Algal group 4 responds strongly to strong upwelling conditions and blooms. The biomass of the smaller phytoplankton forms is strongly controlled by microzooplankton. Algal group 5 is controlled by nutrient limitation and mesozooplankton and remains below $15 \%$ of the total biomass. The choice of the model structure used in this study is also in keeping with the current understanding of the lower trophic levels of the equatorial Pacific (Chavez, 1989; Iriarte and Fryxell, 1995; Lindley et al., 1995; Bidigare and Ondrusek, 1996; Coale et al., 1996b; Chavez et al., 1996; Landry et al., 1996; Latasa et al., 1997; Higgins and Mackey, 2000; Landry et al., 2000a) and the U.S. JGOFS EqPac results (Section 4b).

Based on model-derived results, Christian et al. (2002b) concluded that the iron-mediated removal of surface nitrate by phytoplankton was such that significant inputs of iron were needed to prevent the accumulation of nitrate in surface waters of the equatorial Pacific. This implies that phytoplankton in equatorial waters must have small iron quotas (e.g., less than $\left.0.003 \mathrm{nmol} \mathrm{Fe}(\mu \mathrm{mol} \mathrm{C})^{-1}\right)$. However, the inclusion of variable cellular nutrient quotas, as done in the model used in this study, removes the need for assuming uniformly low cellular iron quotas. The nitrogen to carbon ratios of each algal group remain high (Section 4aii), allowing nitrate to be deposited in the cells, which in turn allows the cellular iron to carbon ratios to be low and variable in the surface waters (Figs. 11A-E). Only the cellular iron quotas of algal groups 4 and 5 decrease to $0.003 \mathrm{nmol} \mathrm{Fe}(\mu \mathrm{mol} \mathrm{C})^{-1}$ (Figs. 11D and E).

\section{Algal group biomass and primary production}

The physiological differences in algal groups are also reflected in the vertical distribution patterns of biomass and primary production rate (cf. Section 4aii). The primary production of algal groups is confined to certain depths; whereas, biomass is more dispersed as a result of vertical advection and diffusion, and mixing in the mixed layer. Deepening of the mixed layer can increase the phytoplankton production by pumping nutrients into the euphotic zone. However, when the mixed layer extends below the euphotic zone, for instance between YD15-60 in the reference simulation, primary production ceases as the cells are moved out of the lighted part of the water column (Figs. 7A-E). Similarly, mixing upwards benefits some algal groups, such as groups 3 and 4, because of increased light (Figs. 7C and D). Other algal groups, such as groups 1 and 2, stop growing because of photoinhibition (Figs. 7A and B). Light inhibition of growth is stronger for algal group 1 compared to algal group 2, and as a result the biomass of algal group 1 in surface waters is lower than its biomass below the mixed layer (Fig. 5A). Algal group 2, in comparison, is abundant within the mixed layer (Fig. 5B).

Within the mixed layer, algal groups 1 to 3 show less temporal variability compared to algal groups 4 and 5, because heavy grazing by microzooplankton on the smaller cells buffers the variability in their biomass. The distribution of the simulated biomass of algal group 5 is higher below the mixed layer compared to the surface waters (Fig. 5E). Nutrient 
limitation (especially iron limitation) is stronger for algal group 5 compared to that for the other algal groups (Fig. 11E). Although light levels are lower below the mixed layer, nutrient concentrations are higher, and this results in optimal growth conditions for this algal group. Also, the simulated mesozooplankton are abundant in the mixed layer (Fig. 12B) which results in removal of algal group 5 in the mixed layer at a rate that is higher than that below the mixed layer. This decrease in grazing pressure towards deeper waters contributes to the increase in algal group 5 biomass towards the bottom of the euphotic zone.

The simulated phytoplankton biomass during YD110-YD160, YD200-YD255, and YD300-YD320 was higher than that observed during the U.S. JGOFS EqPac TS2 cruise (Fig. 17). The TS2 cruise occurred during the passage of a relatively weak TIW (Friedrichs and Hofmann, 2001) and the thermocline depth during the TS2 cruise was deeper than during the YD110-YD160, YD200-YD255, and YD300-YD320 periods (Fig. 3A). The highest simulated phytoplankton biomass values occurred during YD300-YD320, which corresponded to the passage of strong TIWs which can be seen in vertical velocity fields (Fig. 3B). These blooms also correspond to relatively shallow mixed layer depths and cold water temperatures representative of high nutrient concentrations (Figs. 3B and C).

Towards the end of the El Niño period during YD45-75, three consecutive strong IGWs appear in the vertical velocity fields (Fig. 3B) as shifts in velocity from $\sim 20 \mathrm{~m} \mathrm{~d}^{-1}$ to $0 \mathrm{~m} \mathrm{~d}^{-1}$ over $6-8$-days. The passage of the IGWs do not trigger phytoplankton blooms because this period also coincides with the passage of a Kelvin wave, which produces a deep thermocline and deep mixed layer depths (Figs. 3A and C).

The simulated algal group biomass abundance and distribution are realistic as determined from comparison with measurements (Section $4 \mathrm{~b}$ ). However, the simulated primary production values underestimated observed rates (Fig. 18). One potential reason for this mismatch is that the simulated and measured primary production rates may not represent the same processes. During the U.S. JGOFS EqPac cruises net daily particulate carbon production resulting from autotrophic and heterotrophic processes was estimated (Barber et al., 1996). The simulated primary production estimates are based on only production by autotrophic algae. Kirchman et al. (1995) argued that the ratio of heterotrophic bacteria production to primary production was around 0.15 during the TS1 and TS2 cruises. If the observed primary production rates are reduced by $15 \%$, then the simulated mixed layer primary production values (Fig. 18) fall within the observed limits. However, the simulated integrated primary production values are still lower than the observations.

\section{Algal group physiology}

Algal groups 1 and 2 cannot use nitrate as a nitrogen source, and as a result ammonium is depleted in the surface waters (Fig. 13B). However, the cellular nitrogen to carbon ratios for algal group 1 stay close to its maximum values; whereas, those for algal group 2 are below their maximum values (Fig. 10B). This arises because there is no production of algal group 1 at the surface (Fig. 7A) due to light inhibition. Similarly, the cellular iron to carbon 
ratios of algal group 1 are always maximum (Fig. 11A), which indicates that this group is not iron limited either. The effect of the inability of Prochlorococcus spp. to use nitrate on the simulated primary production and carbon fluxes is discussed in the accompanying paper (Salihoglu and Hofmann, 2007).

The simulated cellular iron to carbon ratios of algal groups 1-5 indicate that all groups, except algal group 1, are limited by iron, but that the strength of the iron limitation varies between species (Figs. 11A-E). Algal group 5 is most limited by iron, because the cellular iron to carbon ratios of this group generally stay at their minimum value within the mixed layer (Fig. 11E). Algal groups 2 and 3 are less iron-limited because their iron to carbon ratios remain above the minimum specified iron to carbon ratios of these groups (Figs. 11B and $\mathrm{C}$ ).

The simulated maximum light-limited and nutrient-limited phytoplankton growth rates (Figs. 9A and B) are higher during the first five months of 1992, because higher water temperatures during this time result in higher temperature dependent maximum growth rates $\left(\mu_{m t}(z, t)\right)$ for each group. This results in the maximum growth rates of algal groups $2-5$ occurring just below the mixed layer during the first five months of 1992, although the nutrient concentrations increase towards deeper waters $(120 \mathrm{~m})$. Each algal group reaches its maximum growth rate at different depths and times (Table 6), which reflects the physiological differences among different groups.

The effects of clouds are also reflected in the growth rates of algal groups. The effects of clouds on algal groups 1 and 2 are counterintuitive in that cloudy periods weaken the effect of light inhibition on these groups. This result was especially significant during the first four months of 1992 and resulted in an increase in growth rates of algal groups 1 and 2 in the surface waters. However, although the cloud cover results in an increase in the surface growth rates of algal groups 1 and 2, it does not increase the overall primary production rate of these groups. The decrease in the irradiance reaching the sea surface means less light inhibition for the algal cells at the surface, but results in light limitation of growth occurring at shallower depths (e.g. on YD120, Fig. 9A) . This produces an upwards shift in the primary production vertical profile of algal groups 1 and 2 without increasing the overall primary production. The decrease in irradiance during cloudy times resulted in decreased growth rates for the other algal groups which appears in the simulated distribution as vertical bands of reduced growth rates.

ii. Nutrients. Observations (Martin et al., 1989; Bruland et al., 1994; Johnson et al., 1997) show that the vertical profile of iron in the ocean follows a nutrient-type (e.g., nitrate) distribution. The simulated vertical iron distributions support these observations and suggest that the vertical iron distributions show characteristics of both new-(nitrate) and recyclednitrogen (ammonium) (Figs. 13A and B). The simulated iron concentration is high at the bottom of the euphotic zone $(120 \mathrm{~m})$ due to upwelling of iron-rich waters and is also as high near $80 \mathrm{~m}$ due to efficient remineralization of iron in sinking particles (Fig. 13C). This 
is consistent with observations that show that iron is rapidly recycled in the surface waters (Hutchins et al., 1993; DiTullio et al., 1993; Barbeau et al., 1996).

The simulated silicate concentrations are $\sim 50 \%$ higher than the observations during the second half of the year (Fig. 13D), which may be the result of not including the horizontal advection of silicate. However, observations show that silicate concentrations are always $>2 \mu \mathrm{mol}^{-1}$ in the upper $120 \mathrm{~m}$. The half saturation constant for silicate uptake by diatoms is below this value (Nelson and Treguer, 1992). To compensate for high simulated silicate concentrations, model is tested using a higher silicate half saturation constant $\left(3 \mu \mathrm{mol}^{-1}\right)$. Results did not differ significantly from the reference simulation results. Thus, results for $0 \mathrm{~N}, 140 \mathrm{~W}$ are counter to the suggestion that input of low silica waters to the equatorial upwelling system is a primary cause of the low new production of organic carbon (Dugdale and Wilkerson, 1998).

iii. Zooplankton. Dam et al. (1995) showed that the bulk of the diet of mesozooplankton in equatorial Pacific waters consists of microzooplankton rather than phytoplankton. The simulated distributions support this observation and show that $63 \%\left(9,790 \mu \mathrm{mol} \mathrm{C}\right.$ year $\left.^{-1}\right)$ of the microzooplankton production is cropped by mesozooplankton. High mesozooplankton grazing results in low variability in the microzooplankton biomass (Fig. 12A), and therefore, the variability in phytoplankton concentration is not reflected in the microzooplankton biomass. Any increase in microzooplankton concentration is rapidly removed by mesozooplankton. Thus, variability in mesozooplankton biomass has a similar structure to phytoplankton primary production (Fig. 12B). Because simulated mesozooplankton biomass is overestimated (cf. Section $4 \mathrm{~b}$ ) this is reflected as high grazing control on algal group 5.

iv. Carbon export. The simulated export carbon fluxes are largely controlled by inputs of subsurface nitrate and sinking of particulate matter, as suggested by Eppley and Peterson (1979). However, analysis of the factors controlling the export carbon flux indicate that the conceptual model of Eppley and Peterson (1979) needs to be expanded to include multiple limiting nutrients, such as iron and ammonium. This agrees with the results of other modeling studies (Christian et al., 2002a; Moore et al., 2002a).

The simulated particulate carbon fluxes are driven by primary production, downwelling vertical velocities, and sinking and they are reduced with depth via remineralization (Fig. 14). Downwelling increases the transport of particulate material out of the surface waters. Therefore, the highest carbon export values occur during the downwelling periods that follow a high carbon production period (e.g., YD15-30, YD75-90, YD120-170, YD220-240, and YD300-320, Section 4av).

Moreover, variability in the simulated carbon fluxes is mainly regulated by the vertical velocities rather than being a direct reflection of carbon production. For example, the two consecutive peaks in carbon flux that occur between YD300 and YD330 (Fig. 14), coincide with two periods of downwelling vertical velocities. 
Water temperature also affects the simulated export carbon flux because of the dependency of particulate carbon remineralization on temperature. Warm temperatures during the first part of 1992 (Fig. 3A) produce faster particle remineralization, thus reducing carbon export. For example during the El Niño period (YD1-120), temperatures are such that remineralization rates are almost double the remineralization rates of the cold non-El Niño period.

The model-data comparisons of the export carbon fluxes show that the simulated values overestimate the observations (Fig. 14). One possible explanation for this mismatch is that other macrozooplankton, which are not included in this model, remove biogenic material in the surface waters and can increase the removal of particulate carbon from the surface waters (Wiebe et al., 1979; Steinberg et al., 2001). Also flux feeders (organisms with mucus nets that collect settling particles, Jackson, 1993) that graze below the mixed layer and vertically migrating zooplankton can remove carbon (Longhurst and Harrison, 1988) from the surface layers. The effect of other zooplankton species and vertical migration are not included in the model. Friedrichs and Hofmann (2001) argued that horizontal advection of nutrients is needed to avoid nutrient accumulation in the region. Thus, lack of horizontal advection in the model may be another factor contributing to the high carbon export.

\section{Summary and conclusions}

The results of this study are in agreement with generally accepted explanations for ecosystem processes in the equatorial Pacific region. The phytoplankton are nutrient limited and are dominated by small forms. Rates associated with the dominant algal groups are usually less than their physiologically maximum. The algal groups are cropped to low abundances by microzooplankton grazers, and their sustained growth is dependent on the remineralized products of grazing. This study illustrates the importance of using a multi-component lower trophic level ecosystem model that includes detailed algal physiology and realistic micronutrient dynamics to investigate physical and biological interactions in structuring the phytoplankton community assemblage and in regulating the export carbon flux in the equatorial Pacific. Also, variable cellular nutrient quotas for the algal groups allow for realistic nutrient uptake dynamics.

In the Cold Tongue region at $0 \mathrm{~N}, 140 \mathrm{~W}$, the simulated autotrophic eukaryotes and Prochlorococcus spp. dominate the phytoplankton community. These groups correspond to $69 \%$ and $14 \%$ of the total annual primary production in the region, respectively. During the El Niño period a shift towards smaller forms occur (e.g., Prochlorococcus spp. and Synechecoccus); whereas, under non-El Niño conditions phytoplankton assemblage shifts towards autotrophic eukaryotes. Sensitivity studies designed to highlight important physical and biological processes that affect carbon production and export are described in part 2 of this study (Salihoglu and Hofmann, 2007, this issue).

This study supports the hypothesis that iron has a nutrient-type (e.g., nitrate) profile in the equatorial ocean (Martin et al., 1989; Bruland et al., 1994; Johnson et al., 1997). 
However, the simulated vertical distributions further suggest that iron shows characteristics of both new-(nitrate) and recycled-nitrogen (ammonium). Model results also show that phytoplankton in the Cold Tongue are strongly iron limited even during upwelling periods. However, the algal uptake and iron remineralization formulations included in the model are based on limited observations. In order to better assess the effects of iron on the lower trophic levels and the carbon export, better understanding of iron uptake dynamics by various algal groups, remineralization processes of iron, aeolian iron fluxes, and iron solubility is needed.

The research described in this study provides a framework for future basin-scale and global studies of multi-component ecosystem modeling that includes detailed algal physiology. Continuing advances in computer technology will allow combining sophisticated representations for ecosystems and biogeochemical dynamics in basin-scale and global modeling frameworks. Evaluation and calibration of results from such basin-scale and global models will be possible through new sensors and methods that can monitor phytoplankton species and physiology from space (Sathyendranath et al., 2001; Alvain et al., 2005), as well as in situ measurement arrays.

Acknowledgments. This work would not have been possible without the hard work of the many scientists involved in the collection of the U.S. JGOFS EqPac data sets used in this study. We would also like to thank the TAO Project Office, Dr. Michael McPhaden, Director, for the use of the extensive data available from their mooring array. Thanks to Dr. Paul Ginoux for his atmospheric dust model output. Drs. Antonio Busalacchi, James Christian, Marjy Friedrichs, John Klinck, Raghu Murtugudde, Larry Atkinson and Véronique Garçon provided helpful comments on earlier presentations of this research. This research was generously supported by the National Aeronautics and Space Administration contracts NCC-5-258 and NAG5-11259. The computer facilities and resources were provided by the Commonwealth Center for Coastal Physical Oceanography at Old Dominion University, VA.

\section{REFERENCES}

Alvain, S., C. Moulin, Y. Dandonneau and F. M. Breon. 2005. Remote sensing of phytoplankton groups in case 1 waters from global SeaWiFS imagery. Deep-Sea Res. I, 52, 1989-2004.

Anderson, S. M. and O. A. Roels. 1981. Effects of light intensity on nitrate and nitrite uptake and excretion by Chaetoceros curvisetus. Mar. Biol., 62, 257-261.

Armstrong, R. A. 1999. An optimization-based model of iron-light-ammonium colimitation of nitrate uptake and phytoplankton growth. Limnol. Oceanogr., 44, 1436-1446.

Barbeau, K., J. Moffet, D. Caron, P. Croot and D. Erdner. 1996. Role of protozoan grazing in relieving iron limitation of phytoplankton. Nature, 380, 61-64.

Barber, R. T. and F. P. Chavez. 1991. Regulation of primary productivity rate in the equatorial Pacific. Limnol. Oceanogr., 36, 1803-1815.

Barber, R. T., M. P. Sanderson, S. T. Lindley, F. Chai, J. Newton, C. C. Trees, D. G. Foley and F. P. Chavez. 1996. Primary productivity and its regulation in the equatorial Pacific during and following the 1991-1992 El Niño. Deep-Sea Res. II, 43, 933-969.

Behrenfeld, M. J., A. J. Bale, Z. S. Kolber, J. Aiken and P. G. Falkowski. 1996. Confirmation of iron limitation of phytoplankton photosynthesis in the equatorial Pacific Ocean. Nature, 383, 508-511. Bidigare, R. R. and M. E. Ondrusek. 1996. Spatial and temporal variability of phytoplankton pigment distributions in the central equatorial Pacific Ocean. Deep-Sea Res. II, 43, 809-833. 
Binder, B. J., S. W. Chisholm, R. J. Olson, S. L. Frankel and A. Z. Worden. 1996. Dynamics of picophytoplankton, ultraphytoplankton and bacteria in the central equatorial Pacific. Deep-Sea Res. II, 43, 907-931.

Bissett, W. P., J. J. Walsh, D. A. Dieterle and K. L. Carder. 1999a. Carbon cycling in the upper waters of the Sargasso Sea: I. Numerical simulation of differential carbon and nitrogen fluxes. Deep-Sea Res. I, 46, 205-269.

1999b. Carbon cycling in the upper waters of the Sargasso Sea: II. Numerical simulation of apparent and inherent optical properties. Deep-Sea Res. I, 46, 271-317.

Bruland, K. W., K. J. Orians and J. P. Cowen. 1994. Reactive trace metals in the stratified central north Pacific. Geochim. Cosmochim. Acta, 58, 3171-3182.

Buesseler, K. O., J. A. Andrews, M. C. Hartman, R. Belastock and F. Chai. 1995. Regional estimates of the export flux of particulate organic carbon derived from thorium-234 during the JGOFS EqPac program. Deep-Sea Res. II, 42, 777-804.

Campbell, L., H. A. Nolla and D. Vaulot. 1994. The importance of Prochlorococcus to community structure in the central north Pacific Ocean. Limnol. Oceanogr., 39, 954-961.

Campbell, L. and D. Vaulot. 1993. Photosynthetic picoplankton community structure in the subtropical north Pacific Ocean near Hawaii (station ALOHA)., Deep-Sea Res. I, 40, 2043-2060.

Chai, F., S. T. Lindley and R. T. Barber. 1996. Origin and maintenance of a high nitrate condition in the equatorial Pacific. Deep-Sea Res. II, 43, 1031-1064.

Chavez, F. P. 1989. Size distribution of phytoplankton in the central and eastern Pacific Ocean. Global Biogeochem. Cycles, 3, 27-35.

Chavez, F. P., K. R. Buck, S. K. Service, J. Newton, and R. T. Barber. 1996. Phytoplankton variability in the eastern and central Tropical Pacific., Deep-Sea Res. II, 43, 809-833.

Chavez, F. P., P. G. Strutton, G. E. Friedrich, R. A. Feely, G. C. Feldman, D. G. Foley and M. J. McPhaden. 1999. Biological and chemical response of the equatorial Pacific Ocean to the 1997-98 El Niño. Science, 286, 2126-2131.

Chisholm, S. W., R. J. Olson, E. R. Zettler, R. Goericke, J. B. Waterbury and N. A. Welschmeyer. 1988. A novel free-living prochlorophyte abundancy in the oceanic euphotic zone. Nature, 334, 340-343.

Christian, J. R. and D. M. Karl. 1995. Bacterial ectoenzymes in marine waters: activity ratios and temperature responses in three oceanic provinces. Limnol. Oceanogr., 40, 1042-1049.

Christian, J. R., M. A. Verschell, R. Murtugudde, A. J. Busalacchi and C. R. McClain. 2002a. Biogeochemical modelling of the tropical Pacific Ocean. I. Seasonal and interannual variability, Deep-Sea Res. II, 49, 509-543.

2002b. Biogeochemical modelling of the tropical Pacific Ocean. II: Iron biogeochemistry, Deep-Sea Res. II, 49, 545-565.

Coale, K. H., S. E. Fitzwater, R. M. Gordon, K. S. Johnson and R. T. Barber. 1996b. Control of community growth and export production by upwelled iron in the equatorial Pacific Ocean. Nature, 379, 621-624.

Coale, K. H. et al. 1996a. A massive phytoplankton bloom induced by an ecosystem-scale iron fertilization experiment in the equatorial Pacific Ocean. Nature, 383, 495-501.

Crank, J. 1956. The Mathematics of Diffusion, Oxford University Press, Oxford, 411 pp.

Cuhel, R. L. and J. B. Waterbury. 1984. Biochemical composition and short term nutrient incorporation patterns in a unicellular marine cyanobacterium, Synechococcus (WH7803). Limnol. Oceanogr., 29, 370-374.

Cullen, J. J., M. R. Lewis, C. O. Davis and R. T. Barber. 1992. Photosynthetic characteristics and estimated growth rates indicate grazing is the proximate control of primary production in the equatorial Pacific. J. Geophys. Res., 97, 639-654. 
Dam, H. G., X. Zhang, M. Butler and M. R. Roman. 1995. Mesozooplankton grazing and metabolism at the equator in the central Pacific: Implications for carbon and nitrogen fluxes., Deep-Sea Res. II, 42, 735-756.

DiTullio, G., D. Hutchins and K. Bruland. 1993. Interaction of iron and major nutrients controls phytoplankton growth and species composition in the tropical north Pacific Ocean. Limnol. Oceanogr., 38, 495-508.

Droop, M. R. 1973. Some thoughts on nutrient limitation in algae. J. Phycology, 9, 264-272.

Duce, R. A. and N. W. Tindale. 1991. Atmospheric transport of iron and its deposition in the ocean. Limnol. Oceanogr., 36, 1715-1726.

Duce, R. A. et al. 1991. The atmospheric input of trace species to the world ocean. Global Biogeochem. Cycles, 5, 193-259.

Dugdale, R. C. and F. P. Wilkerson. 1998. Silicate regulation of new production in the equatorial Pacific upwelling. Nature, 391, 270-273.

Dunne, J. P. and J. W. Murray. 1999. Sensitivity of ${ }^{234}$ Th export to physical processes in the central equatorial Pacific. Deep-Sea Res. I, 46, 831-854.

Eppley, R. W. 1972. Temperature and phytoplankton growth in the sea. Fishery Bulletin, 70, 1063-1085.

Eppley, R. W. and B. J. Peterson. 1979. Particulate organic matter flux and planktonic organic matter in the surface layer of the ocean. Deep-Sea Res. I, 30, 311-323.

Falkowski, P. G., Z. Dubinsky and K. Wyman. 1985. Growth-irradiance relationships in phytoplankton. Limnol. Oceanogr., 30, 311-321.

Fitzwater, S. E., K. H. Coale, R. M. Gordon, K. S. Johnson and M. E. Ondrusek. 1996. Iron deficiency and phytoplankton growth in the equatorial Pacific., Deep-Sea Res. II, 43, 995-1015.

Flynn, K. J. 1991. Algal carbon-nitrogen metabolism: A biochemical basis for modelling the interactions between nitrate and ammonium uptake. J. Plankt. Res., 13, 373-387.

Flynn, K. J., K. Davidson and J. W. Leftley. 1994. Carbon-nitrogen relations at whole-cell and freeamino-acid levels during batch growth of Isochrysis galbana (Prymnesiophyceae) under conditions of alternating light and dark. Mar. Biol., 118, 229-237.

Franks, P. J. S., J. S. Wroblewski and G. R. Flierl. 1986. Behavior of a simple plankton model with food-level acclimation by herbivores. Mar. Biol., 91, 121-129.

Friedrichs, M. A. M. and E. E. Hofmann. 2001. Physical control of biological processes in the central equatorial Pacific Ocean. Deep-Sea Res. I, 48, 1023-1069.

Fung, I. Y., S. K. Meyn, I. Tegen, S. C. Doney, J. G. John and J. K. B. Bishop. 2000. Iron supply and demand in the upper ocean. Global Biogeochem. Cycles, 14, 281-295.

Geider, R. J., H. L. MacIntyre and T. M. Kana. 1998. A dynamic regulatory model of phytoplanktonic acclimation to light, nutrients, and temperature. Limnol. Oceanogr., 43, 679-694.

Ginoux, P., M. Chin, I. Tegen, J. Prospero, B. Holben, O. Dubovik and S. J. Lin. 2001. Sources and distributions of dust aerosols simulated with the GOCART model. J. Geophys. Res., 106, 20,225-20,273.

Goldman, J. C. 1980. Physiological processes, nutrient availability, and the concept of relative growth rate in marine phytoplankton ecology, in Primary Productivity in the Sea, P. G. Falkowski, ed., Plenum Press, NY, 179-194.

- 1982. Comparative rapid ammonium uptake by four species of marine phytoplankton. Limnol. Oceanogr., 27, 814-827.

Goldman, J. C. and P. M. Glibert. 1983. Inorganic nitrogen uptake by phytoplankton, in Nitrogen in the Marine Environment, E. Carpenter and D. G. Carpone, eds., Academic Press, NY, 233-274.

Gregg, W. W. and K. L. Carder. 1990. A simple spectral solar irradiance model for cloudless maritime atmospheres. Limnol. Oceanogr., 35, 1657-1675. 
Haney, J. A. and G. A. Jackson. 1996. Modeling phytoplankton growth rates. J. Plankt. Res., 18, 63-85.

Harrison, W. G., L. R. Harris and B. D. Irwin. 1996. The kinetics of nitrogen utilization in the oceanic mixed layer: Nitrate and ammonium interactions at nanomolar concentrations. Limnol. Oceanogr., 41,16-32.

Higgins, H. W. and D. J. Mackey. 2000. Algal class abundances, estimated from chlorophyll and carotenoid pigments, in the western equatorial Pacific under El Niño and non-El Niño conditions. Deep-Sea Res. I, 47, 1461-1483.

Hutchins, D. A. and K. W. Bruland. 1995. Fe, Zn, Mn and N transfer between size classes in a coastal phytoplankton community: Trace metal and major nutrient recycling compared. J. Mar. Res., 53, 297-313.

Hutchins, D. A., G. R. DiTullio and K. W. Bruland. 1993. Iron and regenerated production: Evidence for biological iron recycling in two marine environments. Limnol. Oceanogr., 38, 1242-1255.

Iriarte, A. and D. A. Purdie. 1993. Photosynthesis and growth response of the oceanic picoplankter Pycnococcus provasolii Guillard (clone Omega 48-23) (Chlorophyta) to variations in irradiance, photoperiod and temperature. J. Exper. Mar. Biol. Ecol., 168, 239-257.

Iriarte, J. L. and G. A. Fryxell. 1995. Microphytoplankton at the equatorial Pacific (140W) during the JGOFS EqPac Time Series studies: March to April and October 1992, Deep-Sea Res. II, 42, 559-583.

Ivlev, V. S. 1955. Experimental Ecology of the Feeding of Fishes, Yale University Press, New Haven, translated from Russian by D. Scott, $302 \mathrm{pp}$.

Jackson, G. A. 1993. Flux feeding as a mechanism for zooplankton grazing and its implications for vertical particulate flux. Limnol. Oceanogr., 38, 1328-1331.

Jassby, A. D. and R. Platt. 1976. Mathematical formulation of the relationship between photosynthesis and light for phytoplankton. Limnol. Oceanogr., 21, 540-547.

Johnson, K. S., R. M. Gordon and K. H. Coale. 1997. What controls dissolved iron concentrations in the World Ocean? Mar. Chem., 57, 137-161.

Kana, T. M. and P. M. Glibert. 1987a. Effect of irradiances up to $2000 \mu \mathrm{E} \mathrm{m}^{-2} \mathrm{~s}^{-1}$ on marine Synechococcus WH7803. I. Growth, pigmentation, and cell composition. Deep-Sea Res., 34, $479-495$.

1987b. Effect of irradiances up to $2000 \mu \mathrm{E} \mathrm{m}^{-2} \mathrm{~s}^{-1}$ on marine Synechococcus WH7803. II. Photosynthetic response and mechanism. Deep-Sea Res., 34, 497-516.

Kessler, W. S., M. McPhaden and K. M. Weickmann. 1995. Forcing of intraseasonal Kelvin waves in the equatorial Pacific. J. Geophys. Res., 100, 10,613-10,631.

Kirchman, D., J. Rich and R. T. Barber. 1995. Biomass and biomass production of heterotrophic bacteria along $140 \mathrm{~W}$ in the equatorial Pacific: Effect of temperature on the microbial loop. DeepSea Res. II, 42, 603-680.

Kirk, J. T. O. 1994. Light and Photosynthesis in Aquatic Ecosystems, Cambridge University Press, Great Britain, 509 pp.

Landry, M. R., J. Kirshtein and J. Constantinou. 1995. A refined dilution technique for measuring the community grazing impact of microzooplankton, with experimental tests in the central equatorial Pacific. Mar. Ecol. Prog. Ser., 120, 53-63.

1996. Abundances and distributions of picoplankton populations in the central equatorial Pacific from $12 \mathrm{~N}$ to $12 \mathrm{~S}, 140 \mathrm{~W}$. Deep-Sea Res. II, 43, 871-890.

Landry, M. R., M. E. Ondrusek, S. J. Tanner, S. L. Brown, J. Constantinou, R. R. Bidigare, K. H. Coale and S. Fitzwater. 2000a. Biological response to iron fertilization in the eastern equatorial Pacific (IronEx II). 1. Microplankton community abundances and biomass. Mar. Ecol. Prog. Ser., $\underline{201,17-42 .}$ 
Landry, M. R. et al. 1997. Iron and grazing constraints on primary production in the central equatorial Pacific: An EqPac synthesis. Limnol. Oceanogr., 42, 405-418.

Latasa, M., M. R. Landry, L. Schlueter and R. R. Bidigare. 1997. Pigment-specific growth and grazing rates of phytoplankton in the central equatorial Pacific. Limnol. Oceanogr., 42, 289-298.

Laws, E. A. and T. T. Bannister. 1980. Nutrient- and light-limited growth of Thalassiosira fluviatilis in continious culture, with implications for phytoplankton growth in the ocean. Limnol. Oceanogr., $25,457-473$.

Laws, E. A., P. G. Falkowski, W. O. Smith, H. Ducklow, and J. J. McCarthy. 2000. Temperature effects on export production in the open ocean. Global Biogeochem. Cycles, 14, 1231-1246.

Leonard, C. L., C. R. McClain, R. Murtugudde, E. E. Hofmann and L. W. J. Harding. 1999. An iron-based ecosystem model of the central equatorial Pacific. J. Geophys. Res., 104, 1325-1341.

Li, W. K. W., T. Zohary, Y. Z. Yacobi and A. M. Wood. 1993. Ultraphytoplankton in the eastern Mediterranean Sea: Towards deriving phytoplankton biomass from flow cytometric measurements of abundance fluorescence and light scatter. Mar. Ecol. Prog. Ser., 102, 79-87.

Lindley, S. T., R. R. Bidigare and R. T. Barber. 1995. Phytoplankton photosynthesis parameters along 140W in the equatorial Pacific. Deep-Sea Res. II, 42, 441-463.

Longhurst, A. R. and W. G. Harrison. 1988. Vertical nitrogen flux from the oceanic photic zone by diel migrant zooplankton and nekton. Deep-Sea Res. I, 35, 881-889.

Loukos, H., B. Frost, D. E. Harrison and J. W. Murray. 1997. An ecosystem model with iron limitation of primary production in the equatorial Pacific at 140W. Deep-Sea Res. II, 44, 2221-2249.

Marra, J., R. R. Bidigare and T. D. Dickey. 1990. Nutrients and mixing, chlorophyll and phytoplankton growth. Deep-Sea Res., 37, 127-143.

Martin, J. H., W. W. Broenkow, S. E. Fitzwater and R. M. Gordon. 1990. Yes, it does: A reply to the comment by Banse. Limnol. Oceanogr., 35, 775-777.

Martin, J. H., R. M. Gordon and S. E. Fitzwater. 1991. The case for iron. Limnol. Oceanogr., 36, 1793-1802.

Martin, J. H., R. M. Gordon, S. Fitzwater and W. W. Broenkow. 1989. VERTEX: phytoplankton/iron studies in the Gulf of Alaska. Deep-Sea Res. I, 36, 649-680.

Martin, J. H. et al. 1994. Testing the iron hypothesis in ecosystems of the equatorial Pacific Ocean. Nature, 371, 123-129.

McClain, C. R., R. Murtugudde and S. Signorini. 1999. A simulation of biological processes in the equatorial Pacific Warm Pool at 165E. J. Geophys. Res., 104, 18,305-18,322.

McPhaden, M. J. et al. 1998. The Tropical Ocean-Global Atmosphere observing system: A decade of progress. J. Geophys. Res., 103, 14,169-14,240.

Miller, S. R. and R. W. Castenholz. 2001. Ecological physiology of Synechococcus sp. strain sh-94-5, a naturally occurring cyanobacterium deficient in nitrate assimilation. Applied Environ. Microbiol., 67, 3002-3009.

Moore, J. K., S. C. Doney, J. A. Kleypas, D. M. Glover and I. Y. Fung. 2002a. An intermediate complexity marine ecosystem model for the global domain. Deep-Sea Res. II, 49, 403-462.

Moore, L. R., R. Goericke and S. W. Chisholm. 1995. Comparative physiology of Synechococcus and Prochlorococcus: Influence of light and temperature on growth, pigments, fluorescence and absorptive properties. Mar. Ecol. Prog. Ser., 116, 259-275.

Moore, L. R., A. F. Post, G. Rocap and S. W. Chisholm. 2002b. Utilization of different nitrogen sources by the marine cyanobacteria Prochlorococcus and Synechococcus. Limnol. Oceanogr., 47, 989-996.

Morel, F. M., R. J. M. Hudson and N. M. Price. 1991. Limitation of productivity by trace metals in the sea. Limnol. Oceanogr., 36, 1742-1755. 
Murray, J. W., R. T. Barber, M. R. Roman, M. P. Bacon and R. A. Feely. 1994. Physical and biological controls on carbon cycling in the equatorial Pacific. Science, 266, 58-65.

Murray, J., E. Johnson and C. Garside. 1995. A U.S. JGOFS process study in the equatorial Pacific (EqPac): Introduction. Deep-Sea Res. II, 42, 275-293.

Murray, J. W., M. W. Leinen, R. A. Feely, J. R. Toggweiler and R. Wanninkhof. 1992. EqPac: A process study in the central equatorial Pacific. Oceanography, 5, 134-142.

Murtugudde, R., R. Seager and Busalacchi. 1996. Simulation of the tropical oceans with an ocean GCM coupled to an atmospheric mixed-layer model. J. Clim., 9, 1795-1815.

Nelson, D. M. and P. Treguer. 1992. Role of silicon as a limiting nutrient to Antarctic diatoms: Evidence from kinetic studies in the Ross Sea ice-edge zone. Mar. Ecol. Prog. Ser., 80, 255-264.

Nelson, D. M., P. Treguer, M. A. Brzezinski, A. Leynaert and B. Queaguiner. 1995. Production and dissolution of biogenic silica in the ocean: Revised global estimates, comparison with regional data and relationship to biogenic sedimentation. Global Biogeochem. Cycles, 9, 359-372.

Pacanowski, R. C. and S. G. H. Philander. 1981. Parameterization of vertical mixing in numerical models of tropical oceans. J. Phys. Oceanogr., 11, 1443-1451.

Partensky, F., W. R. Hess and D. Vaulot. 1999. Prochlorococcus, a marine photosynthetic prokaryote of global significance. Microbiology and Molecular Biology Reviews, 63, 106-127.

Partensky, F., N. Hoepffner, W. K. W. Li, O. Ulloa and D. Vaulot. 1993. Photoacclimation of Prochlorococcus sp. (Prochlorophyta) strains isolated from the north Atlantic and the Mediterranean Sea. Plant Physiol., 101, 285-296.

Peters, H., M. C. Gregg, D. R. Caldwell and J. N. Moum. 1981. Equatorial vertical mixing, in Further Progress in Equatorial Oceanography: A Report of the U.S. TOGA Workshop on the Dynamics of the Equatorial Oceans., E. J. Katz and J. M. Witte, eds., Nova Univ. Press, 101-120.

Philander, G. 1990. El Niño, La Niña, and the Southern Oscillation, Academic Press, Inc., Princeton, NJ, 293 pp.

Post, A. F., Z. Dubinsky, K. Wyman and P. G. Falkowski. 1985. Physiological response of a marine planktonic diatom to transitions in growth irradiance. Mar. Ecol. Prog. Ser., 25, 141-149.

Price, F., R. Weller and R. Pinkel. 1986. Diurnal cycling: Observations and models of the upper ocean response to diurnal heating, cooling, and wind mixing. J. Geophys. Res., 91, 8411-8427.

Price, N. M., B. A. Ahner and F. M. M. Morel. 1994. The equatorial Pacific Ocean: Grazer-controlled phytoplankton populations in an iron-limited ecosystem. Limnol. Oceanogr., 39, 520-534.

Qiao, L. and R. H. Weisberg. 1995. Tropical instability wave kinematics: Observations from the tropical instability wave experiment. J. Geophys. Res., 100, 8677-8693.

Richardson, K., J. Beardall and J. A. Raven. 1983. Adaptation of unicellular algae to irradiance: An analysis of strategies. New Phytologist, 93, 157-191.

Rippka, R. et al. 2000. Prochlorococcus marinus subsp. pastoris subsp. nov. strain pcc 9511, the first axenic chlorophyll a(2)/b(2)-containing cyanobacterium (Oxyphotobacteria). Int. J. of Systematic and Evolutionary Microbiol. 50, 1833-1847.

Rocap, G., D. L. Distel, J. B. Waterbury and S. W. Chisholm. 2002. Resolution of Prochlorococcus and Synechococcus ecotypes by using 16S-23S ribosomal DNA internal transcribed spacer sequences. Appl. Environ. Microbiol., 68, 1180-1191.

Roman, M. R., H. G. Dam, A. L. Gauzens, J. Urban-Rich, D. G. Foley and T. D. Dickey. 1995. Zooplankton variability on the equator at $140 \mathrm{~W}$ during the JGOFS EqPac study. Deep-Sea Res. II, 42,673-693.

Roman, M. R. and A. L. Gauzens. 1997. Copepod grazing in the equatorial Pacific. Limnol. Oceanogr., 42, 623-634. 
Sakshaug, E., K. Andresen and D. A. Kiefer. 1989. A steady state description of growth and light absorption in the marine planktonic diatom Skeletonema costatum. Limnol. Oceanogr., 34, 198-205.

Sakshaug, E., S. Demers and C. M. Yentsch. 1987. Thalassiosira oceanica and T. pseudonana: Two different photoadaptational responses. Mar. Ecol. Prog. Ser., 41, 275-282.

Sakshaug, E., G. Johnsen, K. Andresen and M. Vernet. 1991. Modeling of light-dependent algal photosynthesis and growth: Experiments with the Barents Sea diatoms Thalassiosira nordenskioeldii and Chaetoceros furcellatus. Deep-Sea Res. I, 38, 415-430.

Salihoglu, B. 2005. Modeling the effects of physical and biogeochemical processes on phytoplankton species and carbon production in the equatorial Pacific Ocean, Ph.D. thesis, Old Dominion University, $193 \mathrm{pp}$.

Salihoglu, B. and E. E. Hofmann. 2007. Simulations of phytoplankton species and carbon production in the equatorial Pacific Ocean 2. Effects of physical and biogeochemical processes. J. Mar. Res., 65, 275-300.

Sathyendranath, S., G. Cota, V. Stuart, H. Maass and T. Platt. 2001. Remote sensing of phytoplankton pigments: A comparison of empirical and theoretical approaches. Int. J. Remote Sensing, 22, 249-273.

Scanlan, D. J. and N. J. West. 2002. Molecular ecology of the marine cyanobacterial genera Prochlorococcus and Synechococcus. FEMS Microbiol. Ecol., 40, 1-12.

Steinberg, D. K., C. A. Carlson, N. R. Bates, R. J. Johnson, A. F. Michaels, and A. Knap. 2001. Overview of the U.S. JGOFS Bermuda Atlantic time-series study (BATS): a decade-scale look at ocean biology and biogeochemistry. Deep-Sea Res. II, 48, 1405-1448.

Sunda, W. G. and S. A. Huntsman. 1995. Iron uptake and growth limitation in oceanic and coastal phytoplankton. Mar. Chem., 50, 189-206.

Takahashi, T., S. C. Sutherland, C. Sweeney, A. Poisson, N. Metzl, B. Tilbrook, N. Bates, R. Wanninkhof, R. Feely, C. Sabine, J. Olafsson and Y. Nojiri. 2002. Global sea-air $\mathrm{CO}_{2}$ flux based on climatological surface ocean $\mathrm{pCO}_{2}$, and seasonal biological andtemperature effects. Deep-Sea Res. II, 49, 1601-1622.

Takeda, S. 1998. Influence of iron availability, on nutrient consumption ratio of diatoms in oceanic waters. Nature, 393, 774-777.

Vaulot, D., D. Marie, R. J. Olson and S. W. Chisholm. 1995. Growth of Prochlorococcus, a photosynthetic prokaryote, in the equatorial Pacific Ocean. Science, 268, 1480-1482.

Verity, P. G., D. K. Stoecker, M. E. Sieracki and J. R. Nelson. 1996. Microzooplankton grazing of primary production at $140 \mathrm{~W}$ in the equatorial Pacific. Deep-Sea Res. II, 43, 1227-1256.

Walsh, I. D., S. P. Chung, M. J. Richardson and W. D. Gardner. 1995. The diel cycle in the integrated particle load in the equatorial Pacific: A comparison with primary production. Deep-Sea Res. II, $42,465-477$.

Walsh, J. J. 1975. A spatial simulation model of the Peru upwelling ecosystem. Deep-Sea Res., 22, 201-236.

1976. Herbivory as a factor in patterns of nutrient utilization in the sea. Limnol. Oceanogr., 21, 1-13.

Wheeler, P. A. 1983. Phytoplankton nitrogen metabolism, in Nitrogen in the Marine Environment, E. J. Carpenter and D. G. Carpone, eds., Academic Press, NY, 309-346.

Wheeler, P. A. and S. A. Kokkinakis. 1990. Ammonium recycling limits nitrate use in the oceanic subarctic Pacific. Limnol. Oceanogr., 35, 1267-1278.

Wiebe, P. H., L. P. Madin, L. R. Haury, G. R. Harbison and L. M. Philbin. 1979. Diel vertical migration by Salpa aspera and its potential for large-scale particulate organic matter transport to the deep-sea. Mar. Biol., 53, 249-255. 
Wroblewski, J. S. 1977. A model of phytoplankton plume formation during variable Oregon upwelling. J. Mar. Res., 35, 357-394.

Wunsch, C. and A. E. Gill. 1976. Observations of equatorially trapped waves in Pacific sea level variations. Deep-Sea Res., 23, 371-390.

Yu, Z., J. P. J. McCreary and J. A. Proehl. 1995. Meridional asymmetry and energetics of tropical instability waves. J. Phys. Oceanogr., 25, 2997-3007.

Zhang, C. and J. Zou. 1997. Nutrient uptake kinetics and growth under nutrient limitation of Pseudonitzschia. Oceanologia et Limnologia Sinica, 28, 599-603.

Zhang, X., H. G. Dam, J. R. White and M. R. Roman. 1995. Latitudinal variations in mesozooplankton grazing and metabolism in the central tropical Pacific during the U.S. JGOFS EqPac study. DeepSea Res. II, 42, 695-714.

Received: 18 May, 2006; revised: 25 January, 2007. 